\title{
A review on experimental research using scale models for buildings: Application and methodologies
}

\author{
Juan M. Lirola ${ }^{\mathrm{a}, *}$, Estéfana Castañeda ${ }^{\mathrm{a}}$, Benito Lauret $^{\mathrm{a}}$, Mohamed Khayet $^{\mathrm{b}}$ \\ a Architectural Construction and Technology Department, School of Architecture, Technical University of Madrid (UPM), Av. Juan de Herrera 4, 28040 \\ Madrid, Spain \\ b Department of Applied Physics I, Faculty of Physics, University Complutense of Madrid, Av. Complutense, s/n, 28040 Madrid, Spain
}

\section{A R T I C L E I N F O}

\section{Article history:}

Received 16 July 2016

Received in revised form

10 November 2016

Accepted 26 February 2017

Available online 3 March 2017

\section{Keywords:}

Scale models

Building tests

Building simulation

Experimental tests

Principle of similarity

Dimensional analysis

Parallel projection

Dimensionless numbers

Scale effects

Fractals

\begin{abstract}
A B S T R A C T
A complete review on scale model testing for buildings, considering a wide range of methodologies and new manufacturing techniques, in areas such as statics and dynamics, acoustics, lighting, aerodynamics and thermodynamics for energy efficiency is presented. On the one hand, scale model testing for buildings require different considerations and techniques and are usually focused on one specific physical field contributing to the information scattering. On the other hand, they are sometimes too general, theoretical or unpractical. Although commercial computer simulations are first option among professionals, they necessarily simplify complex phenomena and ignore, among other aspects, size effects and latest findings in fractals. The potential of complementary experiments using new manufactured scale models for buildings is raising, however, it is still missing a practical overview through different physical fields specifically for buildings with these considerations. This review gives a wide perspective and unified scope on uses and possibilities of scale model testing for buildings, from the traditional configurations of Leon Battiste Alberti to new possibilities applying complex physics and new techniques of 3D-modelling.
\end{abstract} (c) 2017 Elsevier B.V. All rights reserved.

\section{Contents}

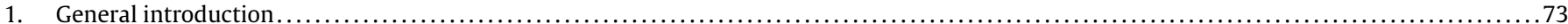

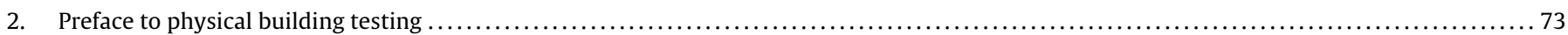

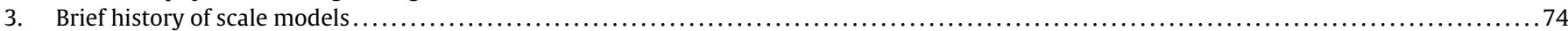

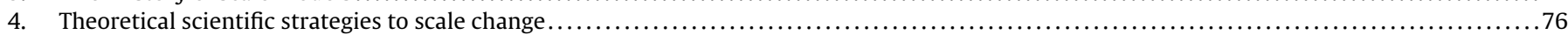

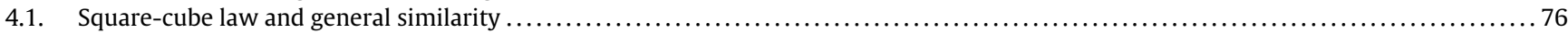

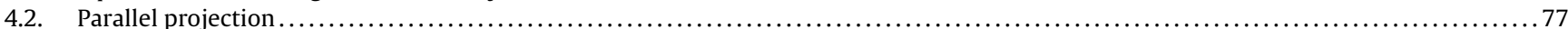

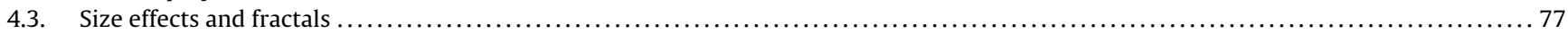

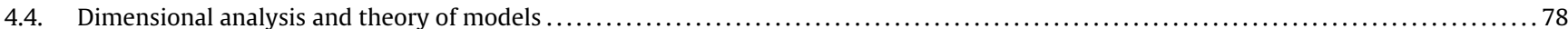

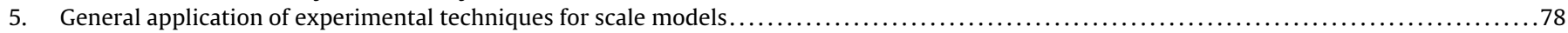

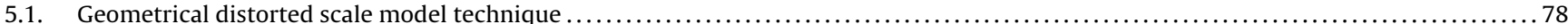

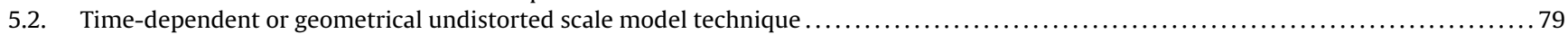

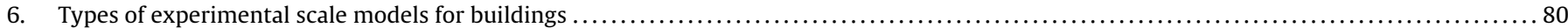

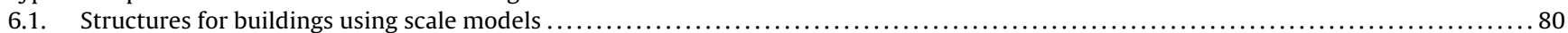

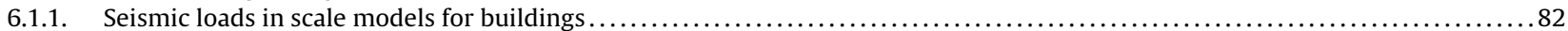

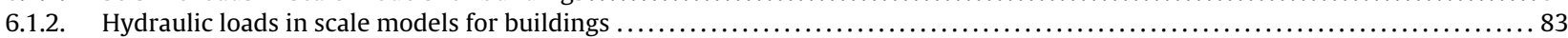

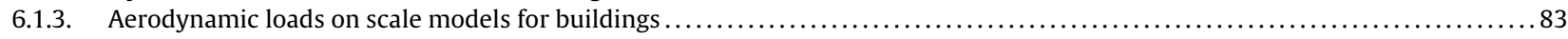

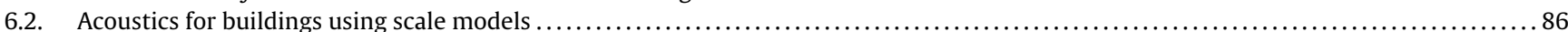

\footnotetext{
* Corresponding author.

E-mail address: juanmi.lirolaperez@upm.es (J.M. Lirola).
} 


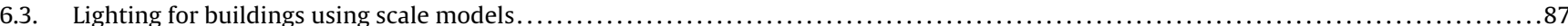

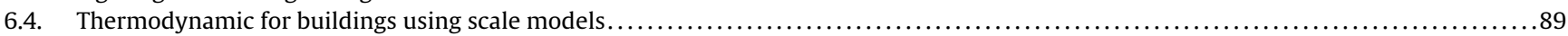

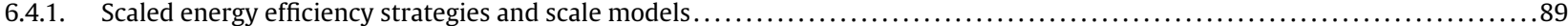

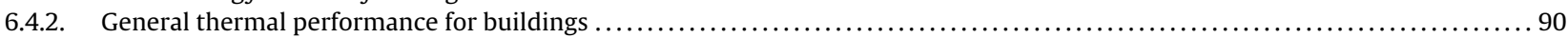

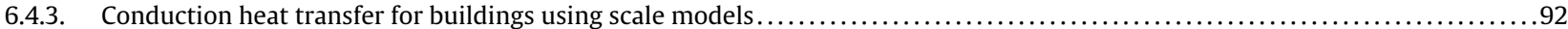

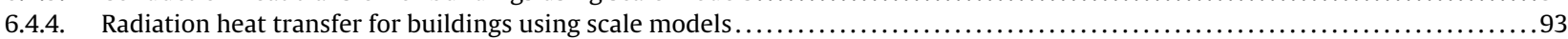

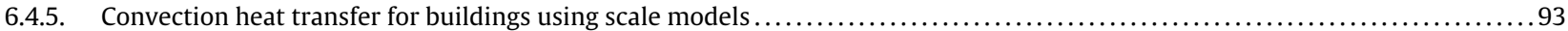

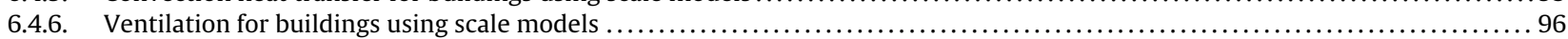

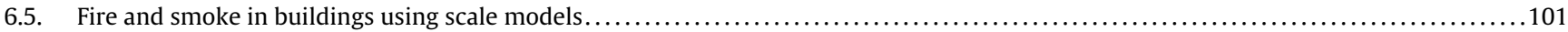

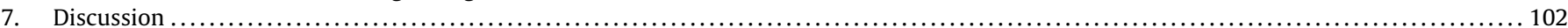

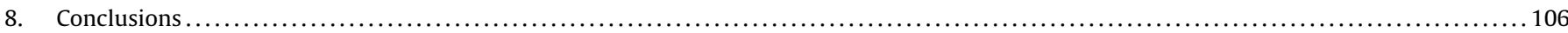

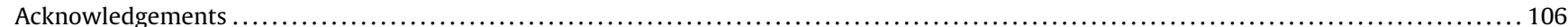

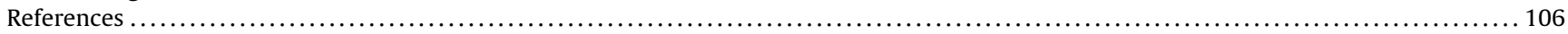

\section{General introduction}

The concept of model is too general and could lead to some confusion if it is not concretely specified. In this scientific review, this concept is based on the definition adopted by [15] according to [185]:

"A model is a device which is so related to a physical system that observations on the model may be used to predict accurately the performance of a physical system in the desired respect"

Prototype would be, therefore, the system for which predictions are to be made [15]. More precisely, in architectural and building technology, these "model devices" would be scale models of buildings or some part of them. "Prototypes" would be their corresponding full-scale buildings.

Consequently, in this case, models are strictly focused on the playback of physical systems being the appearance of models partially left aside in favor of this main aim.

However, for architects, the model's resemblance to the prototype's appearance is important in order to intervene in the design process. For architects, in general, and building designers in particular, there is also an important additional concept related to models named "replica":

"Physical model of a prototype which is geometrically similar in all respects to the prototype and employs identically the same materials at similar locations"[15].

Therefore, the ideal model for them would be a geometrical and functional "replica", that is, a perfectly undistorted scale model which could also reproduce the studied physical system or phenomenon.

Unfortunately, we will see that functional replicas are not always possible for physical and technical reasons. Change of materials or some deviations in their dimensions may occur during scale models' construction.

Functional geometric undistorted models - so evenly scaled geometry - with different materials are called dissimilar material model $[15,150,95]$. Those models intentionally unevenly scaled, with or without equal materials, are called distorted models [95].

In this review, we consider functional distorted and undistorted scale models, however, we pay special attention to those undistorted scale models or replicas of buildings with a practical point of view.

\section{Preface to physical building testing}

Among the range of ways to approach problems concerning experiments with buildings and, leaving aside analytic methods and computer simulations, a classification of three basic experimental methods are possible [206]: full-scale models, experimental modules or test cells [149,80,207] and scale models.
Full-scale models have disadvantages of high costs and space. In some cases, these limits do not exist and complete buildings are built "in situ" to collect experimental data that will be compared with computer simulation results [200].

Test cells or experimental modules, booths or full-scale parts are a less expensive alternative compared with the construction of full-scale buildings. Undertaken tests with these configurations are, for example, studies on effects of new materials and new designed elements in building envelopes [113], or studies on peculiarities of the micro-climate in building site [17]. These tests are sometimes prerequisite for the accomplishment of the final construction.

Scale model tests are experimental techniques for data collection with optimal economic and spatial configurations. The use of these models in different branches of engineering is very versatile and provides experimental data that can validate computer simulations and influence future designs. These techniques are valuable, however, it is considered just as an alternative to simulations. Fig. 1 shows the relation depicted by [108] between classic (analytic approach), computer (simulations) and scale models methodologies. Specifically, it shows the relation between the project difficulty and the relative cost of accomplishment with scale models and other available methods.

According to it, the more difficult the analysis is, the less effective are computer simulations. On the contrary, being the use of scale models for approaching less difficult problems disadvantageous compared with simulations, they are considered advantageous, in some cases even the only alternative, for analyzing the most difficult problems.

There is a critical point in Fig. 1 where calculus with computer and scale model tests curves coincide being both equally cost effective. From this point on, scale models techniques become advantageous by increasing problem difficulty. However, in architectural branch, the resource of tests with scale models is not used compared with other techniques such as simulations.

Usually, there are two main objectives for applying scale modeling tests, design application and validation application [74].

Design applications for comparing scale models with corresponding full-scale buildings are technically more demanding, however, full accomplishment of correspondence between scale models and their prototypes are really difficult to achieve according to the theory $[224,106,147]$.

On the contrary, validation applications are lesser demanding and are applied in many scientific fields $[184,166,4]$.

Whatever objective chose, there are similar theoretical fundamentals or strategies (see Section 4) and they influence the two main groups of experimental techniques [150]: distorted techniques and time-dependent techniques (see Section 5).

Depending on the physical field of testing, different specific scales, devices and measuring equipment are used (see Section 6). 


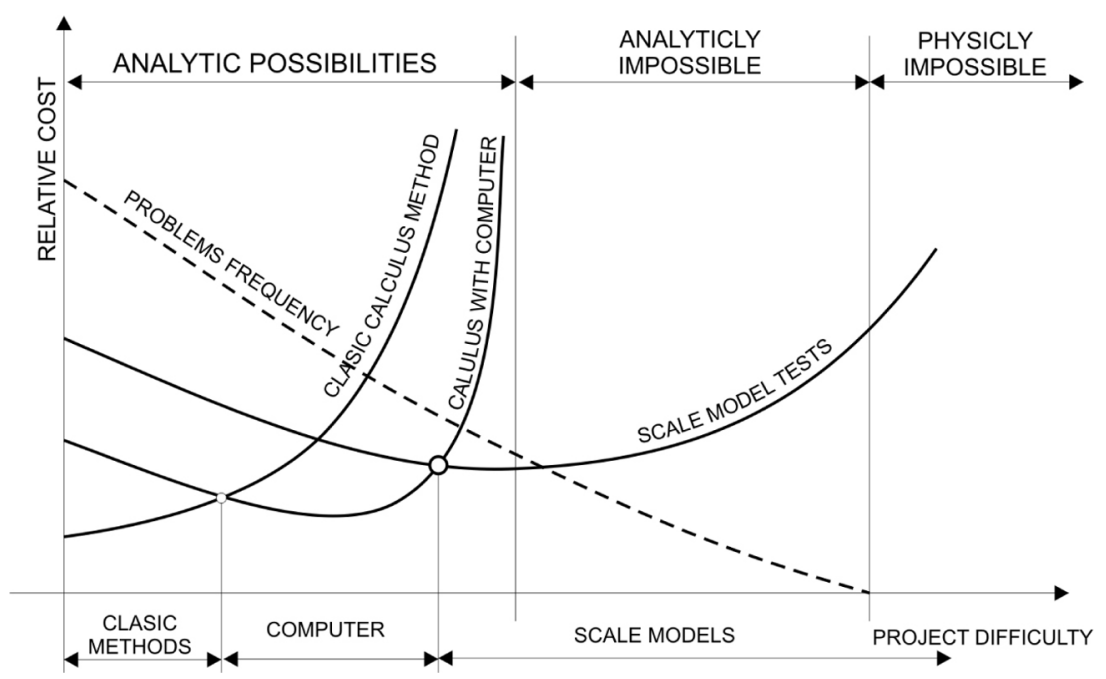

Fig. 1. H. Hossdorf interpretation of the relation between project difficulty ( $x$-axis) and relative cost ( $y$-axis).

Source: [108]

\section{Brief history of scale models}

The use of scale models in order to develop architectural projects was a tradition since Renaissance and this continued in Europe until XVI.

Beginning the XVII Century in Britain, Philibert de l'Orme (1510-70) in his work Le Premier Tome de l'Architecture writes some advises for the development of scale models of buildings.

Sir Balthazar Gerbier (1592-1663) mentions scale models in his work "A Brief Discourse Concerning the Three Chief Principles of Magnificent Building", one of the first treaties of architecture in Great Britain.

Additionally, Robert Pratt (1620-84), knowing classical architecture from Italy and France, recommended the use of scale models following advises of Alberti, Philibert de l'Orme, Vincenzo Scamozzi (1548-1616) and Iñigo Jones (1573-1652). This latter architect used scale models for at least two buildings: Star Chamber (1617) and Banqueting Hall (1619).

Specially scale models became of major importance thanks the influence of Sir Christopher Wren. He built scale models for Pembroke College of Cambridge (1663), Greenwich Hospital, and First Model and Great Model for the San Paul Cathedral in 1670 and 1674, respectively.

Disappeared scale models of the author are Sheldonian Theater of Oxford (1663), Emmanuel College Chapel of Oxford (1667), Trinity College Library of Cambridge (1676) and The Monument of Fish Street of London (1671), among many. However, they were recorded in the first British architectural treaty "The Elements of Architecture" (1624) of Sir Henry Wotton.

The Influence produced by Sir Wren in following architects was great. John Vanbrugh (1664-1726), Nicholas Hawksmoor (1661-1736) and James Gibbs (1682-1754) are examples of architects using scale models in the professional field of architecture [182].

In the early part of the twentieth century Architectural scale models were subjected of a revival called "model boom" [65].

This revival is related to different aspects of this epoch: the development of the projective geometry, the low-cost reproduction techniques and the affinity to Beaux-Arts. All together with the appearance of light-weight materials after World War I intensified the scale models' spread [65].

According to Kenneth McCutchon in one of his articles of "The Architects' Journal", during the epoch between wars, scale models were still the most accurate medium of foreseeing project buildings.

On the one hand, scale model focus was, and still is, on sale purposes and they become customers oriented tools, not only for designing architecture projects [98].

On the other hand, scale models in architecture were close related also to artistic expression influencing the project of architecture.

The arising mass media culture of this period turn scale models into figurative representations of style and design. They contribute, therefore, to spread the International Style and modernism of the new architecture.

As representative event is the exhibition Modern Architecture International Exhibition at New York's MOMA in 1932 in which scale models took primordial importance [65].

After World War II, the use of scale models was still linked with mass media diffusion. Prominent architects such as Mies van der Rohe (1886-1969) and Oscar Niemeyer (1907-2012) used their photographed scale models to spread their concepts of architecture all over the world.

These conceptual scale models linked to ideas of design spread by media were progressively loosing their influence until the $60 \mathrm{~s}$ Richard Meier (1934) is a paradigmatic example of architect after the nineteen-seventies who used scale models as medium for spreading his particular architecture style.

However, although architectural scale models in the early and middle of the twentieth century were mainly mere figurative representations, other kind of scale models began to arouse: functional scale models, and concretely, for structural design optimizations.

Considering Robert Hooke's research (1676) and previous Square-Cube Law of Galileo Galilei (1564-1642) published in 1638, French engineers of the eighteenth century, as B.F. Bélidor (1698-1761) and A.F. Frezier (1682-1773), used intuitive and experimental scale models with weights overhead for checking stability of already built structural designs.

In architecture, Antoni Gaudí y Cornet (1852-1926) was a true pioneer of this kind of models using weights overhead for obtaining lines of forces which set up their designs.

Before Gaudí, engineers just checked arch structures already planned with catenaries, in contrast, Gaudí structural designs were based on direct results of the catenary scale models.

Scale models for testing structures spread up along the middle of the twentieth century for two reasons. On the one hand, it was due 
to consolidation of a new analytic theory: theory of dimensional analysis.

On the other hand, scale models provide didactic possibilities for future technicians and engineers in engineering schools, research institutes and universities.

Other authors were involved on outstanding practical implementation of the dimensional analysis theory in scale models, as it is the case of Heinz Hossdorf [108]. His technical writings on concepts of scaling are based on practical experimentation with scale models and on the observation of nature. He developed and built structural forms at different scales by observing the variation in their mechanical properties.

After the nineteen-sixties, this new technical use for scale models was incorporated and consolidated in addition to those creative-figurative used in architecture.

Scientific methodologies in the second part of the XXth century influenced the use of scale models (see Section 4). Now, they were used as a medium to analyze complex physical phenomena and a new era of functional scale models spreads.

As consequence, two main types of scale models co-existed:

- Representative or figurative scale models: used, not exclusive, but mainly in architecture.

- Functional scale models: used, not exclusive, but mainly in engineering.

Especially, new analytic theories contributed to experimental tests using scale models in fluid dynamic studies.

In the field of structural analysis of buildings and civil constructions, scale models subjected to active or fluent loads were developed. Scale model tests on effects of external loads such as, for example, effects of the dynamic loads, either by water or wind, on structures were done.

In other engineering fields such as such the case of aeronautics, reduced functional or operational models are tested before making full-scale prototypes in order to optimize costs and design. Valuable data in flight are collected with them. To perform wind resistance tests wind tunnels are used.

Using this technique, an increasingly number of scale models of buildings were and are being tested in wind tunnels for studying structural effects of fluids, specially air, on buildings. Overall, these tests are important in those buildings which are subjected to high wind pressure, such as skyscrapers or buildings isolated in special windy areas. However, functional scale models are not only restricted to fluid dynamics, other areas of physics, such as lighting or acoustics, use scale models to study and investigate.

For example, the laboratory Bartenbach [19] has built an "artificial sky" which reproduces the outdoor ambient light. Inside this six-meters-diameter hemispherical dome scale models of buildings are placed to research their lighting parameters. The possibilities for sky replication of this "artificial sky" include adjustable luminance distribution, color temperature and the replica of the solar lighting at any position. They state to offer higher performance compared to any simulation program.

Acoustic studies are another practical use of scale models. They are built to research and verify major projects, where sound is especially relevant, such as auditoriums, concert halls, conference rooms or classrooms $[187,38,170]$. For optimization and research in scale models, devices such as lasers, electrostatic sources and micro-microphones are used. These facilities are used, for example, in le Centre Scientifique et Technique du Bâtiment (CSTB) Grenoble (France) [225].

This "functional boom" of tests using scale models will progress to an apparent end. Parallel to this "boom", in the 1960s, a revolution was about to surge with the breakthrough of integrated circuits and with the appearance of the first Central Processing Unit (CPU) [18].
Although, computer and basic simulations existed before, they were made with huge facilities and systems [92]. The appearance of personal computers and micro-processors brought the possibility of simulation, first, to every scientist and, then, to everyone with user-friendly software.

Consequently, scale model tests would be gradually left aside only used in some exceptional cases. This situation lasts until our days, in which functional or technical scale models are exceptionally used for specific scientific studies and prominent industrial developments.

In the era of the digital revolution in architectural design, model-making can be seen like a laborious and time-consuming preoccupation [204].

Traditional scale model fabrication methods may prove to be very expensive and unpractical in these days.

In the nineteen-eighties, with the development of technology and the use of Computer Aided Design software (CAD) in architectural design, the concept of scale models and drawings has significantly changed [233].

Since then, virtual computerized replicas can be developed. These computer replicas have partially substitute the necessity of building figurative scale models and, furthermore, computer simulations based on those virtual models have "substitute" partially the necessity of experimental tests.

However, simulations have their particular drawbacks and limitations [255] and virtual scale models do not replace, so far, physical built models.

Moreover, 3D digital modeling software based on Non-Uniform Rational B-Splines (NURBS) has opened a new field of complex forms. These forms were very difficult to conceive, develop and represent, let alone manufacturing, until the appearance of Computer Aided Design and Computer Aided Manufacturing (CAD/CAM) technologies [141].

New challenging building designs are possible now and they could be tested through scale models manufactured by means of digital techniques of Computer Numerically Controlled (CNC).

For these reasons, the use of scale models for architects and engineers is still actual and it is increasing with the incorporation of new production of forms and shapes.

The 3D-CAD-software and the use of 3D-printers are improving new type of scale models. These new scale models are playing the roll of intermediate step between 3D-CAD rendered visions and the full-scale buildings [29,37].

Under this point of view, scale model's production may be divided into analogue and digital. Analogue production would be traditional scale model construction and digital production would be instead those models commonly assisted by computer technology, such as laser cutters, CNC milling machines or 3D-printers.

Over the last few years, industrial robots have found increasing applications in manufacturing, mostly by substractive procedures [48], not only of scale models, but also of architectural elements and, hence, opening a new chapter in their fabrication [233].

Some well-known architects such as Toyo Ito, Frank Gehry, Bernhard Franken and the recently passed-away Zaha Hadid (1950-2016) design free-form architecture developed with digital software and CAM technologies, specially laser cutting and milling. Additionally, all of them make use of scale mock-ups for various proposes.

Nevertheless, the relevance in Gehry's models lies, concretely, in assuming and researching sheet-like forms by incorporating in model construction exact equal materials, with analogous limitations - at least in qualitatively constrains - to those elements fabricated for full scale buildings. With this philosophy scale models are built for testing features in acoustics and structural analysis, for example, in 1/10 Walt Disney Concert Hall model [140]. 
These scale model forms built with paper and other sheet materials have important counterparts for testing full scale constructions. These materials may be readily formed by manual methods into curved shapes in space, so long as their forms do not require stretch forming of the material. That would produce plastic deformation in the plane of the surface material. This relationship between material constraints of modelling materials at certain scales and fabrication constraints may only be approximate. However, for schematic design purposes, this approximate correspondence may be sufficient to guarantee the constructability of designed forms [227].

The concept of manufacturing architectural ideas in early stages of design was described in [213], as a method to generate physical descriptions of design ideas. Additionally, Simondetti described additive manufacturing and CAD-CAM technologies of manufacture for small-scale 3D-printed objects to full-scale design representation. He noted that full-scale models advance cognitive processes of design by physical demonstration of their structural behavior as well as their visual presentation [230].

A large number of additive manufacturing (AM) processes are now available; they differ in how layers are deposited to create pieces, in procedures and available materials.

Remarkable examples of AM are 3D-printers, commonly used to produce free-form shapes. This method allows the translation from computerized complex geometry to the physical world [233].

Several digital scale models are printed with 3D-printers or are made so that the process ends in a single integral scale model. Of course, depending on the size of model and 3D-printer, more than one printed section can be assembled into a single large model.

The materials commonly used in commercial 3D printing are plastics such as ABS, PLA, polyamide and hybrid materials based in thermoplastics such as Laywood o Laybrick, which are a mix of recycled wood fibres and polymer binder [194,169].

Furthermore, it is also possible to print using industrial metal powders (steel, stainless steel, copper alloys, iron, aluminum, titanium, bronze, brass, silver, gold), porcelain, wax, sandstone and graphene $(32,35)$. Available materials are being augmented with a variety of additives designed to improve strength, stiffness, weight, thermal and electrical conductivity and many other properties.

There are several examples of 3D-printed architectural scale mock-ups, but just a few of them are used as test models.

The Guggenheim Museum in Taichung, designed by Zaha Hadid Architects, was produced using SLS due to its cost-effective, quick and accurate process, and was mainly used as exhibition model.

The Proto-house, a 3D-printed house at 1/33 scale designed by Materialize Company and the Architectural Association School of Architecture's Design Research Lab, was used to research the architectural potential of the latest SLS technologies. The main issue of this research, was testing the boundaries of large scale 3D printing by designing with computer algorithms micro-organized printed material [28].

Currently, 3D-printing techniques can automate the scale model fabrication. However, the cost of these machines in big formats is too high and this type of devices allows a limited range of materials [84].

Other limitations in 3D-printing process exist such as software available needs, expert knowledge specifications, material properties, surface qualities and accuracy (due to manufacturing methods) [136]. Even with all these inconveniences, Bernard Cache and Patrick Beaucé prognosticate that by numerical manufacturing technique implementations, architectural design is heading towards operating in a fully-integrated CAD/CAM system [25].

Replica or figurative models are still popular [235] and functional scale model of buildings are a way to seek and experiment designs in order to find solutions and, at the same time, to interact with the environment [138]. The use of new production and manufacturing for scale models improves considerably the application and possibilities of functional scale model testing for buildings.

\section{Theoretical scientific strategies to scale change}

This section is a general and historical review of specific theories applied to functional scale models. These theories appeared initially as intuitive approximations to the Principle of Similarity of historical constructed scale models. The early Galileo-Galilei's Square-Cube law (see Section 4.1) is an example.

Influenced by previous discoveries, during the XXth century, some additional theories were simultaneously developed to achieve proper functional scale model designs. Basic and advanced geometric methods such as parallel projection, size effects, fractals (see Section 4.2) and analytic methods such as dimensional analysis (see Section 4.4) are described.

\subsection{Square-cube law and general similarity}

Galileo Galilei was the first to state rules across the scale change influencing the properties of the objects. In particular, he analyses the change ratio of surface to volume across the scale change and their repercussions in structural properties of the objects, in general, and living things in particular.

The Square-Cube law has fundamentals in geometry changes. Hypothetically, changing the scale of an object, such as a cube, its volume will change more rapidly than its total surface, since surfaces change squared the scale and volumes cubed:

$\frac{V_{p}}{A_{p}}=\frac{\lambda^{3} \cdot V_{m}}{\lambda^{2} \cdot A_{m}}=\lambda \cdot \frac{V_{m}}{A_{m}}$

being the $V$ the volume, $A$ the surface and $\lambda$ the scale change of the object. The subscripts $p$ and $m$ denote the prototype and the scale model, respectively.

Consequently, a larger prototype will weight relative more than a scale model and, therefore, a scale model will have more relative section strength than its corresponding prototype.

According to this rule, the form of an increased-scale prototype from a smaller scale-model size will have to change its shape (internal sections) to have equal internal tensions as its original smaller model form. This is caused due to the increase of its self-weight compared with its scale model.

If we observed historical constructions, ancient full-scale building's forms did not change compared with similar smaller building typology forms. Constructors and builders knew, mostly intuitively, that increasing the size of constructions, some measures should be taken into account for increasing strength of their structures or for lighten them to compensate their increasing volume. All these measures were mainly taken in order to maintain intact the Principle of Similarity across the scale change and with it the building typology.

Galileo Galilei's law is the particular case of the general procedure consisting in assigning a scale factor to every parameter geometric or others - involved in the problem of similitude.

For this reason, similitude analysis of physical phenomena between two bodies is far beyond Euclidean geometric similarity due to phenomenological similitude requirements [70]. In this line, it is possible to assign scale factors, $\lambda_{i}$, to every comparison of parameters of the prototype and model.

For achieving perfect similarity, the relation of these scale factors, accordingly to the physical relations of the problem, should be the unity $[108,73]$ :

$\prod_{i=1}^{\infty} \lambda_{i}=1$, 
being $i$ subscript the index of different involved parameters.

It should be noted that the behavior of two similar systems does not imply necessarily that both behave similar. For achieving similar scale model phenomenon, scale factors should be combined in order to get the similarity criteria, that is, satisfying Eq. (2).

\subsection{Parallel projection}

Parallel projection defined by W.J.M. Rankine in 1858 is one of the first geometrical method related to a physical scale change and coherent with Euclidean geometry:

"If two figures be so related, that for each point in one there is a corresponding point in the other, and that to each pair of equal and parallel lines in the one there corresponds a pair of equal and parallel lines in the other, those figures are said to be PARALLEL PROJECTION of each other" [209]

This quotation defines a geometrical definition of parallelism, but W.J.M. Rankine applied it to a system of forces in equilibrium between similar scale models:

"If a balanced system of parallel forces be represented by a system of lines, then any system of lines which is a parallel projection of the first system, will also represent a balanced system of parallel forces"[209].

Consequently, a system of forces of a scale model will be balanced if it is a geometric parallel projection of a balanced system of forces of a larger prototype.

This geometrical strategy was applied exclusively in structural engineering for analysis of static ancient constructions such as arches, vaults and domes. It makes possible to draw structural static analyses as an equivalent system of vector forces of the fullscale building through a small scale replica. Stability, and not the resistance, is the major issue in historic buildings and, hence, the suitability of this method in these cases [79].

Nowadays this traditional geometrical direct approach between scales was left aside in favor of other kind of analyses more sophisticated. However, following the analogy between forces and vectors in [159] there have been some attempt in thermal analogy establishing general geometric similarity between thermal curves of models at different scales under same boundary conditions.

\subsection{Size effects and fractals}

Ideally, the total similitude with a prototype would be only possible if the scale model were tested in a "miniature universe". Due to the impossibility of achieving this, even trying to reach similarity some distortions in phenomenological behavior of scale models appear. These distortions are called scale effects.

According with the definition of scale effects of Valentin Heller [105]:

Scale effects result in deviations between up-scale model measurements and real-world prototype observations due to prototype parameters which are not correctly scaled to the miniature universe resulting in force ratios which are not identical between the model and its prototype.

Apparently, scale models and prototypes tested in the same location to our eyes - better say to our human scale - would have same boundary conditions, but considering different scales of physical phenomena, they are not.

Physical phenomena theories in models at certain scales are still valid, however the influence of size effects becomes larger decreasing in scale. That means that physical laws and their standard equations cannot explain completely situations strong influenced or dominated by size effects [71].
Leonardo da Vinci (1452-1519) states that between to cords the longest is the weakest. Later E. Mariotte (1620-1684) experienced with cords and corroborated that same material cords of different lengths subjected to same loads, are the longest the weakest and concluded that the reason for this phenomenon is that longest cords have faulty places. That is, the material is not isotropic and could have weaker points. The longer the cord is, the major the probability of weak points.

This simple problem with cords presents, in fact, an important issue. At microscopic scales size effects are determinant. However, the question arises when specifying the increasing influence of these size effects at other mesoscales and in material properties.

Studies on scale or size effects in scaling linked with physical theories appeared in the 70s and, concretely, with the use of concrete for scale models to replicate full-scale engineering works and building prototypes [22,23].

Since then, undertaken experiments introduced a new relation between two concepts until now separated: size and statistics [179]. Size effects were a statistical issue since probability of discontinuities in scaling may occur in materials.

W. Weibull (1887-1979) studied the statistical size effects in solid mechanics and his studies were employed after the 1980s in the case of fracture of quasi-brittle materials. Afterward, appeared the Theory of Linear Elastic Fracture Mechanics and the non-lineal Theory of Stress Redistribution and Fracture Energy Release.

Size effects were considered only as a matter for statisticians and, when they appeared, they were simply left aside and considered as random effects.

Being statistical analysis very worthy, other approach to size effects through non-Euclidean geometry appeared.

Scaling an object - model, cube or building - is just an Euclideangeometrical exercise. "Scale" physical phenomena - reaching a "miniature universe" - is not possible, but it is possible to say that some critical phenomena are multiscale [146]. These scales in physical phenomena are progressively approaching geometrical field with findings in non-Euclidean geometries: the fractals.

Phase transformations, laser light formation, superconductivity, laminar to turbulent flow transitions or material failure, among others, are examples. Those phenomena are not possible to explain completely at certain scales with local physical laws [43].

Nevertheless, some authors have already pointed out the relation between size effects of these hypothetical "scales" of a physical phenomenon and its geometric fractal nature. Furthermore, they have evaluated the size effects of some physical phenomena and concluded that they have a fractal behavior. These researches are mostly related to the structural behavior [43] (see Section 6.1).

Heat transfers are also considered in this perspective. Since heat transfer is performed proportional to surfaces, heat exchange analysis of surfaces as fractal geometries increases considerable the surface heat exchange compared with the general mesoscale (human-scale) surface. These considerations would be critical at specific small scales of the considered object [60].

Thermal studies on Rayleigh-Bénard convection could be also an example of specific small-scale properties of a physical phenomena $[161,236]$. Its turbulent convection could derived in some kind of geometrical general patterns [72] such as hexagonal, spirals and straight rolls, looking very closely [229] and depending on the properties of the fluid motion.

A new perspective is opened if we considered that a scale model test is being influenced by a physical phenomenon in one of its scale stages. In this case, the general physical law would be valid but additional considerations of the micro- and mesoscale effects should be also taken into account, for example, due to fractal geometry.

In fact, research on this direction is already been taken specially in the structural field, for example, size-scale effects of cracks and 
Table 1

General bases for dimensional analysis in various branches of physics [224].

\begin{tabular}{lllll}
\hline & \multicolumn{2}{l}{ Basis } & & \\
\cline { 2 - 5 } & Length & Time & Force & Temperature \\
\hline Geometry & $\bullet$ & - & - & - \\
Kinematics & $\bullet$ & $\bullet$ & - & - \\
Statics & $\bullet$ & - & $\bullet$ & - \\
Dynamics & $\bullet$ & $\bullet$ & $\bullet$ & - \\
Thermodynamics & $\bullet$ & - & $\bullet$ & $\bullet$ \\
Heat-mass transfer & $\bullet$ & $\bullet$ & $\bullet$ & $\bullet$ \\
\hline
\end{tabular}

collapse mechanisms under the perspective of fractals are done in $[45,46]$.

\subsection{Dimensional analysis and theory of models}

Dimensional analysis is a theory applied to physical problems and based on mathematical concepts. The mathematical fundamental procedures of the theory are related to homogeneous systems of equations and are explained in detail by several authors $[217,70,111,196,197,39]$.

From the practical point of view, the implementation of the dimensional analysis to resolve physical problems does not imply excessive mathematical procedures. The procedure could be reduced to select a fundamental basis and resolve the corresponding matrix of exponents of a system of equations.

Table 1 shows diverse branches of physics and their corresponding fundamental bases. However, it is just a suggestion, since the study of the fundamental basis is also an issue to be developed and improved.

Most of equations related to dimensional analysis are based on Classical Dimensional Analysis (CDA), that is, they do not discriminate their bases into their axis coordinate system. On the contrary, a discriminated basis in dimensional analysis is called Discriminated Dimensional Analysis (DDA).

The consequences of using DDA are mainly two: introduction of dimensionless ratios between geometric characteristics giving "form factors" and secondly, introducing dimensionless groups that do not really take part of the problem [165,166,4]. However, geometric discretized base in the different coordinates supposes a improvement in some analyses [184].

Some books focus precisely on the engineer practical experimentation through the dimensional analysis [67,224,106]. They explain the general theoretical concepts and give also some examples of physic phenomena applications, on cases such as structural, fluid mechanics, heat transfer and electromagnetic phenomena $[147,224,106]$.

General requirements for achieving phenomenological similarity between scales imply geometric, kinematic and dynamic similarities. With Dimensional Analysis it is not strictly necessary to know physical laws or equations themselves for obtaining dimensionless parameters $[184,93,88,87,94,106]$.

Similarity requirements between model and prototype should fulfill:

$\pi_{\text {prototype }}=\pi_{\text {model }}$,

being $\pi$-parameters dimensionless.

If these parameters are equal, the physical studied response of the functional scale model and prototype would be equal.

This approach considers separately individual parameters involved in the physical phenomenon and, afterward dimensional analysis is applied. With this criteria Kósvar Szirtes bases his procedure of finding the $\pi$-parameters taking into account practical strategies to reach "designed" and convenient dimensionless parameters $[237,12]$.
However, there are other ways for obtaining $\pi$-parameters. According to Shuring [224] there are, on the one hand, the procedure of "Law approach based on governing physical laws" and, on the other hand, the "Equation approach based on governing equations".

Apart from using the governing equations, additional similarity of the boundary conditions should be fulfilled. Consequently, from the governing equations and boundary conditions, the equality of dimensionless parameters is required for phenomena similarity [73].

Whether using the known physical laws of the phenomenon or considering the hypothetical involved parameters, the advantage using this method to analyze scale changes is, basically, that variables can be combined in such a way that ratios between them become dimensionless.

These dimensionless values can have a physical meaning, revealing specific properties of the phenomenon being studied. A well-known example, among many, is the Reynolds number $(R e)$ for turbulent fluid motions.

Each physical problem has it own main dimensionless numbers, therefore, depending on the study the use of them is different. If the parameter time is considered, the applicability of the method turns more specialized [99].

In Section 6 on types of experimental scale models, main dimensionless parameters concerned to each phenomenon are specified.

\section{General application of experimental techniques for scale models}

Functional scale models are previously analyzed theoretically to search for possibilities of achieving similar behavior response in different physical phenomena.

In general, the requirements for phenomenological similarity between two scales are $[105,106,184,154]$ :

- Geometrical similarity.

- Kinematic similarity.

- Dynamical similarity.

These three requirements would be relatively important depending on the study case. Additionally, similar boundary conditions would also be required.

These three conditions for achieving similarity are enough in most of the cases, however, in those cases in which temperature plays a role, it should be added:

- Thermal similarity.

Unfortunately, it is impossible to get all similarities simultaneously. In this situation the functional scale model should be built in such a way that the involved phenomena could be considered "similar". For this aim, designers weights up similarity priorities that should be unavoidable considered for the scale model.

For this purpose, scale models could be classified in two main groups. On the one hand, scale models with geometrical distortions - unevenly scaled - for achieving similarity (see Section 5.1) and, on the other hand, scale models without geometrical distortions evenly scaled or undistorted (see Section 5.2).

\subsection{Geometrical distorted scale model technique}

This technique is based on generating geometrical distortions on scale models and, optionally, also in boundary conditions for compensating some changes occurring in physical laws across the change of scale. 
As an example, if a reduced scale model with thinner walls than its prototype is considered, the wall's conductance of the scale model increases linearly with the reduction of thicknesses of their walls; therefore, the reduced scale model will have more heat transfer by conduction than its prototype. For avoiding this extra heat losses, wall's thicknesses of the model should be maintained - or even increased. Those geometrical distortions may cause a heat transfer by conduction in the scale model similar to its prototype.

There are two main strategies used in this technique. First strategy is based on the analysis of the phenomenological laws of physics - thermal, structural, acoustic, etc - searching for relations between their parameters depending on geometrical variables.

Changing the length of the geometric variables, new conditions and values will appear for obtaining equal phenomenological response. This strategy could apply theoretical considerations related to Square-Cube law and general similarity (see Section 4.1).

Based on this strategy some authors like Grimmer $[95,96]$ developed their own distorted scale models but introducing some variations.

In his thermal study Grimmer makes some initial calculations before changing the scale of the model. He calculates conductances of the components of the reference prototype separately - walls at different orientations, roof and floor.

Then, he calculates, also separately, the heat capacity of the internal components that are able to absorb heat in the prototype. Massive walls, furniture or bookshelves are elements susceptible to absorb and retain heat.

Once this is already done, conductances are multiplied by their corresponding total areas. He calls them "total conductances", however, they could be interpreted also as "loss factors" with units $W /{ }^{\circ} \mathrm{C}$.

Already calculated loss factors of the walls, floor and ceiling, all are summed.

He does not make the calculation of the loss factor of glazed surfaces. It means that he is considering the case in which the heat gains are being taking place through glass and no heat loss occurs through them.

Then, he divides the loss factor of the opaque surfaces by the total glazed surface area. Thus, he obtains a loss factor parameter as a ratio of loss factor of opaque elements to the glazed surface it is a normalized loss factor parameter.

With this normalized parameter the invariability rule across the scale change is set. So, the "distribution" of the value of the loss factor among the various components (walls, roof and floor) of the scale model takes place producing components of convenient thicknesses.

The result is a distorted scale model, which theoretical similar thermal behavior but with no formal resemblance to the original prototype [95,96].

This example of Grimmer is representative and it is using normalized parameters for defining the adequate geometrical distortion for the scale model.

Other authors $[184,106,56]$ use the strategy based on dimensional analysis theory (see Section 4.4).

In this second strategy, after obtaining the dimensionless parameters of a specific problem, whether by the known physical laws or by its list of involved parameters, the comparison of $\pi$-parameters of the prototype and model could be accomplished.

The replication of the physical phenomenon may rest on one or several important $\pi$-parameters depending on the problem. The designer should determine which of them are absolutely necessary for similarity.

Sometimes, by observing these important $\pi$-parameters, it is possible to determine the total or partial conditions for achieving similarity. These conditions could be very diverse depending on the case.
As this technique has no geometrical restrictions, changes on geometrical characteristic of the model are allowed and, therefore the distorted scale model is built.

If after theoretical analysis, the necessary changes of the scale model do not relate to geometrical changes, just changes on material properties or boundary conditions, a functional undistorted scale model with possibilities of time-dependent control would be possible (see Section 5.2).

\subsection{Time-dependent or geometrical undistorted scale model technique}

This technique corresponds to proportional undistorted scale models, that is, those in which every geometry is evenly scaled in accordance to the scale factor.

If even their materials are equal, they could be called replicas. If their materials are different, they are called dissimilar material model [15].

Antoni Gaudí y Cornet could be considered an early precursor of these models if we consider the catenarie models as a kind of "dissimilar material model". In his models the final form and design of the full-scale prototype are somehow recognizable.

Sometimes in structures it is possible to keep the external appearance of the model with the prototype changing the properties of the structural material - no its geometry -, choosing a denser or lighter for example, or changing the corresponding load pressure [27].

This technique use also approaches through phenomenological laws of physics (see Sections 4.1 and 4.2) but, in contrast to Section 5.1, with strong restricted geometrical conditions. For this reason, the only way to approach similarity is:

- Material properties: dissimilar material model.

- External conditions or boundary conditions.

If instead of applying the laws of physics on undistorted scale models for buildings, a dimensional analysis strategy is developed (see Section 4.4), all or almost every $\pi$-parameters involved in the studied phenomenon will not match in any case. It means that Eq. (3) will not be fulfilled. Consequently, the scale model will be affected directly by scale or size effects (see Section 4.3).

This undistorted scale model technique is used mainly by engineers in structures because structures do not have, in general, a strong time-dependence constraints compared with fluid dynamics or thermodynamics.

In thermodynamics, for example, even being undistorted scale models replicas of their prototypes, uncontrollable variables like ambient air temperatures at outdoor climate or in laboratory, result into unavoidable transient different thermal responses than their respective prototypes.

These differences are related to their increase - or decrease - in thermal mass, which is caused by the simple fact of the proportional variation of the thickness of the walls, among other components.

However, in the case of thermal responses, it is possible to avoid the influence of time on undistorted scale models if they are subjected to quasi-stationary conditions, that is, reducing their time-dependence [212,159].

Differences in analysis between quasi-stationary and nonstationary situations on undistorted models are remarkable. While in quasi-stationary or stationary conditions reaction's time is less or not contemplated in scale model's indoor or outdoor temperature changes and, therefore, is not affected by the change of scale, in non-stationary situations reaction's time to scale model's indoor temperature changes has to be considered unavoidably, with the difficulty that it entails. 
In these latter cases, data recorded by scale models will not resemble the corresponding of prototypes. For that reason, the appropriate transformation of model's recorded data must be done. Corrections to experimental recorded data should be undertaken, such as, phase shift of temperatures, radiation and internal air properties corrections, in order to match data with those of the prototype [159].

\section{Types of experimental scale models for buildings}

Buildings are subjected to many physical phenomena such as the case of gravity, aerodynamics, thermodynamics or hydraulics, among others.

The scope of experimentation with scale models of buildings is very diverse and not necessarily implies the use of a complete scale model of a building. Sometimes, tests related to buildings with scale models are done only with specific parts involved in the studied case.

In this section functional scale models for buildings are classified according to the principal phenomenon involved, as different cases will required different strategies of similarity criteria and analysis.

Thus, each following subsection will count with an overview of the technical particularities for experimentation in its field.

In this way, main criteria of similarity for each case are exposed together with their respective dimensionless numbers if applied. Additionally, construction techniques and complement facilities pertinent in each case are described.

In following tables on scale model for buildings, the column of "Analysis" is related to the applied analytic strategy for scale models.

These strategies are divided in four: "Dimensional", "Similitude", "Statistic" and "Simulation".

"Dimensional" and "Similitude" are those methods already mentioned in Sections 4.4 and 4.1. "Statistic" refers to statistical strategy mentioned briefly at page 77 in Section 4.3. Finally "Simulation" are those scientific papers based mainly on simulations but additional partial scale model were built in order to validate them.

\subsection{Structures for buildings using scale models}

To summarize in one unique method the procedure of structural analyses with scale models is difficult, mainly because there are many ways to approach a structural problem and the creativity using scale models plays also a big role.

Historically, one of the fields closer to architecture is the structural stability of constructions. Not only the structural stability is fundamental, but also the structural challenges have been historically a benchmark for prominent buildings full of meaning.

Structural challenges have been undertaken, and originally the builders had no other option than to test these challenges in form of scale models. These tests prevented the possibility of casualties in cases of high risk of collapse, for example.

Harry S. Harris [101] defines a structural model as:

"any physical representation of a structure or a portion of a structure. Most commonly, the model will be constructed as a reduced scale."

This section analyses general structural scale models used for buildings, more frequently of reinforced concrete and structural steel but also of brickwork under gravitational or dead loads.

Following subsections classify scale models according to loads in motion, such as the movement of earth in an earthquake (see Section 6.1.1) or the movement of fluids, such as water (see Section 6.1.2) and wind (see Section 6.1.3).

Note that this classification could be widen to other kinds as those made by Harry S. Harris [101] classifying structural models as: elastic, indirect, direct, strength, wind effects and dynamic models.
With the spread of the dimensional analysis (see page $78 \mathrm{Sec}$ tion 4.4) and theory of similitude (see page 76 Section 4.1), critical analyses of historical buildings with scale models are made [110].

The center of their analyses are arches and vaults made with masonry structures and under the scope of Galileo Galilei's SquareCube law - so stresses grow linearly with increasing in size of these constructive solutions.

These studies analyze the Square-Cube law versus the Principle of Similarity - implicitly the Dimensional Analysis - in masonry structures. They mention the limit of the structures through the change of scale, establishing this limit in form for critical stability.

From this point of view previous historical buildings were analyzed and, it was concluded that historical architectural forms are comprehend in a range of dimensions without compromising the stability of the structure [79]. In other words, historical building structures were oversized, far from their critical point.

Only in very extreme cases with very large spans in historic building structures are critical and the Square-Cube law becomes essential. In those extreme cases, distortions through lightweight structures and additional tensors were employed [79].

Antoni Gaudí y Cornet optimized his building designs precisely with catenary models achieving new forms [109].

Other case of study is the cupola of Santa Maria del Fiori scale model [122]. In this scale model, constructions techniques used in Renaissance were evaluated.

Historically, double curvature shells with reinforced concrete were tested in the middle of the nineteenth century through scale models. For example, Eduardo Torroja Institute, was one of the centers on developing these tests.

Reinforced concrete roofs were studied because its double curvature nature [27].

In this epoch computer analyses were extremely complicated and scale models were considered ideal to get experimental data.

Material properties play a fundamental role in structural similarity. The relation of stress and strains of the material used in the scale model and in the prototype should be equivalent, that is, the Young's modulus. Additionally, Poisson's ratio should be also equivalent.

If these conditions are accomplished, assuming same load per surface equivalence, the scale of stress are equal.

In order to build functional structural scale models for buildings, full-scale material properties, such as maximal strength or density should be determined.

From these full-scale material data, other properties of the material of scale model can be calculated.

After selection of the ideal material for the scale model, other decisions can be made, for example, once the material density of the scale model is fixed, additional loads can be estimated.

Some authors opted to use totally different material, as in those scale models using litargel [27], that is, a mixing of litargio, glicerina and water. This material is sufficient rigid for not collapsing and sufficient flexible for deformations requirements. In the case of reinforced concrete, no scale wires simulating full-scale corrugated reinforcement of the full-scale prototype were considered.

Equal materials could be used in scale models, for example reinforced concrete. This could be also down-scaled with a new dosification and aggregate size.

Some Ph.D. Thesis took advantage of the theory of scale models to develop their research with concrete structures. In [50] a research on the pre-stressed concrete beams with the help of scale model beams of dimensions $44 \mathrm{~mm} \times 65 \mathrm{~mm}$ and a length of $1000 \mathrm{~mm}$ were undertaken. As corrugated steel wire was used a piano wire.

Heinz Hossdorf (1925-2006) opted to use also same material in his scale models for replicating full-scale reinforced concrete. With his work, he filled the gap left on the scale shell structures 
Table 2

Summarized general experimental structural tests with scale models.

\begin{tabular}{|c|c|c|c|c|c|c|}
\hline \multirow[t]{2}{*}{ Author } & \multicolumn{6}{|l|}{ General characteristics } \\
\hline & Dimensions (m) & Scale & Type & Analysis & Material & Test \\
\hline$[24]$ & $3.20 \times 1.53 \times 1.25$ & $1 / 4$ & Building & Dimensional & Concrete & Airblast \\
\hline [134] & $0.06 \times 0.08 \times 0.4$ & $1 / 5$ & Column & Dimensional & Concrete & Strength \\
\hline [122] & $\emptyset 11$ & $1 / 5$ & Dome & Dimensional & Masonry & Construction \\
\hline \multirow[t]{2}{*}{ [137] } & $0.0123 \times 0.0125 \times 0.2$ & $1 / 40$ & Beam & - & Concrete & Strength \\
\hline & $0.12 \times 0.12 \times 0.01$ & $1 / 40$ & Slab & Similitude & Concrete & Strength \\
\hline \multirow[t]{3}{*}{ [178] } & $0.107 \times 0.05 \times 0.0325$ & $1 / 2$ & Probe & Similitude & Masonry & Strength \\
\hline & $0.05 \times 0.025 \times 0.016$ & $1 / 4$ & Probe & Similitude & Masonry & Strength \\
\hline & $0.036 \times 0.016 \times 0.011$ & $1 / 6$ & Probe & Similitude & Masonry & Strength \\
\hline [61] & $3 \times 4 \times 0.81$ & $1 / 3$ & Building & Dimensional & Wood & Strength \\
\hline [112] & $1.75 \times 3.6 \times 1.65$ & $1 / 2$ & Building & Dimensional & Adobe & Strength \\
\hline [90] & $0.05 \times 0.08 \times 0.381$ & $1 / 8$ & - & Similitude & - & - \\
\hline
\end{tabular}

built during the most prominent buildings and designs [47]. Among them, special interesting are the cases using micro-concrete for replicating reinforced concrete full-scale prototypes [108].

This micro-concrete was used with pre-tensed structures, mostly roofs. Some examples of this kind are the structural scale models of the Sydney Operal Hall, University Roof of Basilea Library, Milan Pirelli skyscraper and the Olympic Games Swimming-pool roofs in Tokyo.

The first regulated use of scale models to evaluate structures was registered in New York regulations in 1969, however, under restricted conditions (Table 2 ).

Afterward, the Committee 444 of the American Concrete Institute (ACI) was constituted for establishing the proper conditions in scale model experimentation for acceptance as assessment method. The Committee was dedicated to the recommendations in concrete for scale models to be tested. It served very much in scale models tested under seismic phenomena (see Section 6.1.1). The article 19.2.4 of the ACI-318-95 on Building Structure Requirements for Structural Concrete permitted specifically scale models of experimental shells.

Since the establishment of the regulations in scale models in concrete structures, tests are spread in laboratory for obtaining structural performance of whole buildings or parts of them $[134,137,90]$.

Concrete structures are the most frequent cases among functional structural scale model tests. However, there were also masonry scale models although they were not very spread.

Structural behavior comparison of masonry between different scales is possible, although the strength and stiffness are not similar. For this reason, tests with not-so-reduced scale models of prototypes were done, specifically at $1 / 2,1 / 4$ and $1 / 6$ scales, and were subjected to compression [178].

Limits of scale modeling in structural masonry are suggested to be $1 / 12$, other authors set the reasonable limit to $1 / 2,1 / 3,1 / 4$ and $1 / 6[178]$.

Metal structures were also tested through scale models. Thomas M. Marray researched quarter scale models of a thru-fasterner in metal building roof system supported by Z-purlins and subjected to gravity loads [186].

In general, whatever material is used in the scale model, loads are conditioned by them. For example, the use of litargel influenced the considerations of the loads, since its density was relatively more than the actual concrete. Thus, only this material weight load without any additional dead loads - was necessary to achieve equal ratio of load per surface compared with the full-scale prototype [27]. The initial weight of the scale model structure influences other additional dead loads to be applied for achieving proportionality between scale model and prototype.

Load stages, so time-dependent processes, in the scale model are also very important. Gradually loading must be taken into account, so gradual loads are occurring in real world, brusque load cases and their consequent cracks should be avoided.
For achieving this goal, some authors use loads hanging under scale models and over a pond full of water. Each load has a float keeping them floating over the surface of the water and avoiding them to act on the scaled element. For progressive loading, the pond is gradually emptied, therefore, the loads are progressively acting [27].

Other historical important issue were measure devices. They were a very strong determinant to be planned forehand because of their weight and size.

For collecting information about flexural actions or moments and about deformation, fleximeters and extensometers were used, respectively [27].

Today, the 1981 recommendations of scale models up to $1 / 5$ scales for structural tests alluding reasons of load bearing and instrumentation system adapted to the scale size are obsolete [181]. These restrictions are overcome with new technology and minituarization.

Apart from the measure devices, there were other ingenious methods to measure the initial effects of the weight load on a structural scale model, and thus to discover the first cracks in form of isostatic lines.

For this, a fine varnish layer were spread over the surface of the studied body [27]. In this way, first movements are visible through these cracks. If litargel were used, thereafter a fine lead oxide layer is applied to penetrate cracks and for arising these lines.

Decisions about materials, loads and measure devices are simple compared with the interpretation of the results. This is the most difficult point of scale model testing.

Although theoretical similarity conditions are possible to be determined, exact practical equivalences between stresses of scale models and prototypes are not easy to achieve. Thus, results have to take into account carefully previous conditions of the designed scale model: geometric and load similarity.

It is for granted that errors may occur. For this reason, assuming differences of results, the question would be to what extend are errors' approach acceptable.

Supposing we assumed a certain approximation error, lets say $10^{-2}$, and the material and loads of the full-scale are known, consequently its total weight and maximal tension, i.e. $30 \mathrm{~kg} / \mathrm{cm}^{2}$. The assumed error means that tensions for the full-scale would be in a certain range of error, $0.3 \mathrm{~kg} / \mathrm{cm}^{2}$. If the scale model has proportional coherent weight as the scale factor $1 / 10$ - considering adequate material density -, the maximal tension would be scaled proportional to the prototype's, $3 \mathrm{~kg} / \mathrm{cm}^{2}$. The material density is chosen in a way that no additional loads are required. From this scale model's tension, the assumed error result is $0.03 \mathrm{~kg} / \mathrm{cm}^{2}$.

However, measure devices' have normally their own error range, i.e. $10^{-4}$. Therefore, if we divide the model's acceptable error of the tension by device's error, $0.03 / 10^{-4}$, we will obtain $300 \mathrm{~kg} / \mathrm{cm}^{2}$ that would be the required Young' modulus of the scale model's material for obtaining measurement in the 
Table 3

Summarized experimental seismic tests with scale models.

\begin{tabular}{|c|c|c|c|c|c|c|}
\hline \multirow[t]{2}{*}{ Author } & \multicolumn{6}{|l|}{ General characteristics } \\
\hline & Dimensions (m) & Scale & Type & Analysis & Material & Facility \\
\hline [254] & 0.16 & $1 / 5$ & - & Dimensional & Concrete & - \\
\hline [181] & $0.025 \times 0.05 \times 0.035$ & $1 / 14.4$ & Beam & Dimensional & Concrete & Shake table \\
\hline [135] & $0.051 \times 0.038 \times 0.255$ & $1 / 6$ & Beam & Dimensional & Concrete & Mechanisms \\
\hline [89] & $1.6 \times 1 \times 2.55$ & $1 / 3$ & Building & Dimensional & Concrete & Shake table \\
\hline [246] & 0.34 and $\emptyset 0.076$ & $3 / 16$ & Columns & Dimensional & Concrete & Shake table \\
\hline [188] & - & - & Columns & Similitude & Concrete & Shake table \\
\hline [63] & $\emptyset 0.4$ & $1 / 50$ & Arch & - & Masonry & Shake table \\
\hline [243] & $1.71 \times 2.18 \times 2.65$ & $1 / 4$ & Building & Dimensional & Masonry & Shake table \\
\hline [30] & $0.051 \times 0.0825 \times 0.38$ & $1 / 8$ & Column & Similitude & Concrete & Shake table \\
\hline [201] & $0.148 \times 0.096 \times 0.094$ & $1 / 2$ & Masonry & Dimensional & Masonry & Compression \\
\hline [66] & $0.5 \times 0.032 \times 0.52$ & - & Frame & Similitude & Steel & Shake table \\
\hline [190] & $0.75 \times 0.625 \times 1$ & $1 / 3-1 / 4$ & Masonry & Similitude & Masonry & Shake table \\
\hline
\end{tabular}

acceptable range of assumed error without requiring additional loads in the scale model, that is, with only its weight load [27].

Nowadays, these scale models are not so vital with the use of structural simulations and with the well-known field of the structural engineering.

Already in 1988 there were comparisons of scale models versus 3D-computer calculations. Irwin G. Cantor published a paper comparing both procedures [42]. In his papers it claims onto the validity of scale models in their rolls of useful procedure to understand and check the computer results.

In the seventies a new theory enriching the structural analysis raised with the research of a new geometry concept: the fractals [22].

Fractals are linked to the concepts of geometry and scale. Fractal geometry is proved to be present in nature and, it is already proved, it has influence in size effects at different scales of materials. Additionally, it is improving the knowledge in structural behavior, overall in the non-linear behavior, and is helping to interpret results of structural scale models.

The symposium which took place in Turin in 1995 was an example of the advances in the influence of size effects through fractals in the structural scale models [43]. There, scientists from different countries exposed their researches related to the fractal nature of the behavior of the scale model structures.

After the symposium more specific researches appeared with specialized structural cases $[45,46,44]$.

Studies of structural size effects can be approached from this perspective. For example the study of size effects on masonry under compression. Additionally, other improvements such as the use of today new 3D-printed manufactured scale models, has helped to further the understanding of collapse mechanism in masonry. This approach has been first introduced by Prof. Phillipe Block, together with Prof. John Ochsendorf at MIT [31].

Structural tests were made to 3D-printed complex masonarylike vaults in [32] for investigate the stability and collapse mechanisms of discrete structures under e.g. support displacements or concentrated live loads. This approach has provided new insides into the stability of masonry domes giving additional reasons for scale models as invaluable design tools in building structures and exposing additive manufacturing as appropriate technique to achieve this purpose.

\subsubsection{Seismic loads in scale models for buildings}

The complexity of earthquakes' mathematical models and their transient nature makes necessary to consider tests of whole structures under their effects.

Historically, the only way to test in reality these effects was using functional scale models of buildings. Thereafter, these scale model tests were compared with the analytic simulations.
Scale models of structures of buildings subjected to mobile loads suffer the same problems as those under static loads. Equally, they also use the same kind of procedures to get properties of materials comparable to those of the prototype, such as, micro-concrete (Table 3).

These procedures can be summarized into [254]:

1 In functional undistorted scale models, dead loads are reduced linearly with scale model reductions, and therefore, stresses due to dead loads are considerable less than those from their prototypes of reference. To avoid this inconvenient, whether a denser material or increased loads in scale models is possible.

2 More quality control of the construction since tolerances for scale models are smaller than for corresponding prototype's.

3 Both, concrete and steel behavior, vary across scale changes. Specially, the apparent strength of the concrete increases with the decrease in scale. This is a consequence of the mixed material being scaled down or of using micro-concrete.

However, even if the concrete is not scaled, there is an increase of strength due to the less probability of internal small cracks in the scale model, so the presence of weaknesses is proportional to the volume, according to Keith [254].

Considering reinforced concrete structures in scale models, if the strength increases compared with loads, their stiffness will increase also. Since stiffness is one of the principal issues in seismic calculus, this should be considered in seismic tests.

4 The corrugated bars of the reinforcement are often replicated with plain wires in scale models and this also contributes to less internal cracks.

5 Shrinkage and creep increase with increasing moisture transfer and scale models have more transfer surfaces available with respect to their volumes [100].

However, according to White and Chowdhury [252] the presence of fewer cracks in scale models will not produce any measurable differences in moments and deflections.

In 1959 the Symposium RILEM [181] in Madrid focusing on the general aspects of dynamic modeling theory and material behavior, accuracy predictions through small-scale tests were addressed. There, similarity strategies for motion testing such as elevated tanks with mercury in it to simulate water, brass to simulate steel or hanging loads or springs to simulate rigidities of the walls were presented.

To perform scale models under load motions, techniques such as the case of "shaken tables" were applied up to 1968. Those tests were carried out with sinusoidal motion.

Later, shaken tables improved incorporating electro hydraulic mechanisms to replicate more complex motions. 
Grant Keith Wilby in his Ph.D. Thesis used shaken tables with electro hydraulic devices for replicating more accurate earthquake motions [254]. Facilities such as the shaken tables of the UC Berkeley with $6 \mathrm{~m} \times 6 \mathrm{~m}$, of Istituto Sperimentale Modelli e Strutture in Bergamo, of Laboratorio Nacional de Engenharia Civil in Lisbon and of Institute for Research and Testing in Materials in Ljubljana, Yugoslavia [181] were some of them.

In cases where gravity effects are small compared to seismic effects, the model without simulation of extra gravity forces are adequate. In those cases, in which gravitational and inertial effects are equally important a full similitude should be achieved [181].

In these cases, in which the physical phenomenon is complex, dimensional analysis is an alternative for obtaining correspondences between scale models and prototypes [254]. Dimensional analysis gives similitude requirements and the perfect match between both, prototype and scale model, would be the fulfillment of the condition of equal $\pi$-parameter (see Eq. (3) page 78 Section 4.4).

If some of them are not fulfilled, the alteration of other $\pi$-parameters should be taken into account for maintaining similitude, causing distortion in the models.

In seismic testing, inertial and restoring force are essential for dynamic responses. If the ratio between both are equal in the prototype and in the scale model, the response would be equal.

The application of the dimensional analysis gives the possibility of two strategies: whether to use the similitude of Cauchy or the similitude of Froude [254].

Cauchy similitude implies the use of free mass scale factor, however, carrying the variability of time affecting acceleration in the scale model. Consequently, it affects to:

- Horizontal acceleration: the applied horizontal acceleration can increase relatively easily.

- Vertical acceleration (gravitational): difficult to apply. Some strategies are setting additional loads but this is not exactly as gravity works. If it is a steel model, a magnetic field could be applied at the floor for increasing its weight with less height. A centrifuge rotational force can also be applied, but this is difficult to accomplish [254].

Seismic testing with scale models serves for analyzing specific parts of structures, completing experimentally other structural simulations. For example, the study of a column of a bridge which is particular sensible component to seismic movements [246], or the study of structural column responses of concrete and Engineered Cementitious Composite (ECC) for buildings [30]. ECCs are fiber-reinforced high-performance material with a good damage tolerance.

Other study with new material composition is the particular case of the performance of the Autoclaved Aerated Concrete (AAC) confined masonry buildings [243]. In this case, a full-scale building is simulated under laboratory control conditions through three $1 / 4$ scale models with two different constructions: lightweight prefabricated slabs and reinforced concrete slabs.

Traditional construction tests, such as an existing single-storey traditional adobe building are taking place through its corresponding $1 / 2$ scale model [112]. The scale model was built with unreinforced adobe masonry and was subjected to horizontal loads. Used scales for testing adobe buildings with shaking tables are in the range of $1 / 1.5,1 / 2.5,1 / 3,1 / 5$ and $1 / 10$.

An example of steel scale models under seismic motions is an experimental model consisting on a steel frame for studying collapsing events by exceeded bearing capacity and by dynamic instability. P-Delta effect, that is, reduction of resistance in structures subjected previously to lateral deformation - is observed.
The effects of the dynamic loads are replicated by a shaking table method [66].

These situations constitute a nonlinear analysis even with materials with a well known mechanical properties.

\subsubsection{Hydraulic loads in scale models for buildings}

The scale model subjected to hydraulic pressure are mainly related to engineering field. Dams, ports and dikes are the most common cases.

Fluid dynamic is a phenomena which implies uncertainties and a lack of proper comprehensive analytical law, for these reasons, it is adequate for scale model research.

Water movements affecting buildings are rare. However, some typologies could be analyzed under this perspective, for example, scale models to evaluate the performance of evaporation from indoor swimming pools [10,214].

In this case, the scale basin of the swimming pool was inserted into a climatic chamber for air temperature and relative humidity control. Additionally, a water heat system was incorporated.

The mass transport coefficient has the same significance as the convection coefficient concerning heat transfer. Dimensionless numbers such as Sherwood and Schmidt, equivalent respectively to Nusselt and Prandtl in convective heat transfer, are used. If scale model's and prototype's diffusivity, viscosity and velocity of air are equal, the mass transport coefficient correspondence is a geometric relation.

Dimensional analysis gives the main $\pi$-parameters to take into account in cases of dynamic similarity. Froude (Fr), Reynolds $(R e)$, Weber $(W)$, Cauchy $(C)$ and Euler $(E u)$ numbers are the main dimensionless numbers. Specifically, in hydraulic phenomena $F r$ and $R e$ are considered depending on the physical nature of the problem.

In problems where frictions effects are negligible or turbulent, $\mathrm{Fr}$ is to be considered, while if specific boundary effects of the viscous layer are expected, Re number is applied [105].

\subsubsection{Aerodynamic loads on scale models for buildings}

These tests are originally from aeronautics. Airplanes are tested in wind tunnels to prove their aerodynamic performance and they are subjected to wind pressures.

Wind tunnel tests for buildings were also undertaken since buildings are also subjected to air pressures (Fig. 2). Overall, it is interesting for testing building structures subjected to high wind pressures and suctions such as skyscrapers or large span roofs of auditoriums or halls in which suction pressures of wind could cause forced detachment or collapse.

Indoor air movements are also originated by differences in air pressures or temperature differences. However, these phenomena are not treated in this section but in thermodynamic Section 6.4. Usually, this kind of air convection movement does not compromise the integrity of structures.

Real dynamic loads on buildings, such as wind loads, are very difficult to foresee. The solutions to these uncertainties are mostly whether to increase safety factors of structures in simulations or

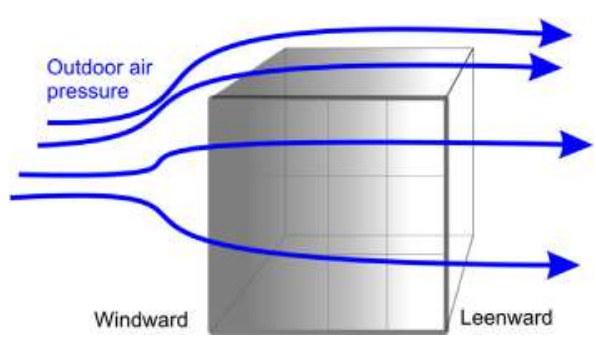

Fig. 2. Outdoor air pressure in a generic cubic scale model. 
Table 4

Summarized experimental aerodynamic tests with scale models.

\begin{tabular}{|c|c|c|c|c|c|c|}
\hline \multirow[t]{2}{*}{ Author } & \multirow[t]{2}{*}{ Dimensions (m) } & \multicolumn{5}{|c|}{ General characteristics } \\
\hline & & Scale & Type & Analysis & Material & Facility \\
\hline [59] & - & - & Building & - & - & - \\
\hline \multirow{2}{*}{ [117] } & 1.2 height & $1 / 450$ & Tower & Dimensional & Epoxy/aluminium & Wind tunnel \\
\hline & - & $1 / 60$ & Tower part & - & - & Wind tunnel \\
\hline [156] & $0.11 \times 0.11 \times 0.73$ & $1 / 500$ & Urban & Similitude & Frame/foam/balsa & Wind tunnel \\
\hline [175] & $0.12 \times 0.14 \times 0.14$ & $1 / 160$ & Urban & Dimensional & - & Wind tunnel \\
\hline [167] & $0.137 \times 0.091 \times 0.04$ & $1 / 100$ & Building & Similitude & Plexiglas & $1.1 \times 0.8 \times 4$ \\
\hline \multirow[t]{2}{*}{ [211] } & $1.44 \times 1.03 \times 0.36$ & $1 / 150$ & Building & Simulation & - & Wind tunnel \\
\hline & $1.15 \times 0.57 \times 0.10$ & $1 / 100$ & Building & Simulation & - & Wind tunnel \\
\hline [256] & $0.14 \times 0.14 \times 1.05$ & $1 / 400$ & Building & Similitude & - & Wind tunnel \\
\hline [218] & $0.178 \times 0.1 \times 0.07$ & $1 / 200$ & Building & Similitude & - & $3 \times 1.5 \times 11$ \\
\hline
\end{tabular}

to determine more accurately wind loads using functional scale models in wind tunnels.

In aerodynamics two types of testing are differentiated [175]. On the one hand, the aeronautical aerodynamics, which is working on fuselage and perturbs very little the wind flow.

On the other hand, the civil aerodynamics, which bodies under wind pressure are not exactly aerodynamic-shape structures.

These two types make the difference in the analytic calculus procedure being more difficult with not-aerodynamic-shaped bodies analysis.

These differences applied to functional scale model testing for building are important since architects should consider if their building designs are aerodynamic or not.

Considering the most common case in buildings - a nonaerodynamic form or parallelepiped - to determine the scaled wind loads over it, dimensionless numbers related to dynamic flows should be considered.

Simultaneous satisfaction of Eq. (3) is impossible, hence, those with less importance are left aside.

The main dimensionless numbers related to dynamic flows are:

- Euler number, $\mathrm{Eu}$, that is, the relation between pressure forces and inertial forces. In wind tunnels with scale models for buildings, Euler number used to be doubled and it is called pressure coefficient. It is an alternative parameter to $R e$ in situations were Re is negligible [215].

- Mach number $M$ is the relation between the fluid flow velocity and the sound velocity in this specific fluid, $U_{\infty} / a_{\infty}$, being $U_{\infty}$ the fluid velocity and $a_{\infty}$ the sound velocity. It is also related to the compressibility of a fluid. With $M$ numbers below 0.3 in fluid movements the phenomenon are considered as incompressible flow.

- Reynolds number, $R e$, is the most significant parameter. It is the relation between inertial and friction forces. A low Reynolds value means large viscosity forces compared with convective forces in the fluid, and the flow would be laminar. On the contrary case, fluid's turbulence will not be amortiguated by their viscosity and therefore the turbulence persists.

If $\rho$ is the fluid density, $U$ is the fluid velocity, $L$ is the characteristic length and $\mu$ is the dynamic viscosity of the fluid, Re number is expressed as follows:

$R e=\frac{\rho \cdot U_{\infty} \cdot L}{\mu}$,

If a scale model and its prototype building are immerse in equal fluid, then the product $\left\{U_{\infty} \cdot L\right\}$ should be equal, that means, if the scale model is $1 / 100$ then the velocity of the wind should be 100 times greater than reality. As consequence, $M$ number would increase in the same proportion and, therefore, the fluid regime could exceed the values for incompressible fluids.
In general, there is a contradiction between the possibilities of maintaining Re and $M$ numbers. The requirements of both numbers could be relax in cases of tests with bodies with edges (no in case of fuselage), that is, with standard parallelepiped buildings (Table 4).

Overridden a critical value of the Re number, its value is independent of dimensionless forces and moments. The reason is that in tests with edged bodies, film layers are easily detached from their surfaces at low $R e$ values. So, the pre-requisite of the correspondence of air Reynolds number affecting a scale model and its prototype building is unnecessary so far Reynolds is over a critical value [175].

There are other characteristic $\pi$-parameters related to building tests in wind tunnels to consider:

- Jensen number, Je [119], is used in cases of reproduction of wind over grounds (atmospheric boundary layer), where influence of turbulence in urban areas is studied. It is the relation between the characteristic length of the model, $L$ and the characteristic length of the roughness of the ground $z_{0}$. Reaching Je number correspondence between model and prototype, the equivalence between indoor turbulence of the tunnel and natural flow wind are pretended $[175,231]$. In other words, there would be equivalence of whirlpools of the air of the tunnel and whirlpools of the natural air. Je number could influence at a certain rate but it is insignificant reaching certain values depending on the bodied studied [62].

- Strouhal number, St, indicates the influence of non-stationary movements, for example, periodic frequencies [175,231]. Being $n$ the characteristic frequency, the $S t$ is the relation $\left\{n \cdot L / U_{\infty}\right\}$.

- Cauchy number, $C$, demands similarity of elastic properties between scale model and prototype. Buildings will have a response to wind depending on their damp coefficient and elastic properties. Therefore, the $C$ number similarity will be required. It is defined as the relation $\left\{E /\left(\rho \cdot U_{\infty}^{2}\right)\right\}$.

Building testing priority in wind tunnels should be previously established due to the impossibility of fulfillment with every $\pi$ parameter.

Messeguer [175] recommends to relax conditions of Je because of the relative similarity of open field turbulences. St, C, Eu and $M$ numbers could be left aside so far the problem is not involving directly these phenomena.

Consequently, Re number is unavoidable in cases of wind pressure over buildings structures. The similarity of flow pressures is assured with the similarity of Re numbers, and in civil structures it is only necessary to assure Re numbers over a critical value [175,231].

Aerodynamical scale models for architects could be classified into different types according to test classes [175]:

1 Topographic models: urban scales in the range of $1 / 5000$ and $1 / 2000$. The roughness of terrains is increased to avoid unrealistic aerodynamic surfaces. 
2 Direct measures of pressures on rigid bodies: scales in ranges of $1 / 500$ and $1 / 75$. The scale models for buildings in this kind of tests should have natural frequencies higher than flow frequencies for avoiding natural vibrations of scale models.

3 Aereo-elastic models for buildings: scale models in ranges of $1 / 300$ and $1 / 100$. Scale models' movements should be similar to prototypes'. Natural frequencies and damping should be also similar. Usually, these tests are done with rigid scale models with elastic supports.

Technical Universities built wind tunnels as educational and research media. In the Escuela Técnica Superior de Aeronáutica of the Technical University of Madrid, some wind tunnels were built in the 70 s for testing $[220,219]$. They exist today and tests with prominent buildings are undertaken.

Most tests related to buildings in wind tunnels are high-rise buildings such as the test performed in 1975 by Dalgliesh [59]. This consisted on a scale model of a glazed 57-storey building to test wind pressures over the structure and cladding of the façade. Other measured tests with scale models were done in 1976 for the $555 \mathrm{~m}$ height full-scale CN Tower of Toronto, Canada. The 1/450 scale model was tested in wind tunnel [117]. Complementary to this, a partial 1/60 scale model test of the upper levels and adjacent parts of the shaft were performed. The dimensionless numbers for achieving similarity considered mass scaling of the inertial and flow forces, stiffness properties between the elastic forces of the tower and the inertial forces of the flow, and damping with dissipated and inertial forces of the tower. The full-scale reinforced concrete tower was scale-modeled with a metalized epoxy commercially available (Devcon A) with comparable modulus of elasticity, density and damping. Apart from high building tests, some other typologies such as intermediate high buildings were tested [231,215]. By intermediate high buildings are understood those whose height is between $20 \mathrm{~m}$ and $120 \mathrm{~m}$ and whose ratio of height to minimum width are under 4.

With these characteristics, Thor [231] built a scale model of a mid-rise building to test in wind tunnel for comparing it with other studies in which typical high skyscraper towers are involved.

One of the problems encountered in wind tunnel testing of lowrise buildings is the determination of the geometric scale. Other problem is the appropriate modeling of the atmosphere surface layer (see Jensen number on page 84).

In [62] was tested in wind tunnel the roughness length of the ground area, $z_{0}$, before the building to be studied. Therefore, the atmospheric boundary layer of the surface were calculated. Consequently, the comparison between the height of the atmospheric boundary layer and the height of the building could be done. Additionally, Re number were also calculated being $L$ the characteristic length as the average of the width and height of the wind tunnel's work section. Finally, with the viscosity of the fluid air, the velocity in which air becomes turbulent could be calculated.

The Jin Mao Building with $420.5 \mathrm{~m}$ height, the Chinese tallest building in Mainland, was tested under wind tunnel pressures simulating those of the Typhoon Rananim in August 2004 [156]. Comparisons with the scale model were possible because real fullscale measurements were taken in the building during this period. The ratio width-height was about 7 , being therefore an out-ofstandard slender in China regulations.

This $1 / 500$ scale model was a rigid model, made with balsa and foam and mounted on a metal frame rigidly connected to a force balance reaction bar. For considerations of surrounded flow conditions of the terrain into the wind tunnel, a matrix of cubes of different sizes and some additional barriers were placed before the wind generator. Wind force measurements were taken on the building model with six-component high-frequency force balance.
[24] used a 1/4 scale model of a reinforced concrete structure of a building to study the airblast effects on its structure. Airblast could be cause by bombs. The structure was tested with and without external Concrete Masonry Unit walls. The materials of the scale model and the theoretical full-scale prototype were equal.

Datin built a $1 / 3$ scale model for testing wind effects on a lightframed wood structure [61]. The use of experimental methodology was necessary because of the unpredictable of the wind distribution pressure on the structure. The origin of this study was the observation of the effects of hurricanes on the new-built wooden structures supposed to be resistant to such loads. In this case they paid special attention to geometric similarity. The results are comparable up to the yield point or elastic limit, since the wood material is not scaled and could fail differently from the full-scale prototype. A 50-yearreview on the use of computational wind engineering (CWE) serves also as critical review for scale models for buildings used in wind tunnels [33].

In this study, there is a specific section on reduced-scale windtunnel testing in CWE. It tries to answer the question whether wind tunnel tests are competing or complementing the computational fluid dynamics (CFD).

In it six main difficulties using scale models in fluid dynamics are initially mentioned. However, three of them are amended according to the number of successful researches and, finally, three cases where CWE are preferred to scale model in wind tunnel tests remain:

1 Small wind flow and dimensions. Scale changes can provoke radical changes of flow regimes.

2 Large wind flows with large scale factors. Scale changes can provoke also flow regime changes.

3 Meteorological phenomena such as tornadoes and downbursts.

It is recommended to use CWE instead of scale models in cases where the similarity conditions would be strongly violated. There are concerns about wind tunnel testing, however, some have reached good agreement even with large scale factors.

Normally, CFD simulations are compared with wind tunnel experiments or with full-scale prototypes. Even in some cases with both, such as the case of [241] analysis of wind flow around buildings and their effects on roof-mounted solar panels.

It considers simultaneously two energy efficiency strategies in buildings: wind turbines and solar panels. Buildings with combination of these two systems have to be in wind exposed locations and, additionally, the roof-mounted panels must resist wind pressures. The $1 / 250$ scale model was compared with its full-scale prototype. The dimensions of the scale model were $0.16 \mathrm{~m} \times 0.08 \mathrm{~m} \times 0.08 \mathrm{~m}$. The mounted panels are tilted in two situations, $10^{\circ}$ and $30^{\circ}$. Since these panels are tilted both cases, favorable and unfavorable wind direction, were analyzed.

[210] studies also the performance of a design wind tower in wind tunnels using particle image velocimetry (PIV) measurements. The wind tower was built at $1 / 16$ scale and was set due to wind tunnel's dimensions, $0.6 \mathrm{~m} \times 0.26 \mathrm{~m}$. In this case, the test is more like industrial test than integrated building test since it studies only the performance of wind towers without interaction of other external building spaces.

Finally, additive manufacturing technologies (see page $76 \mathrm{Sec}$ tion 3) are used to produce scale models for wind tunnel tests. AM technology and materials can significantly reduce time and costs associated with the fabrication of scale models suitable for wind tunnel testing [104]. The conclusions about suitability, time and costs in this article could be extrapolated from aeronautical field to buildings. 
Table 5

Summarized experimental acoustic tests with scale models.

\begin{tabular}{|c|c|c|c|c|c|c|c|}
\hline \multirow[t]{2}{*}{ Author } & \multirow[t]{2}{*}{ Dimensions (m) } & \multirow[t]{2}{*}{ Scale } & \multicolumn{5}{|c|}{ General characteristics } \\
\hline & & & Type & Analysis & Material & Facility & Media \\
\hline [91] & $2.26 \times 0.45 \times 1.81$ & $1 / 4$ & Wall & Statistic & Concrete & Lab. & Air \\
\hline [202] & $1.92 \times 0.24 \times 0.20$ & $1 / 50$ & Urban & Similitude & $\begin{array}{l}\text { Varnished } \\
\text { Wood }\end{array}$ & $\begin{array}{l}\text { Semi } \\
\text { Anechoic }\end{array}$ & Air \\
\hline [116] & $1.2 \times 1.2 \times 1.2$ & $1 / 15$ & Urban & Similitude & $\begin{array}{l}\text { Varnished } \\
\text { MDF }\end{array}$ & Anechoic & Air \\
\hline [85] & $4 \times 5 \times 2$ & $1 / 10$ & Building & - & $\begin{array}{l}\text { Varnished } \\
\text { Plywood }\end{array}$ & - & $\begin{array}{l}\text { Air } \\
\text { Nitrogen }\end{array}$ \\
\hline & - & $1 / 5$ & Building & - & Foam plastic & Reverb. & Air \\
\hline [152] & $\begin{array}{l}0.96 \text { height } \\
\text { - }\end{array}$ & $\begin{array}{l}1 / 50 \\
1 / 10\end{array}$ & $\begin{array}{l}\text { Building } \\
\text { Material }\end{array}$ & Similitude & $\begin{array}{l}\text { Polystyrene } \\
\text { Cardboard }\end{array}$ & $\begin{array}{l}- \\
\text { Reverb. }\end{array}$ & $\begin{array}{l}\text { Air } \\
\text { Air }\end{array}$ \\
\hline [121] & $2.85 \times 13.13 \times 2.04$ & $1 / 10$ & Building & Similitude & $\begin{array}{l}\text { Varnished } \\
\text { Lacquering } \\
\text { MDF wood }\end{array}$ & Reverb. & Air \\
\hline [78] & - & $1 / 25$ & Building & - & GRC/Corian & - & - \\
\hline [120] & $\begin{array}{l}- \\
-\end{array}$ & $\begin{array}{l}1 / 10 \\
1 / 50\end{array}$ & $\begin{array}{l}\text { Reflectors } \\
\text { Building }\end{array}$ & $\begin{array}{l}\text { Similitude } \\
\text { Similitude }\end{array}$ & $\begin{array}{l}\text { Varnished } \\
\text { MDF }\end{array}$ & $\begin{array}{l}\text { Semi } \\
\text { Anechoic }\end{array}$ & $\begin{array}{l}\text { Air } \\
\text { Air }\end{array}$ \\
\hline [118] & $1 \times 1 \times 6$ & $1 / 10$ & Urban & Similitude & $\begin{array}{l}\text { Metal } \\
\text { Acrylic } \\
\text { Polyurethane }\end{array}$ & Reverb. & Air \\
\hline [216] & $1 \times 0.01 \times 1.3$ & $1 / 20$ & Wall & Similitude & $\begin{array}{l}\text { MDF wood } \\
\text { Aluminium }\end{array}$ & $\begin{array}{l}\text { Hemi } \\
\text { Anechoic }\end{array}$ & Air \\
\hline
\end{tabular}

\subsection{Acoustics for buildings using scale models}

The purpose of room acoustic modeling is to predict and evaluate acoustic behavior of rooms before building them.

Scale models for acoustic studies are focused mainly on those buildings with high requirements on acoustic performance, such as the case of auditoriums and concert halls [121,168,120].

An innovative acoustic example was the model used for the design and construction of Segerstorm Hall Orange County Performing Arts Center opened in New Zealand in 1986. It was developed and built by Marschall Day Acoustics Company. The novelty of the model was the asymmetrical design of the space [170].

However, the scope of acoustic scale models are wide spread to cases of scale models research on acoustics of simple rooms [85] or street acoustic analyses [202,116,151,118,216].

For room acoustic predictions, there are three modeling methods [168]:

- Wave-base acoustic method: acoustic quantities are defined as functions of space and time in a homogeneous and bounded space. They use numerical methods as finite difference and finite elements for resolving the equations.

- Geometrical acoustics method: also called ray acoustic method because high frequency sounds are considered as traveling straight lines. In this class, also ray tracing, beam tracing and image source method are included.

- Diffusion equation method: an energy-based model derived from the analogy between the sound energy density of sound particles and the density of sound particles traveling at velocity $\{c\}$ along the straight lines.

Sound transmissions in buildings could be by air-, structure- and duct-borne sounds. Firstly, theoretical prediction methods of airborne sounds use also discretization methods for analyses, such as finite elements, finite differences or boundary element methods.

Secondly, structure-borne sound methods are studied through mechanical excitation of structural elements. Vibration in this case plays a very important role. The source of vibration could be inside or outside buildings.

Finally, duct-borne sound methods are originated by fan or interaction between duct discontinuities and unsteady air flow.
Structure and duct-borne methods use mostly analytic methods for evaluation.

For experimental sound tests, especial laboratory or chambers are used. They are two main types of chambers:

- Anechoic chamber for sound absorption tests. This room is designed so that it absorbs completely the sound.

- Reverberation chamber for sound reverberation tests. This room is designed so that to create a diffuse sound field.

One of the tested building in acoustic chamber was, for example, a $1 / 10$ scale model of the new Danish Radio Concert Hall [85] (Table 5).

To control the influence of the increased air absorption at high frequencies is one of the main problems in down-scaled models for studying acoustics, thus, the atmospheric attenuation increases with the reduction of the scale model. Sometimes, this air effect in air-borne sound could be considered replacing air by other gas in the scale models. Nitrogen gas was used by Nagata advisor to reduce air absorption in scale models of concert halls [187,116]. Other strategy is to dry the air about 2\% [116].

Another difficulty is to find model's building materials having similar absorption characteristics that their prototype's. In Danish Radio Concert Hall scale model a varnished MDF board and plywood to avoid unwanted absorption were used.

Despite these difficulties, the main advantage of scale models versus simulations is the precise reproduction of diffusion and diffraction.

Common methods used in room acoustic prediction are image and ray-tracing methods. These methods are based on geometrical straight-line mirror-reflected models and do not take into account wall surfaces having diffusive properties. In this line, it was undertaken the study of a concert hall with seating audience and absorption banners material through a scale model. These furniture were previously inserted in a 1/10 scale model reverberation chamber to calculate their absorption [121].

Sometimes it is not necessary to build the total internal envelop of the building in the scale model for obtaining experimental sound tests. In the Grand Theater in SPAC, an 1/10 internal "open-air" scale model is built [120]. This scale model consists on the reproduction of the reflectors at scale in a chamber avoiding the construction of the entire building scale model. Any building enclosure such as 
walls and ceiling of the building was considered, thus, just the early sound was tested.

A 1/50 scale model experiment on sound propagation in streets is developed in [202,116]. For similarity requirements with so small scale (urban area) ultrasonic sound sources, adapted receivers and digital processing for reduction of excessive atmospheric attenuation were needed.

The Building façades were simulated as wooden cubes of $5 \mathrm{~cm}$ side. In order to satisfy acoustic laws, similarity for the sound absorption by building façades, wooden cubes were varnished to be very reflective. The absorption of these cubes were measured by ultrasonic method and were compared with the absorption coefficients measured in streets. Road and pavement were simulated by a wooden varnished rigid plane. Irregularities of the façade of the street were simulated by applying equal statistic irregularities in cubes' positions of scale model's façade.

Jang measures the effects of noise reduction by vegetation in residential buildings using scale models. Previously, complete testing absorption coefficients of scale model materials were measured in a reverberation chamber [118]. A city street was scaled including those materials with equal absorption performance as real vegetation and buildings. The measurements were conducted in a semi-anechoic room.

Design improvements of a façade to traffic street on a 1/50 scale model was studied in [151]. In the scale model, different material were considered for mocking up surfaces such as asphalt road and concrete wall. Previous studies conducted in a reverberation chamber were undertaken for setting the absorption coefficient of these materials.

This paper showed that $3 \mathrm{~mm}$ thick dense polystyrene is a good material for simulating asphalt roads and vertical walls of apartment buildings. Other materials were tested, concretely, $4 \mathrm{~mm}$ polystyrene and $0.5 \mathrm{~mm}$ and $1 \mathrm{~mm}$ cardboard.

Two scale models were built, on the one hand, a single building isolated with a sound source simulating traffic noise and, on the other hand, the building model surrounded by four more buildings with a sound source simulating traffic noise.

Other example of scale model street tests is the study of the influence in the street noise of the eaves of a new building façade [216]. For this purpose, a 1/20 scale model was used for validating the finite difference model. Instead of building the complete building at this scale, they proposed to consider a unique scale model for the 5 th and the 15 th stories.

In this experimental test, the difference between stories were the incidence angles of the sound, therefore, $80^{\circ}$ and $60^{\circ}$ for the 15 th and 5 th scale model stories, respectively.

There are some examples of universities and companies engaged with this acoustic research methodology. On the one hand, National Taiwan University of Science and Technology partnered with Nagata Acoustics Company developed a 1/10 scale model of Grand Theater of Taipei. It was built on the campus university of the same city to design and record its internal acoustic performance [187].

On the other hand, Technical University of Einhoven incorporated systematically in its laboratories the possibility to develop scale models for acoustics [38]. These models incorporate coated materials having equal absorption coefficients than materials used in real building. They measure scale model acoustic responses for predicting the acoustical behavior of future buildings.

New manufacture techniques (see page 76 Section 3) through Computer Numerically Controlled (CNC) milling machine for sound and lighting scale model testing were undertaken in the Taichung Metropolitan Opera. Several sheets of plywood were cut to create the substructure while inner curves were created with extruded polystyrene blocks [102]. This model demonstrates the suitability of subtraction procedures to create accurate functional scale model for buildings.

\subsection{Lighting for buildings using scale models}

Lighting scale models are considered those scale models exposed to real or artificial sun or sky.

Apparently, lighting scale models could be considered unnecessary. Every scale model casting shadows under the sun is already a lighting scale model and this, furthermore, is also very well simulated in computers.

Considering sunlight totally parallel, scale models casting shadows would be equal to those of full-scale buildings. However, sun-lighting scale models overestimate daylight performance, so, they are over-lighted.

Unfortunately for architects, scale models built and exposed to sunlight are not actually representative of the intensity of indoor daylights of full-scale prototypes.

Besides, some drawbacks for using scale models in lighting tests are meant by different authors [3]. Firstly, costs involved in the construction of scale models and transport to artificial skies. Secondly, time necessary to obtain detailed scale models and, finally, difficulties of scaling innovative materials.

Drawbacks related to artificial skies are connected with possible simulation errors [3]. Specific drawbacks in artificial scanning skies dealing with too large scales are, on the one hand, horizon line errors, and on the other hand, parallax errors in which scale models receive different quantities of daylight and sunlight.

Scale model assessments of daylight performance with sky simulators show overestimation on plane illuminances and on daylight factor profiles due to modeling details, reflectance, glazing transmittance and photometers discrepancies.

However, even considering these drawbacks with scale models, those properly scaled improve those simulations by computers.

Simulation programs are very accurate in casting shadows produced by the sun or sky, but they cannot reproduced exactly total incident radiations due to the complexity of the phenomena.

Complex reflections are taking place, and even if they were possible to compute all of them, the resources involved for doing it would not compensate the results.

Consequently, for avoiding problems of complex phenomena daylight reproduction, scale models are built. For avoiding problems related to similarity of scale models subjected to sunlight with their prototypes, artificial skies are built.

A scale model under the sun and the sky rays could be differently assessed since light possesses different ranges of waves. Depending of the light's waves considered, the studied matter is different:

- Visible radiation of light.

- Heat radiation of light.

Each of them is linked to different issues. Visible light is related to aspects of quality of illuminance of rooms or architectural spaces. This is the aspect addressed in this section. Heat radiation instead is studied for building energy efficiency purposes and it is analysed in Section 6.4.4 on radiation.

Measurements of daylight are standardized by the International Commission on Illuminance (CIE). Specific program procedures are setting the irradiance data and illuminance measurements. These data are important since they are used for computers simulations and scale models replications.

Different studies can be undertaken in the field of daylighting, such as daylighting and pollution, daylighting, illuminance, luminance, daylight factor, daylight glare and lighting control techniques [6]. 
Daylighting is any method by which natural light - sky diffuse or sun direct - is brought into a room to replace or supplement artificial lighting. For achieving this goal, daylighting system in buildings are improved and could be classified, according to [8], into two simple daylighting strategies.

On the one hand, side-lighting using building's walls to light inner spaces and, on the other hand, top-lighting: using building's roofs to light inner spaces.

Concretely, scale models subjected to daylight can be classified into three types of scale models [35]:

- Massing models for the study of solar access.

- Models for studying the building's light performance.

- Models for testing individual apertures, glazing, shading devices or advanced daylight systems [174].

Depending on the purpose of the scale model Bodart proposes four ranges of scales [35]:

- From $1 / 500$ to $1 / 200$ - preliminary concepts, massive and casting shadow generations.

- From $1 / 200$ to $1 / 50$ - direct sunlight penetration into a building.

- From $1 / 50$ to $1 / 10$ - refinements, inside views and diffuse and direct daylights. Internal walls are to be modeled very carefully because the influence in light distribution is very high. Material reflectances are key points when similitude is sought.

- From $1 / 10$ to $1 / 1$ - integrate critical industrial components and final evaluation.

Different types of artificial skies are possible: mirror skies, dome skies, spotlight skies or scanning skies [253].

Sizes of scale models under artificial skies are to be taken into consideration because parallax errors increases with increasing size of scale models. Therefore, the maximum scale factor is conditioned by the dimensions of the vault of artificial skies. Estimation of the maximal dimensions of scale models are generally a $10 \%$ of the diameter of artificial skies.

Different scales models for lighting studies are analyzed by $R$. Knowles [139]. He uses architectural functional scale models to illustrate examples of illuminances, indoor architectural cases and outdoor areas of neighborhoods.

Some components, like windows in buildings or transparent elements, are fundamental since through them light enters architectural spaces.

Scale models' windows are to be designed with similar glazing properties as full-scale building's but with less thickness - for example, from $6 \mathrm{~mm}$ to $3 \mathrm{~mm}$. If there is no possibility of using reduced window thicknesses, it is better no use any at all, however, reducing iluminance factors. In daylight, at incident angles up to $60^{\circ}$, glass materials should consider rays reflections.

[240] built a 1/10 scale model to investigate lighting discrepancies between a full-scale building and its scale model. The conclusions draw a relative divergence of $+30 \%$ to $+35 \%$ more in the scale model than the full-scale prototype.

In this paper, a list of potential source of errors in scale models were presented. They were divided into geometrical and photometrical (reflectances, transmittances and sensors).

The test setup comprised a $20 \mathrm{~m}^{2}$ full-scale single office room equipped with side lighting windows and its two $1 / 10$ scale models placed within identical outdoor daylighting conditions. Differences between these scale models were concretely some values of their surface reflectances.

In these tests and coinciding with the luxmeters, one camera and other six were placed on the scale model and on the full-scale module at different parts, respectively, in direction to the sky for comparing sky similitude at every moment when calculating the view factors.

Assessments of the capability of existing simulation methods to predict the performance of Complex Fenestration System (CFS) were undertaken in other paper [164]. For validation of these simulations scale models were used.

This scale model consisted on a cubic box of dimensions $0.8 \mathrm{~m}$ $\times 0.8 \mathrm{~m} \times 0.6 \mathrm{~m}$ of a room of $4 \mathrm{~m} \times 4 \mathrm{~m} \times 3 \mathrm{~m}$ with an opening on the roof of dimensions $0.2 \mathrm{~m} \times 0.2 \mathrm{~m}$.

The internal surfaces of the $1 / 5$ scale model were painted with matte black paint with a reflectance of $4.5 \pm 1 \%$. Photocells were set inside the scale model on the floor and walls, and on the opening level for external illuminance measurements. A fish-eye camera was placed inside for measuring the external luminance distribution.

Natural daylight used in building design was studied with simulation and scale model in the research of [52]. For this purpose a $1 / 20$ scale model of a room of dimensions $6 \mathrm{~m} \times 6 \mathrm{~m} \times 3 \mathrm{~m}$ was built. Measurements were taken considering equal subdivision areas of the floor room and a photometer in each of them. A total of 15 photometers were used.

This model has the possibility of change one of the walls with different windows sizes. For consideration of relative position of the light source respect to the scale model, instead of changing the sun position, an horizontal and angular adjustable table was considered.

Other study addresses the performance of daylighting with sun and sky simulators for shading systems on scale models [3]. Photometric data and digital images of the luminous environment were taken.

A scanning artificial sky were used in the tests undertaken by [253]. This sky consisted on hemisphere subdivision of the model sky for sky luminance measurements according with CIE in the International Daylighting Measurement Program (IDMP).

This dome was subdivided into 145 circular areas each considered as uniformed luminance. Its areas were simulated by means of circular luminaries located on each hemispheric surface according to their angular coordinates. The luminance distribution of the sky was achieved with different values of luminance of each luminaries. This artificial sky was independent of the sun simulator [253].

The sun was simulated with a theater luminarie positioned $8 \mathrm{~m}$ away from the stand of the model. This luminarie was modified for reproducing the principal photometric characteristics of the sunlight: luminous beam with parallel rays and uniform value of luminance on the plane of the model. The projector was equipped with a $1200 \mathrm{~W}$ halogen lamp.

In this research, the model tested inside this artificial sky and sun simulator was a $1 / 10$ scale [253]. It consisted on the interior space of a classroom with dimensions $9 \mathrm{~m} \times 6 \mathrm{~m} \times 3 \mathrm{~m}$ with two windows on the south façade of dimensions $3 \mathrm{~m} \times 2 \mathrm{~m}$ and the sill being at $0.9 \mathrm{~m}$ from floor level. Ceiling was white and walls were blue painted, with reflectances of 0.72 and 0.48 , respectively. The upper part of the wall has an ivory finish (0.61) and the floor was made of red brick (0.33). All material were considered as Lambert diffusers. Different shading devises were tested under artificial scanning sky and each with two sets of measurements: CIE-clear and CIE-overcast skies. A mirror artificial sky was used in the study of a four storey atrium scale model [68]. It had $0.5 \mathrm{~m} \times 0.5 \mathrm{~m} \times$ $0.293 \mathrm{~m}$ dimensions and was placed into a squared, wall-mirrored artificial sky of dimensions $2.4 \mathrm{~m} \times 2.4 \mathrm{~m} \times 1.2 \mathrm{~m}$ for reproduction of the standard International Commission on Illumination (CIE) sky.

An example of the combination of simulation and scale model is found in [133]. This research is attempting to show how the daylight illuminance can be integrated into an architectural design using the daylight analysis software RADIANCE and a scale model for validation. 
Table 6

Summarized experimental lighting tests with scale models.

\begin{tabular}{|c|c|c|c|c|c|c|}
\hline \multirow[t]{2}{*}{ Author } & \multicolumn{6}{|c|}{ General characteristics } \\
\hline & Dimensions (m) & Scale & Type & Analysis & Material & Facility \\
\hline [252] & $0.7 \times 0.7 \times 0.3$ & $1 / 10$ & - & Similitude & - & Artificial mirror \\
\hline [240] & $0.65 \times 0.3 \times 0.25$ & $1 / 10$ & - & Similitude & - & Outdoor \\
\hline \multirow[t]{2}{*}{ [164] } & $0.8 \times 0.8 \times 0.6$ & $1 / 5$ & - & Similitude & Wood/matt & Outdoor \\
\hline & $0.8 \times 0.8 \times 0.6$ & $1 / 5$ & - & Similitude & Wood/matt & Artificial \\
\hline [52] & $0.3 \times 0.3 \times 0.15$ & $1 / 20$ & - & Similitude & - & Outdoor \\
\hline [3] & $0.9 \times 0.6 \times 0.3$ & $1 / 10$ & - & Similitude & - & Scanning simulation \\
\hline [203] & $0.43 \times 0.42 \times 0.44$ & $1 / 10$ & - & Similitude & Glass & Outdoor \\
\hline [68] & $0.5 \times 0.5 \times 0.293$ & $1 / 4^{*}$ & Atrium & - & - & Artificial mirror \\
\hline [133] & $1 \times 1.1 \times 0.65$ & $1 / 20$ & Atrium & Simulation & - & Pyramid-shaped \\
\hline [259] & - & - & Room & Similitude & - & Outdoor \\
\hline \multirow[t]{4}{*}{ [34] } & $0.68 \times 0.84 \times 0.54$ & $1 / 5$ & Room & Similitude & - & Artificial \\
\hline & $0.34 \times 0.42 \times 0.27$ & $1 / 5$ & Room & Similitude & - & Outdoor \\
\hline & $1.9 \times 1.9 \times 1.5$ & $1 / 2$ & Room & Similitude & Double pipe & Outdoor \\
\hline & $0.38 \times 0.38 \times 0.3$ & $1 / 10$ & Room & Similitude & Double pipe & Outdoor \\
\hline$[221]$ & $1.2 \times 1.2 \times 0.35$ & $1 / 10$ & Room & Similitude & Wood & Outdoor \\
\hline
\end{tabular}

For this purpose, the built Seoul Museum of Art (SMOA) and, specifically, its atrium was reproduced in simulation and scale model. With the scale model test, indoor illuminance measurements were collected under clear sky with sun. The corresponding full-scale atrium had dimensions of $20 \mathrm{~m} \times 21.7 \mathrm{~m} \times 13.1 \mathrm{~m}$ and the scale model built was $1 / 20$ scale size. Nine measurements points of illuminance were considered.

Energy requirements and visual comfort are intertwined. An example is the study of [259] in which the influence of shading controls for visual comfort and energy demands in buildings were studied. For that a mock-up room and the corresponding scale model were compared. The mock-up room has dimensions $6.8 \mathrm{~m}$ $\times 2.7 \mathrm{~m} \times 2.8 \mathrm{~m}$ with an outer and inner window. Before the inner window was incorporated, an illuminance meter and a camera was introduced. In this case, details of the scale model were missing.

Artificial skies oversee natural conditions of real weather and submit scale models to their restricted dimensions. For this reason, a simultaneously comparison of an artificial sky and real sky tests with scale models were undertaken [34]. The authors undertake a critical analysis of scale models subjected to direct sunlight for assessment of indoor daylight. One of his conclusions is that the presence of direct solar radiations introduce anomalies in daylight performance of scale models, therefore, it is better to undertake outdoor sun lighting scale model tests under diffuse radiation.

There have been comparative analyses between computer simulations and scale-model photometry under real skies in literature [221]. Some discrepancies are found in values obtained between virtual and scale models attributed to factors such as: sky luminance distribution functions, iluminance sensor sizes and levelling and fidelity with which scale models replicate full-scale rooms.

Scale model's photometry has generally good estimations of real sky component of the daylight compared with computer simulations. This is due to the algorithm used for computing the daylight distribution.

[221] proposes a Normalized Daylight Performance Index (NDI) for effective comparisons between scale models and simulation photometries. To do this, he builds three $1 / 10$ scale models of wood and places them outdoors without any obstructions. They were painted matte white and sensors were placed indoors at a height equivalent to $0.75 \mathrm{~cm}$ in the full-scale prototype. Full-scale room was $12 \mathrm{~m} \times 12 \mathrm{~m} \times 3.5 \mathrm{~m}$ dimensions with one complete glass wall of dimensions $11 \mathrm{~m} \times 2.10 \mathrm{~m}$.

Strictly tests under weather conditions are also developed. A small-scale test cell under real weather conditions for evaluation of the performance of an electrochromic window (EC) was tested [203]. This test cell is considered a 1/10 scale model of an unfurnished cubic room. The cell was equipped with several sensors to monitor the illuminance both, direct and diffuse, and also, vertical and horizontal.

Table 6 shows a summary of the lighting tests with scale models

\subsection{Thermodynamic for buildings using scale models}

This section is related to the analysis of heat transfer combined with other forms of energy, such as the case of mass transport (ventilation) in functional scale model for buildings.

Thermodynamic phenomena are influenced by two different physical fields: thermal and fluid dynamics. Both processes intertwine and influence heat transfers.

Conduction and radiation are main heat transfer processes.

Convection is not exclusively heat transfer because more processes are taking place, however, it is conventional adopted as heat transfer [143].

Those three simultaneously yield thermal performance of building prototypes or scale models (see Section 6.4.2). Specially, convection is linked with scale model testing (see Section 6.4.5). Radiation and conduction are also addressed using scale models but, in any case, it is not so widespread like convection (see Sections 6.4.4 and 6.4.3). Finally, ventilation, as complex physical phenomenon, focus much attention in research papers (see Section 6.4.6)

Energy efficiency analyses for buildings could have different level of observation. These levels are related to the considered scale.

Traditionally, there are three scales of observation, macro-, meso- and microscale. Applying this criterion to energy efficiency for buildings, it could be said that it exists energy efficiency scales, and consequently, scales in energy efficiency strategies (see Section 6.4.1). Depending on the scale of observation of the building, that is, urban, zones, buildings or materials, there would be different kind of scale models and procedures.

\subsubsection{Scaled energy efficiency strategies and scale models}

Different scales in energy efficiency analyses exist, from cities to material properties of buildings [41]. These different approaches result in a scope of scales of energy efficiency strategies: macro-, meso- and microscales.

For example, configurations of city areas (macroscale) can influence the energy consume in their zones. Singular zones within urban areas could provoke specific differences in climate parameters, and consequently, conditioning the energy consume of their buildings (mesoscale). Designed energy efficient buildings in some zones could perform better than other zones in which there are buildings with no energy efficiency considerations. Specific 
materials of buildings could be more adequate for certain site and building orientation (microscale).

Consequently, there is a range of testing possibilities in energy efficiency and in thermal performance in particular. Therefore, scale model tests reflect, at reduced scales, these specific strategies studied among all possibilities.

In this section two main scale strategies are mentioned:

- Urban scales: mainly corresponding to macro- and mesoscales ranges.

- Building scales: corresponding to meso- and microscales ranges.

Some authors such as M. Kanda et al. [125,123,124] research on ranges macro- and mesoscales in urban areas applying similitude strategies for their functional scale models.

Scale models of urban areas are mostly undertaken with arrays of cubes as building scale models tested in wind tunnels or outdoor conditions.

Special mention should have the scale model called Comprehensive Outdoor Scale Model (COSMO). COSMO is a 1/5 scale model of an urban area with an array of 512 hollow cubes of $1.5 \mathrm{~m}$ side of concrete simulating outdoor buildings in a total surface area of $100 \mathrm{~m}$ $\times 50 \mathrm{~m}$. It is located at the Nippon Institute of Technology in Saitama, Japan.

Under this specific scale range, a review on the subject is done in 2006 by this author [123]. For approaching the phenomenon, $\pi$-parameters, Richardson, $R i$, and Reynolds numbers, $R e$, were considered.

Other authors as M. Park et al. [198] used also COSMO facility for their researches. They selected different sections of the cube array facility for studying effects of urban vegetation on outdoor air environment.

[192] studies heat transfer on a leeward building of the COSMO facility. [129,126,127] tested also there their numerical models of urban heat exchange using experimental measurements of this outdoor scale model.

An example of urban scale modeling is the evaluation of urban energy exchanges using an scale model placed outdoor in a building-street canyon surface array [199].

Overall, radiation absorption and heat storage are higher in arrays with deeper canyons. In this case, no special matching procedures were taken to get similarity with urban areas, however, these concrete blocks of COSMO facility could resemble to concrete blocks of buildings, since it is equal material.

Additionally, in the test set, ground properties are also similar to the constructions in this area. Turbulent fluxes, which are dependent of wind speeds and air temperatures, are especially influenced by physical scaling effects.

This author uses Richardson number ( $R i)$ to obtain the surface roughness with the condition of near-neutral stability. $R i$ expresses the relation of buoyancy flow and the flow gradient term.

A combination of air movement study and surface heated radiation on street canyons was carried out into a wind tunnel in [5]. Low wind speeds were produced $0.5-1 \mathrm{~m} / \mathrm{s}$ for inducing low Froude numbers ( $F r$ ) which determine the characteristic of the flow: small $\mathrm{Fr}$ responds to buoyant flows while large $\mathrm{Fr}$ responds to forced convective flows.

In this case, similar Reynolds number, $R e$, is not necessary for similarity between edged bodies, however, its value must be over a certain critical (see page 83 of Section 6.1.3). This limit for street canyons are around 13,000.

Dimensions of the scale model street canyon were $0.20 \mathrm{~m} \times$ $0.20 \mathrm{~m} \times 1.80 \mathrm{~m}$, thus, the aspect ratio of its width respect to its height is 1 and its height respect its length is 9 .

The surfaces of the street canyon and floor were made of aluminium plates, corrections to these low-roughness surfaces were considered. The heated mat provided a power of $1680 \mathrm{~W}$ and were attached at the back of the aluminium plates.

Flow field in this test was taken with Particle Image Velocimetry (PIV) method. This system consists on the introduction of particles in the flow motion. These particles are so thin that trace the flow with certain precision. For visualize them, a light is incorporated to see the obtained field.

Other methods for tracing particles are Laser Doppler velocimetry and Hot-Wire Anemometry. The temperature control of different plates of scale models were controlled with proportional integral derivative(PID) controllers.

At meso- and microscale analysis some buildings or room models are built.

Since energy efficiency in buildings is very complex and many variables [11] are involved, strategies to make energy efficient building are very diverse. There are, among others, bio-climatic passive methods [191] or active mechanical methods [11].

Similarly, scale models reflect different aspects of these applied strategies of energy efficiency, such as the use of trombe walls as passive regulatory elements [95] or air conditioning and forced ventilation [115] as active methods.

Those using passive regulation strategies, such as the case of insulating material or Trombe wall, address the problem by focusing on processes of conduction and radiation capture. This is the case of experiments carried out by [96].

Scale models applying passive natural ventilation strategies [206] or those with active strategies of forced heated ventilation [115] have mainly focus on patterns of air movements and its influence on the temperature gradient existing within, that is, they focus on convection processes. In this case, heat transport processes have much to do with fluid dynamics and with the correspondence between scales.

The ideal analysis would address three heat transfer mechanisms, conduction, radiation and convection simultaneously. Unfortunately, it exists a special difficulty modeling simultaneously convective fluid motion processes, natural or forced, together with heat transfer processes [206].

\subsubsection{General thermal performance for buildings}

This specific section is centered in general analysis of the thermal performance of scale models for buildings. This performance are to be compared with general thermal performance of the corresponding full-scale prototypes.

General thermal performance includes conduction, convection and radiation and it is not focusing on a specific isolated thermal phenomenon like other tests on convection processes, for example.

Concretely in buildings, the studies of P.D. Grimmer $[95,96]$ are developed at outdoor conditions. These experimental tests published in 1978 were conducted in Los Alamos Scientific Laboratory.

The thermal response of the building prototype is replicated by reduced passive boxes under weather conditions. Distortions in these scale models by adjusting the thicknesses and surfaces for thermal simulation purposes were considered (see page 79 in Section 5.1). Thermal performance and effects of leakages on models were studied.

In 1981, [150], presented a thesis analyzing thermal transfers related to change of scale with distorted models. Cubic scale models were also considered but, in this case, no full-scale building correspondence existed.

Scale models for studying heat thermal transfers were classified by means of their boundary conditions.

Other classification criteria could be location - at climate or in laboratory -, or fluid conditions - ventilated or not -, etcetera.

For this thesis, several cubes of various scales $1,1 / 2$ and $1 / 4$ were built. Maintaining unchanged cube's side walls, roofs and floors; the front and rear panel varied to convenience with scale. 
Table 7

Summarized experimental thermal tests with scale models.

\begin{tabular}{|c|c|c|c|c|c|c|}
\hline \multirow[t]{2}{*}{ Author } & \multicolumn{6}{|c|}{ General characteristics } \\
\hline & Dimensions $(\mathrm{m})^{\mathrm{b}}$ & Scale & Type & Analysis & Facilities & $\begin{array}{l}\text { Tunnel (m) } \\
\text { Wind }\end{array}$ \\
\hline \multirow[t]{2}{*}{ [212] } & $0.57 \times 0.57 \times 0.39$ & $1 / 6$ & Building & Similitude & Passive/active & - \\
\hline & $0.29 \times 0.29 \times 0.19$ & $1 / 12$ & Building & Dimensional & - & - \\
\hline [96] & $0.61 \times 0.61 \times 0.305$ & $1 / 4$ & Building & Similitude & Passive & - \\
\hline \multirow[t]{2}{*}{ [150] } & $0.91 \times 0.91 \times 1.06$ & $1 / 2$ & Building & Statistic & Passive/active & - \\
\hline & $0.45 \times 0.45 \times 0.53$ & $1 / 4$ & Building & Statistic & Passive/active & - \\
\hline [113] & $1 \times 1 \times 1$ & $1 / 7$ & Building & Dimensional & Active & - \\
\hline [114] & $0.28 \times 0.46 \times 0.25$ & $1 / 12$ & Building & Dimensional & Passive & - \\
\hline [115] & $1 \times 1 \times 1$ & $1 / 7$ & Building & Dimensional & Active & - \\
\hline [173] & $0.11 \times 0.11 \times 0.033$ & $1 / 5$ & Wall & Similitude & Active & - \\
\hline [199] & $20 \times 16.4 \times 0.4$ & $1 / 30^{\mathrm{a}}$ & Wall & Similitude & Active & - \\
\hline [125] & $12 \times 9 \times 0.4$ & $1 / 50$ & Urban & Simulation & Passive & - \\
\hline \multirow[t]{2}{*}{ [124] } & $10 \times 2 \times 0.15$ & $1 / 50$ & Urban & Simulation & Passive & - \\
\hline & $100 \times 50 \times 1.5$ & $1 / 5$ & Urban & Simulation & Passive & - \\
\hline \multirow[t]{2}{*}{ [129] } & $10 \times 2 \times 0.15$ & $1 / 50$ & Urban & Simulation & Passive & - \\
\hline & $100 \times 50 \times 1.5$ & $1 / 5$ & Urban & Simulation & Passive & - \\
\hline [180] & $3.46 \times 1.22 \times 2.38$ & $1 / 2$ & Building & Simulation & - & - \\
\hline \multirow[t]{2}{*}{ [251] } & $10 \times 2 \times 0.15$ & $1 / 50$ & Urban & Simulation & Passive & - \\
\hline & $100 \times 50 \times 1.5$ & $1 / 5$ & Urban & Simulation & Passive & - \\
\hline [128] & $100 \times 50 \times 1.5$ & $1 / 5$ & Urban & Dimensional & Passive & - \\
\hline [192] & $100 \times 50 \times 1.5$ & $1 / 5$ & Urban & Dimensional & Passive & - \\
\hline [198] & $100 \times 50 \times 1.5$ & $1 / 5$ & Urban & Dimensional & Passive & - \\
\hline [238] & - & - & Urban & - & Passive & - \\
\hline [81] & $0.05 \times 0.21$ & - & Wall & - & Active & $1 \times 1 \times 0.5$ \\
\hline [214] & $0.8 \times 0.8 \times 1$ & $1 / 3$ & Building & Similitude & Passive & - \\
\hline \multirow[t]{4}{*}{ [159] } & $1.2 \times 1.2 \times 1.2$ & $1 / 2$ & Building & Dimensional & Passive & - \\
\hline & $0.6 \times 0.6 \times 0.6$ & $1 / 4$ & Building & Dimensional & Passive & - \\
\hline & $0.3 \times 0.3 \times 0.3$ & $1 / 8$ & Building & Dimensional & Passive & - \\
\hline & $0.1 \times 0.1 \times 0.1$ & $1 / 24$ & Building & Dimensional & Passive & - \\
\hline
\end{tabular}

a Not explicitly mentioned in documentation. Here suggested under the scale view-point.

b Width $\times$ length $\times$ height

Knowing characteristics of the permanent walls, he analyses necessary distortions of the remaining parts of the scale model in order to have a similar thermal behavior as their prototypes.

The main conclusion of his thesis verifies the adequacy of this technique for simulating heat transfers with passive scale models at outdoor and under direct solar radiation. Needed is only the use of scale factors in geometry, in thermal mass, in natural convection and in temperature stratification.

In 1990 an article dealing with a general procedure for modeling small scale buildings is presented in the International Journal of Energy Research. It is a fairly comprehensive study including a part corresponding to theoretical analysis for dimensional convection transfers and an experimental part with a 1/10 scale model of a prototype building built in Ife, Nigeria [114].

In this study, the geometry between the scale model and the prototype were preserved as close as possible, likewise construction materials. However, the location of the scale model for collecting data was different from the location of the full-scale prototype. The prototype was in Nigeria while the scale model was built and tested in the laboratory of the University of Trieste, Italy (Table 7).

The same team that made the earlier study used the theory of dimensional analysis for studying a small basic two-storey building but, in this occasion, including heating and air conditioning in the scale model. Its shape was cubic with two floors and it has an occupancy estimation of five adults. It had brick walls envelope with $15 \%$ holes. Slabs of concrete were used to form floor and ceiling. Theoretical procedures concluded with twenty dimensionless parameters.

Later, they conducted tests through computer simulations [113].

These experimental results showed that the reduced model, according to the author, is able to reproduce realistic behavior of the full-scale prototype. Although, in this case, there was no built full-scale prototype for direct assessment of this outcome.
Later, the same author replicates a prototype with HVAC system through a scale model $[114,115]$. These tests are developed in laboratory.

Long-term physical thermal phenomena could be shorten in time using scale models. As example, a study on indoor-insulated external building wall used scale models for avoiding long period tests of full-scale prototypes [173].

For this study, similarity laws for correspondences between the scale model and the prototype were used. The model was scaled evenly, with same materials, same water chemical potential and temperatures.

With these conditions, scale model's time was squared proportional to the scale. In this occasion, the scale of the model was arbitrarily chosen. A $1 / 5$ scale model of the studied wall was built. The corresponding time scale of such a model was $1 / 25$, therefore, one year could be simulated in just two weeks. It was tested in autoclave chamber and its results show good agreement with the numerical results.

Heat transfer phenomena through architectural building components using dimensional analysis are done in the Ph.D. Thesis of $\mathrm{L}$. Mudarra [184]. Her thesis establishes a theoretical discussion of the convenience of different bases for application of dimensional analysis theory (see Section 4.4). Also, it exposes typical architectural configurations of walls, however, it is restricted to the theoretical field.

Considering the analysis with Discriminated Dimensional Anal$y$ sis (DDA) (see Section 4.4) the distribution of exponents in the dimensional matrix is different and, consequently, Reynolds, $R e$, and Nusselt number, $N u$, do not appear directly, but some equivalents. However, the use of DDA enriches the analytical approach of energy balance equations $[165,166,4]$.

Dimensional analysis is also proposed to study some existing full-scale constructions. [16] proposed it to analyze an existing 


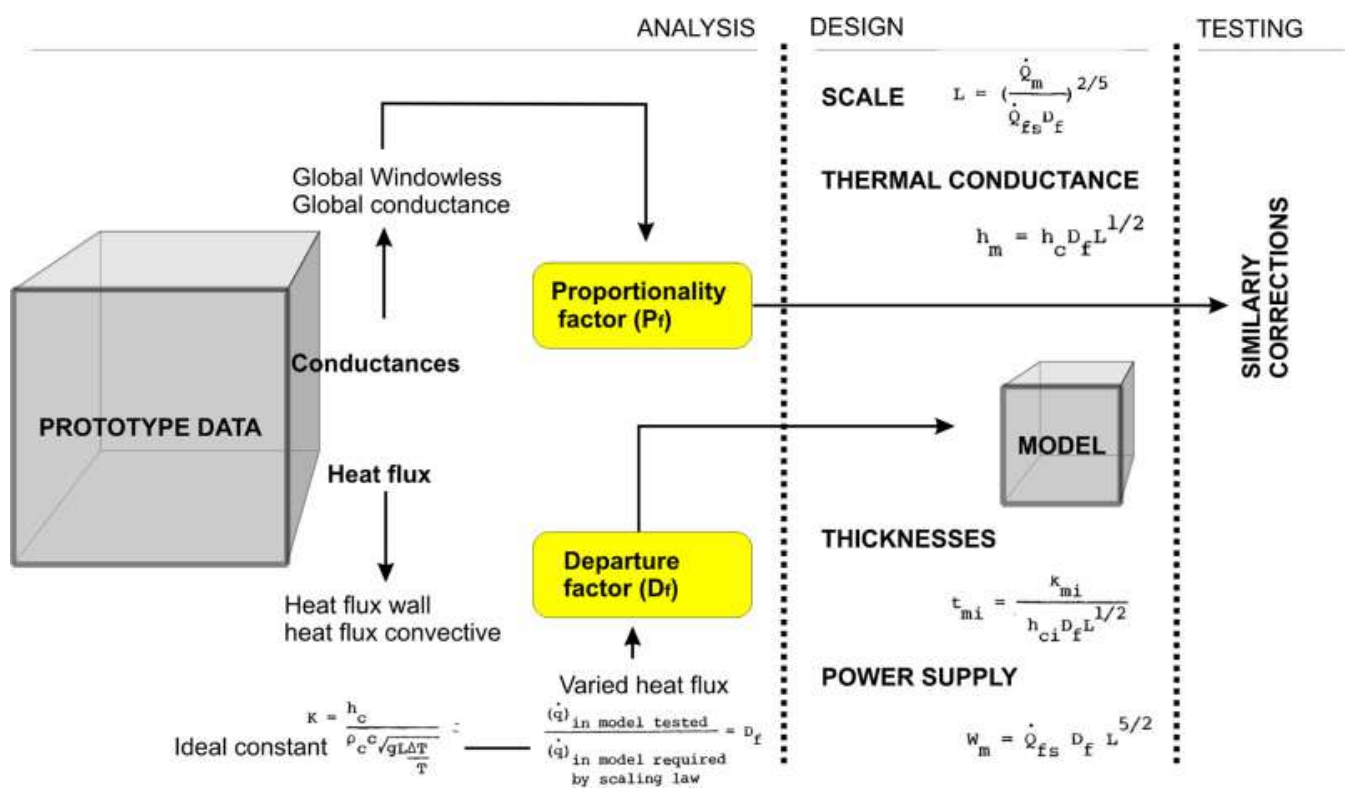

Fig. 3. Summarized procedure of convection heat transfer scaling according to K. Ruberg [212].

full-scale mechanically ventilated double glazed façade energy performance of a building.

A $1 / 6$ scale model of a basic thermal cell called Thermisches Modellhaus at the Universität der Künste Berlin (UdK Berlin) and an additional $1 / 24$ scale model replica built with financial support of the International Excellence Campus Moncloa of Madrid were compared in [159].

These two models, considered as small replicas of simple architectural spaces, were exposed to laboratory and outdoor conditions in order to see different scale effects in thermal transfers.

Also, in [159], three cubic models provided with internal temperature sensors were tested. These tests were similar, apparently, to those made in Los Alamos Laboratory by [95] in the nineteenseventies but with the difference that these three cubic scale models have not suffered distortions in order to get convenient temperatures.

His study is framed on the energy efficiency in buildings under the premise that environmental conditions of scale models and their corresponding prototypes are exactly the same. The study focus on finding specific scale factors of internal air temperatures originated by weather conditions.

Additionally, these tests took advantage of miniaturization of the new and cheap technology developed by Arduino motherboard [9] for incorporating a handmade circuit system of temperature sensors controlled by original computer code for recording data.

The influence of construction components in thermal building performance can also be tested with scale models.

For example, different heat mitigation strategies in different seasons with the use of a urban courtyard with scale model tests [238]. In this case, scale model's roof typology could be changed with different materials: black card-board, white gravels and soil with grass.

A $1000 \mathrm{~W}$ lamp was used as heat source and a $22 \mathrm{~W}$ desk fan as a wind source. Air temperature was recorded within the courtyard and on the roof, additionally, the albedo of these materials were measured with an spectrophotometer. Other strategies as the performance of three passive roof cooling systems were analyzed in [214]. For this purpose a representative scale model of dimensions $0.8 \mathrm{~m} \times 0.8 \mathrm{~m} \times 1 \mathrm{~m}$ was built. Its roof could be interchanged with different solutions: $2.5 \mathrm{~cm}$ thick material, $2 \mathrm{~cm}$ water bag, $6 \mathrm{~cm}$ water pond and with a shield protection at $0.5 \mathrm{~m}$ from the roof. Only one of the walls had a window of dimensions $0.4 \mathrm{~m} \times 0.5 \mathrm{~m}$. Neither materials of the scale model nor scale changes considerations were described.

In undistorted scale models there is heat flux increase through their envelopes due to reductions of their envelope thicknesses. In these cases, [212] proposed a correction factor called departure factor, $D_{f}$.

This departure factor corresponds to the ratio between heat flux in the model "tested" and the heat flux in the model "required by the scaling law".

Fig. 3 shows the procedure based mainly in theoretical initial characteristics of the prototype to be tested. Thermal characteristics related to conductance (Global and Global windowless) are taken into account as well as ratios of wall and convective heat fluxes. These ratios should be maintained constant in the change of scale. If there are not, then departure factors correct these deviations.

By means of the so-called departure factors, others parameters of future scale models are calculated. After obtaining these parameters, scale models could be built.

However, thermal behavior of these built models could be deviated from initial condition criteria, as example, deviations in the proportionality factor could occur. For this reason some experimental tests are necessary to be undertaken in order to assess if value factors of proportionality, theoretical and empirical, do agree.

Summarizing, in this section, general heat transfer considerations with scale models are considered, but it would be interesting and necessary to see how is scale affecting at the three thermal transfer processes separately: conduction, radiation and convection.

\subsubsection{Conduction heat transfer for buildings using scale models}

According to Fourier's Law heat transfer by conduction is proportional to surfaces and inversely proportional to thicknesses of the considered bodies.

Therefore, down-scaling from prototypes to corresponding undistorted scale models will cause squared-scale decreases of heat conduction because of their decreasing value of surfaces. Simultaneously, it causes their linear-scale increase of heat conduction because of their reduction of envelope's thickness. Therefore, undistorted scale models of prototypes, considering that they do 
no change materials and there are no differences in temperatures of indoor and outdoor surface layers, heat conduction will theoretically decrease linearly across down-scaling.

Although it is already known that conductivity changes occur with material's temperature changes, in architecture field, building's prototype and their corresponding scale model's materials will not change their temperatures so radically to cause significant changes in conductivity properties.

Mainly heat transfer by conduction takes place through surfaces, however also by edges, corners and existent thermal bridges.

These additional heat conduction transfer ways make theoretical calculations of heat transfers by conduction just mere approximations.

Practical assessments of heat transfers by conduction may differ considerably. Authors like $[150,159,143]$ take these considerations into account in their respective studies.

\subsubsection{Radiation heat transfer for buildings using scale models}

Consistent with the equation of heat transfer by radiation between two surfaces with Stefan-Boltzmann constant, the amount of energy released due to radiation is proportional to surfaces, that is, squared of the scale change.

Considering undistorted scale models of buildings, heat transfers by radiation are proportional to surfaces and, hence, their corresponding prototypes will lose four times more heat by radiation than their half-scale models.

There are no many tests on scale models of buildings related to radiation. It is possible to mention in this line the use of four built scale models to validate analytic calculations of sunshades [208].

In this research models M-1 and M-3 were constructed with horizontal sunshades, whereas Models M-2 and M-4 were constructed with proposed sunshades over south façade windows. Static sunshades are most effective for solar control inside buildings.

The static sun shading design methodology is validated with the help of small scale modeling experimentation techniques. Depending upon the solar intersection over south façade wall, sunlit area and shaded area have been correlated with temperature inside these models to decide the effectiveness of the proposed sunshade.

All four experimental models were constructed in Pilani, Rajasthan (India) with brick-cement construction materials and polyurethane foam insulating material.

Other case of heat transfers by radiation is a $1 / 6$ scale model room with radiant floor for evaluation of the impact of its internal furniture [83]. It analyses the scale effects in radiation and convection.

\subsubsection{Convection heat transfer for buildings using scale models}

In natural or free convection, there is no forced air movements, thus air movements are originated by gradients of temperatures (Fig. 4).

Convection heat transfer coefficients are based on experimental results [177]. These experimental results are obtained through

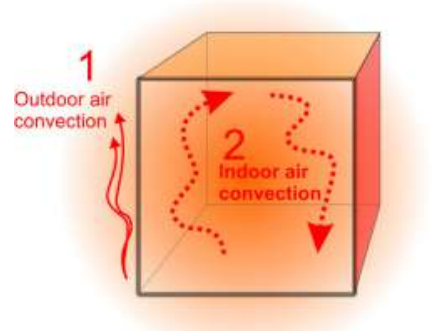

Fig. 4. Cases of air convection in a generic cubic scale model: $\{1\}$ Outdoor air convection and $\{2\}$ indoor air convection.
Table 8

Convection heat transfer coefficients extracted from reduced-scale models and implemented in building energy simulations (BES) [177].

\begin{tabular}{llllll}
\hline \multirow{2}{*}{ Author model (year) } & \multicolumn{6}{c}{ Building energy simulations } \\
\cline { 2 - 6 } & EPS-r & E+ & IES & IDA & TAS \\
\hline MCAdams (1954) & $\bullet$ & - & $\bullet$ & $\bullet$ & - \\
CIBS (1979) & $\bullet$ & - & - & - & $\bullet$ \\
BLAST (1981) & - & $\bullet$ & - & - & - \\
TARP (1983) & - & $\bullet$ & - & - & - \\
NBS detailed convection(-) & - & $\bullet$ & - & - & - \\
NBS polynomial (1976) & - & $\bullet$ & - & - & - \\
Jayamaha (1996) & $\bullet$ & - & - & - & - \\
\hline
\end{tabular}

full-scale test cells and, in cases, in which it is not possible to build a full-scale prototype, scale models are used.

Usually, these scale models have not the intention of being compared with full-scale prototypes, they are only used for obtaining the convection coefficients at different stages.

As those coefficients are obtained by dimensionless numbers, the application to other size cases are supposed for granted if these dimensionless numbers are in an equal range.

Afterward, those coefficients would be implemented, for example, in simulation programs (Table 8 ).

Analyses of air convection could be divided into two groups (see Fig. 4):

1 Firstly, outdoor air motions produced by differences in temperatures without any wind influence (see Fig 4- $\{1\}$ ).

2 Secondly, indoor air motions $[73,74]$ as free (natural) air motions generated by indoor air gradients of temperatures [51] (see Fig 4- $\{2\})$.

These tests related to free convection are not usually taking place in wind tunnels, instead heating sources are used for obtaining temperature differences enough to cause indoor or outdoor air motions.

Boundary conditions should take into account air temperature fields since these are causing free convection.

Most of these experiments with scale models pursue to determine convective heat transfer coefficients, $h$. They are undertaken in small portions of surfaces that could be considered as scale models of full-scale cases.

For this purpose two- and three-dimensional tests are done and their configurations allow us to considered them such as a kind of scale models or simple test cells for obtaining equivalence of these coefficients. They are performed with heated flat surfaces at different positions.

The criterion of classification of convective heat tests used by [2] is based in their configuration: vertically, horizontally, bidimensional or three-dimensional.

A typical test configuration is two plates, horizontal or vertical, one in front of the other at different temperatures with floors and ceilings adiabatic. This is reflected in the characterization performed by [195] for such problems.

The aspect ratio of these two-dimensional tests are shown in Table 9 and the three-dimensional tests are studied in Table 10 $[1,2]$. They are especially interesting for our review, as well as those performed with air as fluid.

Dimensional analysis (see Section 4.4) is used for approaching convective flow phenomena. If free convection is happening, Nusselt number $(\mathrm{Nu})$ is defined initially as function of Prandtl $(\mathrm{Pr})$ and Grashof number ( $\mathrm{Gr}$ ). The combination of $\mathrm{Gr}$ and $\mathrm{Pr}$ numbers gives the Rayleigh number $(R a)$. Ra determines which principal heat process is taking place, whether convection or conduction. Depending on ranges of $R a$ of the fluid, $N u$ number will take certain values and consequently their convective coefficients, $h$. 
Table 9

Free convection coefficients in two-dimensional tests enclosures based in [2]. All considered as reduced-scale model tests.

\begin{tabular}{|c|c|c|c|c|c|}
\hline Author & Dimensions (m) & Scale $^{\mathrm{a}}$ & Fluid & Range Ra & Correlations vertical \\
\hline [21] & $0.762 \times 0.254 \times 0.127$ & $1 / 20^{\mathrm{a}}$ & Water & $1.6-5.4 \times 10^{9}$ & \\
\hline [245] & $0.2525 \times$ Var. $^{b} \times 0.1016$ & $1 / 20^{\mathrm{a}}$ & Air & $3.5-5.5 \times 10^{6}$ & $N u=0.254 \times G r^{0.26}$ \\
\hline [189] & $0.833 \times 0.305 \times 0.152$ & $1 / 20^{\mathrm{a}}$ & Water & $2.3 \times 10^{10}-1.1 \times 10^{11}$ & $N u_{L}=(0.748-0.762) \times G r^{0.26}$ \\
\hline [226] & $0.181 \times$ Var. $^{\mathrm{b}} \times 0.305$ & $1 / 8^{a}$ & Air & $1.8-3.6 \times 10^{6}$ & \\
\hline [157] & $0.546 \times 0.914 \times 0.244$ & $1 / 10^{\mathrm{a}}$ & Air & $10^{9}-10^{11}$ & $N u=0.224 \times R a_{H}^{1 / 4}$ \\
\hline [7] & $-\times 0.366 \times 0.244$ & $1 / 10^{\mathrm{a}}$ & Air & Laminar & \\
\hline [40] & $0.196 \times 0.15 \times 0.15$ & $1 / 20^{\mathrm{a}}$ & Air & $2.5-8.5 \times 10^{6}$ & \\
\hline
\end{tabular}

a Not explicitly mentioned in documentation. Here suggested under the scale view-point.

b Variable.

Table 10

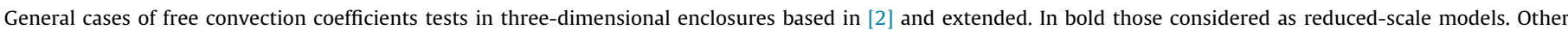
remaining are considered as $1 / 1$ test-cells.

\begin{tabular}{|c|c|c|c|c|c|}
\hline Author & Dimensions $(\mathrm{m})^{\mathrm{b}}$ & Scale ${ }^{a}$ & Fluid & Range Ra & Correlations vertical \\
\hline$[176]$ & $\begin{array}{l}3.60 \times 7.35 \times 2.40 \\
3.60 \times 7.35 \times 3.60 \\
3.60 \times 3.60 \times 2.40\end{array}$ & $1 / 1$ & Air & $10^{9}-10^{11}$ & $\begin{array}{l}N u=0.22 \times R a^{0.32} \\
h=1.873 \times \frac{\left(\Delta T^{0.32}\right)}{H^{0.05}}\end{array}$ \\
\hline [212] & $\begin{array}{l}3.45 \times 3.45 \times 2.34 \\
3.45 \times 3.45 \times 1.80\end{array}$ & $1 / 1$ & Air & - & - \\
\hline [86] & $3.70 \times 9.20 \times 2.5$ & $1 / 1$ & Air & - & - \\
\hline [36] & $0.305 \times 0.305 \times 0.305$ & $1 / \mathbf{8}^{\mathrm{a}}$ & Water & $3 \times 10^{9}-6 \times 10^{10}$ & $\mathbf{N u}=0.62 \times R \mathbf{a}^{1 / 4}$ \\
\hline [55] & $--\times--\times 0.60$ & $1 / 4^{\mathrm{a}}$ & Freon & $2.7-3.3 \times \mathbf{1 0}^{10}$ & - \\
\hline [103] & $0.25 \times 0.25 \times 0.25$ & $\mathbf{1} / \mathbf{1 0}$ & Air & Turbulent & $\begin{array}{l}\mathbf{N u}=\mathbf{0 . 1 0 3} \times \mathbf{R} \mathbf{a}^{1 / 3} \\
\text { If } T_{\text {wall }}>T_{\text {air }} \\
\mathbf{N u}=\mathbf{0 . 0 6 3} \times \mathbf{R} \mathbf{a}^{1 / 3} \\
\text { If } T_{\text {wall }}<T_{\text {air }}\end{array}$ \\
\hline [26] & $3.40 \times 4.00 \times 2.6$ & $1 / 1$ & Air & - & $\begin{array}{l}h=3.08 \times(\Delta T)^{0.25} \\
h=2.88 \times(\Delta T)^{0.25}\end{array}$ \\
\hline [171] & $2.20 \times 2.20 \times 2.20$ & $1 / 1$ & Air & - & $\begin{array}{l}h=1.98, \Delta T=4.6^{\circ} \mathrm{C} \\
h=2.98, \Delta T=11.5^{\circ} \mathrm{C} \\
h=3.34, \Delta T=13.7^{\circ} \mathrm{C}\end{array}$ \\
\hline [49] & $2.80 \times--\times 2.80$ & $1 / 1$ & Air & - & $\begin{array}{l}h=4.1, \Delta T=3.7^{\circ} \mathrm{C} \\
h=2.80, \Delta T=0.83^{\circ} \mathrm{C}\end{array}$ \\
\hline [223] & $4.00 \times 4.95 \times 2.70$ & $1 / 1$ & Air & - & (only horizontal) \\
\hline [130] & $2.35 \times 2.95 \times 2.08$ & $1 / 1$ & Air & - & $h=1.983 \times(\Delta T)^{0.25}$ \\
\hline [131] & $2.35 \times 2.95 \times 2.08$ & $1 / 1$ & Air & - & $\begin{array}{l}h=2.10 \times(\Delta T)^{0.23} \\
h=2.30 \times(\Delta T)^{0.24}\end{array}$ \\
\hline [13] & $2.78 \times 2.78 \times 2.30$ & $1 / 1$ & Air & - & $\begin{array}{l}N u=0.289 \times(G r)^{0.293} \\
h=1.823 \times \frac{(\Delta T)^{0.293}}{H^{0.121}}\end{array}$ \\
\hline
\end{tabular}

a Not explicitly mentioned in documentation. Here suggested under the scale view-point.

b Width $\times$ length $\times$ height.

Theoretically, some convection coefficient values are calculated through Nusselt number, $\mathrm{Nu}$. If Nusselt number is dependent of $\mathrm{Ra}$ number, that means that changes in Ra ranges due to scale and temperature difference changes will provoke, consequently, changes in convection coefficient values.

Fig. 5a and b show Ra value changes depending on scales considered, $L$, and on temperature differences between the surfaces of a body and the ambient.

However, these theoretical curves in Fig. $5 \mathrm{a}$ and b are still a matter of experimentation and corroboration due to the complexity of the problem. Therefore many authors have experienced and theorized by more than a century on the general concept of coefficients of convection [1].

[64] proposed to study natural convection through different temperature ranges to cases where there are specific heat sources.

[172] published a book that reviews the problem of convection in enclosures.

In 2006 effects of thermal boundary conditions of natural convection in a square enclosure were studied [20].

Subsequently, it was studied the same case but with a linear heat source on the walls in [222].

In 2011 laminar convection is studied in a cube with two sides subjected to heat [239].
According to all these studied correlations of convective heat transfer coefficients, they could be presented as three main forms [2]:

$N u=C_{1} \times R a^{n_{1}}$,

$h_{v}=C_{2} \times(\Delta T)^{n_{2}}$,

$h_{v}=C_{3} \times \frac{\Delta T^{n_{3}}}{H^{n_{4}}}$.

being $N u$ Nusselt number and $R a$ the Rayleigh number. $h_{v}$ is the convective heat coefficient, $\Delta T$ is the gradient of temperatures, and finally, $C$ and $n$ are experimental coefficients. Numeral subscripts correspond to different sequences of parameters.

In general, coefficients $n$ are considered as $1 / 4$ for laminar regimes and as $1 / 3$ for turbulent flow regimes. Values of $C$ provides defined discrepancies, although it is accepted laminar between 0.516 and 0.726 , and turbulent between 0.056 and 0.130 [2] However, these values were precised more accurately by other researchers and depend on the considered $R a$ range.

Among these correlations in Eqs. (5)-(7), only the last one has a direct geometric parameter, $H$. This $H$ is the characteristic length of the studied surface. Theoretically, this correlation is directly affected by geometric factors in scale change. 


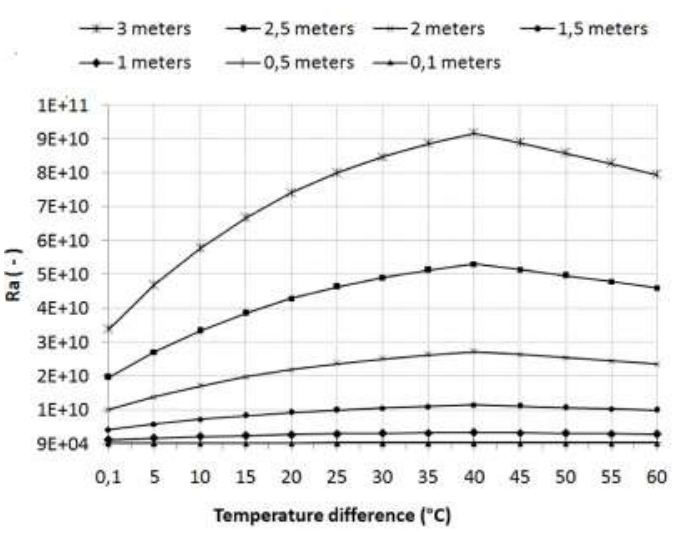

(a)

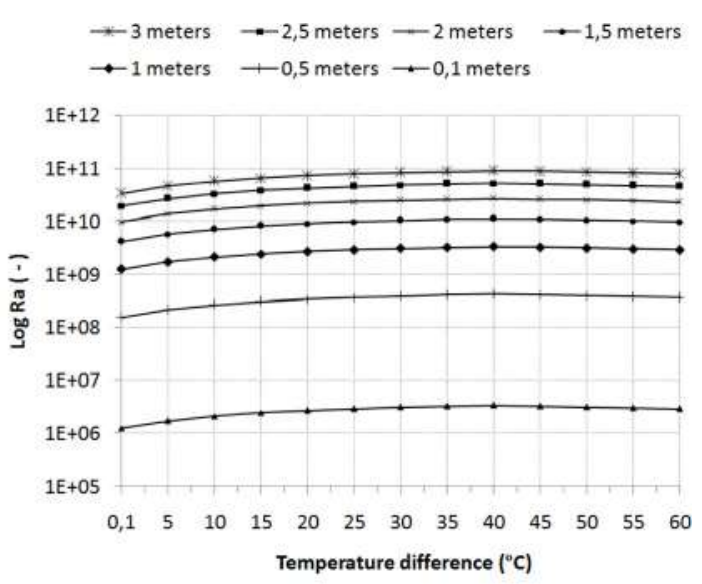

(b)

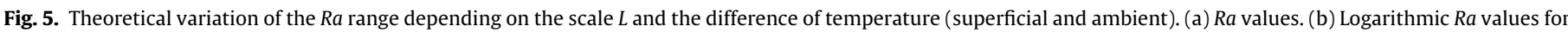
depicting the variations at low scales.

Eq. (5) is dimensionless and, therefore, its application to study some similitude between scale models and prototypes consists in achieving same ratio of $R a$ numbers. To obtain same ratio of $R a$ numbers means changes in temperature differences since $R a$ changes cubed with length and, at the same time, corresponding air properties changes with temperature changes (Fig. 5a and b).

Experimentally is proved that the coefficient $n_{1}$ and $C_{1}$ are changing also with the type of air regime, turbulent or laminar, and these are to be considered in the change of scale.

Equally, Eq. (6) are taking into account air regimes and their corresponding coefficients, but, on the contrary, it depends only on the difference of temperatures of considered surfaces and their surrounded air, so for similarity criteria of convective heat transfers gradient of temperatures of scale models and prototypes should be equal.

Fig. 6 show theoretical variations of convective coefficients from different authors depending on scale changes.

It is valid for all graphics that difference of temperatures corresponding to $0.1^{\circ} \mathrm{C}$ are always laminar regime $\left(G r<10^{9}\right)$ (Fig. 6).

However, in scale models up to $1 \mathrm{~m}$ high and up to $5^{\circ} \mathrm{C}$ temperature differences between air surface and ambient air are related to turbulent regimes $\left(G r>10^{9}\right)$ (Fig. 6a-d).

Under $1 \mathrm{~m}$ height air regime is at every temperature difference entirely laminar (Fig. 6e and f).

There are more variations of convective coefficients at reduced scales (Fig. 6e and f) while at larger scales the values remain relatively closer to each other (Fig. 6a and b).

These graphics show the influence of scale sizes on air regimes. From one scale to another, air regimes have different evaluations and, consequently, changes in convective coefficients occur.

One question would be which temperature change is necessary to keep the same Rayleigh air regime and its convective coefficients during scale changes.

For this purpose, Fig. 7 shows the increment of temperature necessary for maintaining equal Rayleigh regime in the reduction of scale.

Following the dashed line of lineal tendency of these increments, it is clear that down-scaling causes a rapidly increase of temperature needed for maintaining the air regime. These necessary temperatures are impossible to achieve with common techniques (calefactors, heat plates, etc.). It is worth to point out that the graphic shows temperature logarithms in order to see differences clearer.
Seeing the situation in the other way around, to maintain air Rayleigh regimes from scale models of buildings to other replicas at larger scales - or full-scales - it is necessary to decrease air temperatures drastically (almost frozen) at the first stages in up-scaling (from 0.1 to $0.5 \mathrm{~m}$ ).

These radical changes in temperatures are related to power differences in Rayleigh's regimes between scales. While a $3 \mathrm{~m}$ high room could have Rayleigh's regimes about $10^{8}$ to $10^{10}$, a scale model could be at about $10^{4}$ to $10^{6}$, being those differences of regime really considerable.

This is not the first attempt to depict Rayleigh regime changes, Rayleigh-Bénard (RB) thermal convection were studied and generalized by [97].

This case of convection is produced in spaces with lower heated surfaces and colder upper surfaces. They could be seen at small scale in boiled fluids with great differences of temperature. In this study $\mathrm{Nu}$ and $\mathrm{Re}$ numbers are functions, on the one hand, of $\mathrm{Ra}$ number and, on the other hand, of $\operatorname{Pr}$ number. Pr defines the implicit characteristic of the fluid.

This kind of RB convection could be also a theoretical case in which a room is heated by a radiant floor and the roof or ceiling is colder.

Based in Grossmann-Lohse general theory, $R a$-Pr-range values of scales between $0.1 \mathrm{~m}$ (considered a model) and $3 \mathrm{~m}$ (considered a building room height) is shown in Fig. 8.

Internal air properties are considered between $10^{\circ} \mathrm{C}$ and $50^{\circ} \mathrm{C}$ and also two types of fluids: air and water. Water is included because some built scale models for convection experiments are using indoor water for reproducing more accurately internal air movements.

Fig. 8 shows that the case with water remains in the low-Re region under 50 , what means that there are no remarkable influence of the movement of the bulk for considering two different layers in the convection.

On the contrary, the range of values adopted by air is being affected by the regime $\mathbf{I}_{l}$. In this regime, temperature layers are dominant versus cinematic layers and there are no influence of bulks.

One might be confused by the fact of considering Re number in a case of natural convection and that is because the Grossmann-Lohse theory contemplates the influence of the bulk as a kinetic movement or "current" of the core of the "cell" generated by the natural convection.

Apart of the general unification theory of RB convection of Grossmann-Lohse, all mentioned authors until now dedicate their 


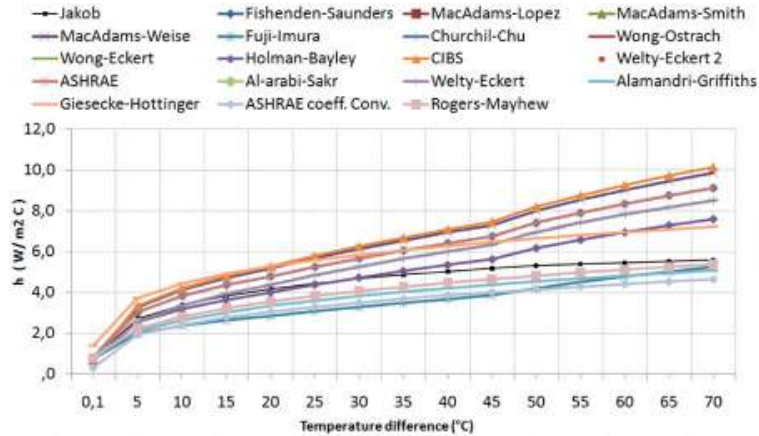

(a)

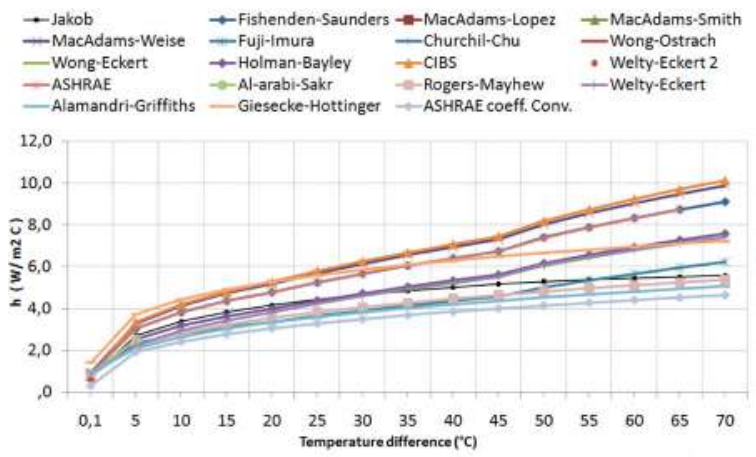

(c)

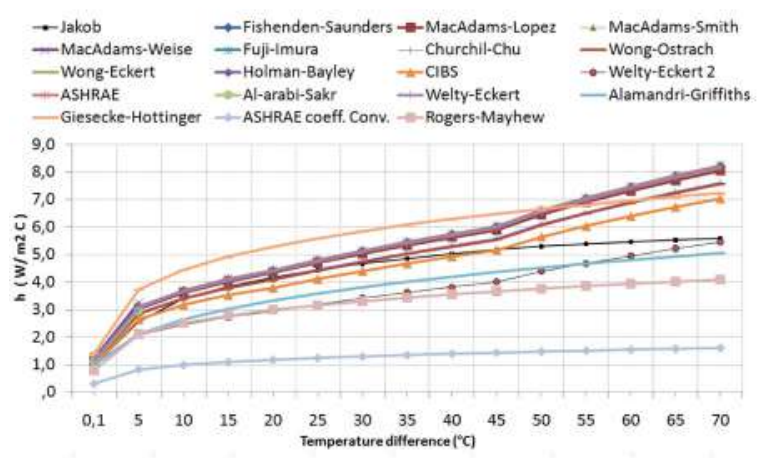

(e)

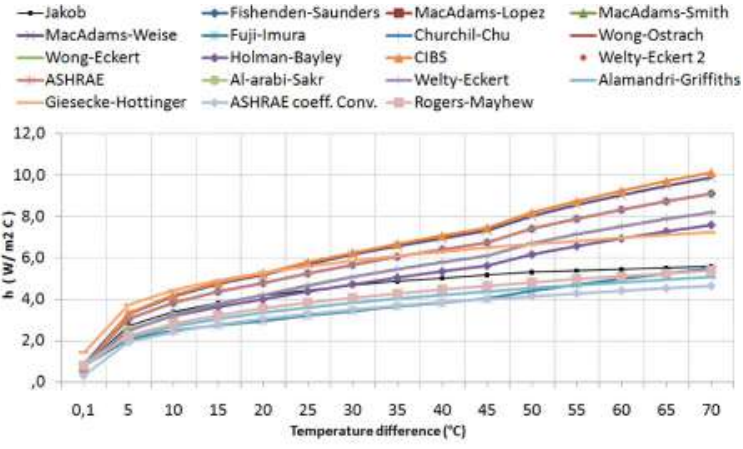

(b)

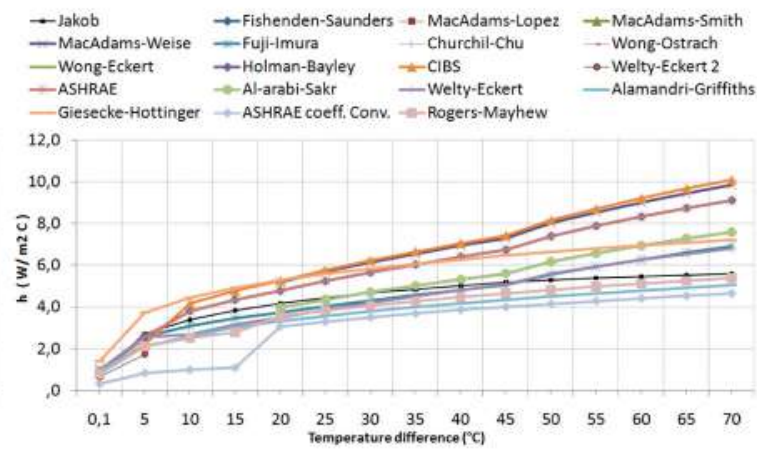

(d)

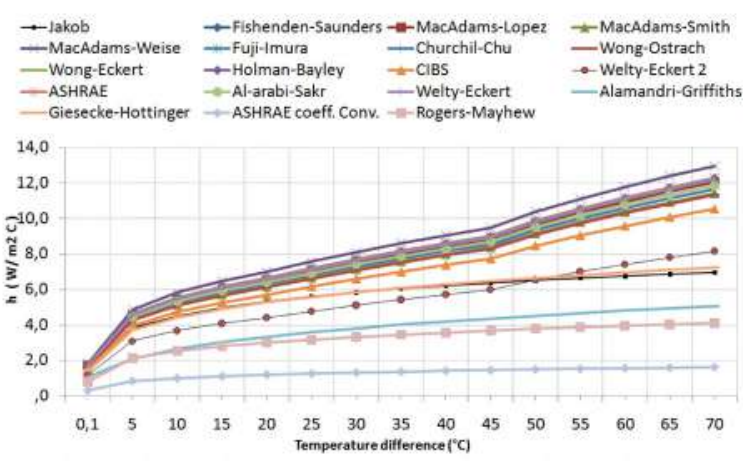

(f)

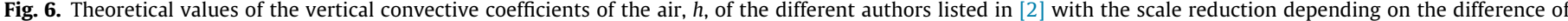

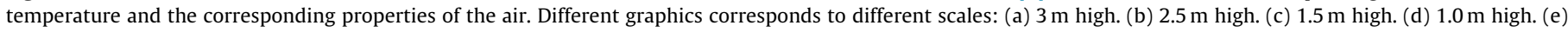
$0.5 \mathrm{~m}$ high. (f) $0.1 \mathrm{~m}$ high.

studies to restrictive specific cases of convective heat transfer coefficients and correlations, but they do not study focusing on test sizes neither scale changes.

The problem arises when scale models are done for predictions of convective heat transfers of not-yet-built larger prototypes. In this line, [212] attempts to get this goal with good results at steady state conditions.

Another approach to the problem could be multiscale (page 77 of Section 4.3), that is, to know the behavior of the convective phenomenon at the same approximate scale as the scale model. By knowing scale stages of this phenomenon, it would be possible to assess how far this phenomenon influencing a scale model.

The ideal situation would be some conjunction of the scaled physical phenomenon and the scale model. And precise this leads to cases of multiscale physic problems [153,142,229,72] but these studies are beyond this present review.
6.4.6. Ventilation for buildings using scale models

Building ventilation systems are numerous. A classification of these systems could be seen in [132].

Additionally, building ventilation could be caused by a combination of phenomena of heat transfer and air motion difficult to determine. They depend on many factors, temperature differences, wind speed, fluid viscosity, pressure and position of the studied surface.

Relations between those are described by continuity, momentum and energy equations, that is, conservation of mass, inertial forces and temperature of the fluid, respectively. Together, these three are known as Navier-Stokes equations.

In general, to achieve similitude between scale models and prototypes, geometric similarity is required. To achieve air flow similarity additional requirements for dynamic similarity are needed, i.e., fluid streamlines in scale models and prototypes should be similar [73], and thus, Navier-Stokes governing equations. 

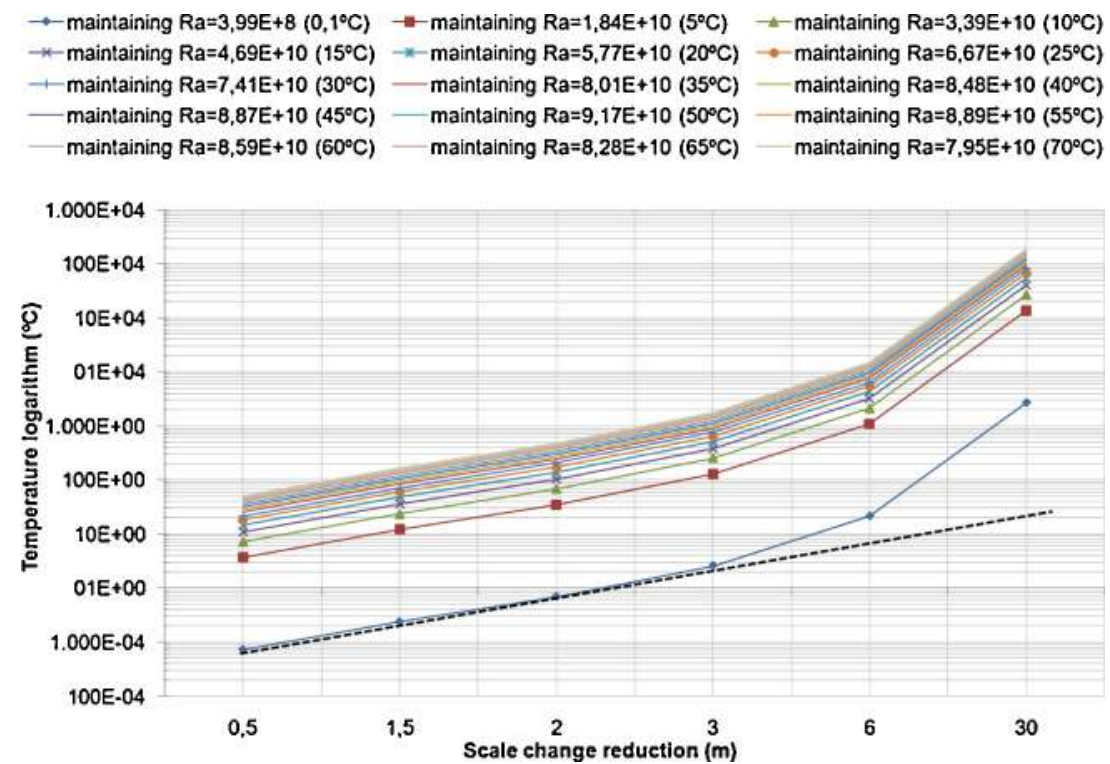

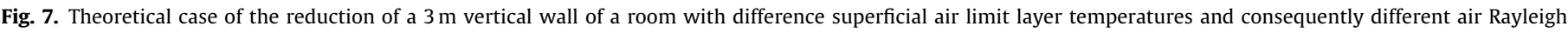

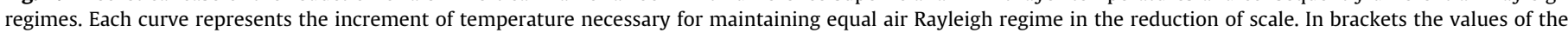
original difference air temperatures near the $3 \mathrm{~m}$ vertical wall. Dashed dark line: lineal tendency.

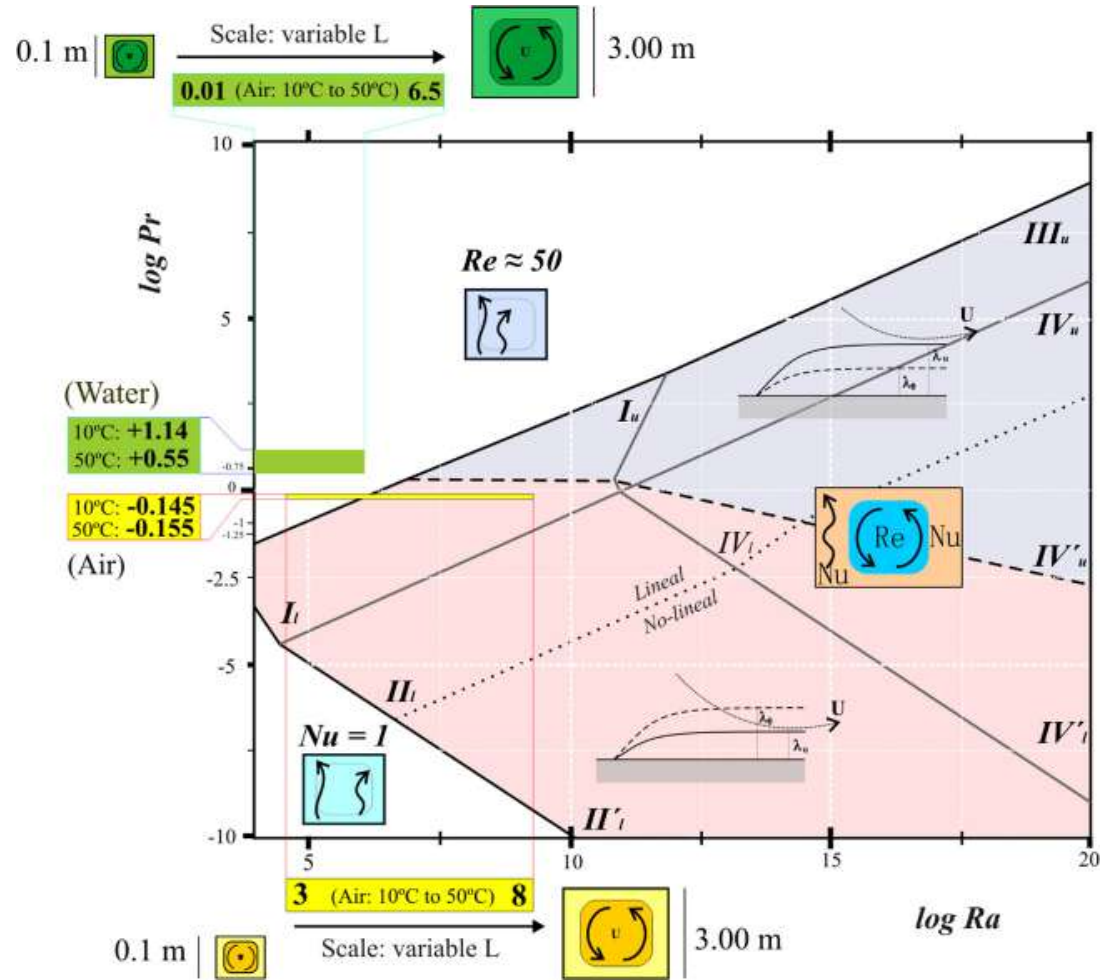

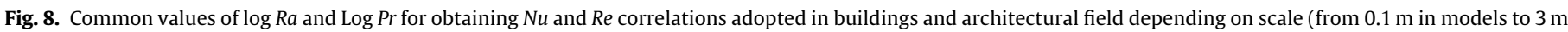

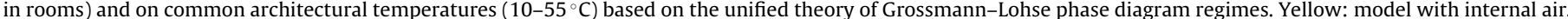

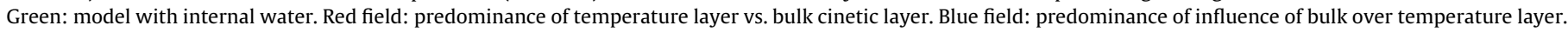
(For interpretation of the references to color in this legend, the reader is referred to the web version of the article.)

Boundary conditions could be very diverse depending on the study case.

These analyses of air motions in scale models for buildings could be divided into three groups (see Fig. 9):

1 Firstly, forced outdoor air motions produced by any mechanisms such as ventilators or wind. Wind pressure on buildings are addressed in Section 6.1.3 (Fig $9-\{1\}$ ).
2 Secondly, building ventilation rates, corresponding to envelope flow exchanges (Fig $9-\{2\}$ ).

3 Finally, forced indoor air motion $[73,74]$ (Fig $9-\{3\}$ ). Free (natural) air motion is excluded since this case is generated by gradients of temperatures instead of forced air movements [51] and, it is specifically addressed in Section 6.4.5.

These three cases are intertwined and they could be influenced by the effects of thermal processes (Fig. 9 Right). 

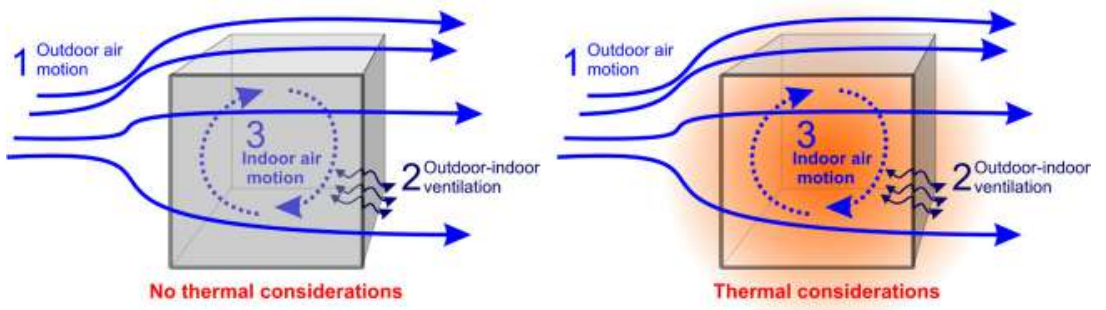

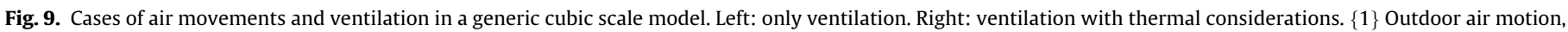
$\{2\}$ outdoor-indoor ventilation and $\{3\}$ indoor air motion.

The first case of outdoor air movements (Fig $9-\{1\}$ ) is related mainly to ventilation of urban configurations or air motions pressures over isolated buildings. This case is studied in Section 6.1.3.

The second case of ventilation (Fig $9-\{2\}$ ) is also one of the main issues in architecture and research in this area. Most of these indoor-outdoor exchange ventilation studies for buildings with scale models are tested in wind tunnels for reproducing outdoor air pressures.

The third case of indoor air motion (Fig $9-\{3\}$ ) is linked with the indoor comfort of rooms and are mainly tested in laboratory. In this case, these studies are very close related to convective air movements and are influenced by internal gradient of temperatures. For this reason, these cases are linked with the Section 6.4.5 on convective heat transfers.

In every case, the use dimensional analysis (see Section 4.4) for approaching ventilation phenomena is common in engineering but not in architectural field [76].

The reason of using dimensional analysis is that air motion is still a complex phenomena with no-unique explanatory law. Newton's cooling law in convection is a rough definition of convective coefficient rather than a phenomenological law of convection and Navier-Stokes equations are difficult to resolve, for these reasons dimensionless numbers are often used for approaching this phenomenon.

Some dimensionless numbers provide information about air motion phenomenon. For example, in forced or free ventilation, the turbulent or laminar regime flow could be determined by $R e$ number.

If air flow implies forced flow, boundary conditions would be related to mechanical or natural forced ventilation systems with Reynolds, $R e$, Froude, $F r$, and Peclet, $P e$, numbers as fundamentals.

In compressible air flows, so fluid with density differences caused by pressure differences, Archimedes number $(A r)$ is considered. If density differences are caused by temperature differences, Grashof number $(\mathrm{Gr})$ is used instead.

When the fluid is equal in scale models and in prototypes, the relevant $\pi$-parameters are Re and Fr. Prandtl number, Pr, would be equal so far their absolute temperatures do not differ considerably. In general, effects of density variations could be negligible in architectural field.

Natural ventilation of buildings uses natural forces of wind pressure and stacks effects [132]. The stack effects are originated mainly due to difference of temperatures and they are dominant in moments of low wind speed.

In general, supposing a very clear directional windy day, air is flowing over a surface of a building, forced convection by wind is taking place.

In forced convection cases, $\mathrm{Nu}$ is a function of $\mathrm{Pr}$ and $\mathrm{Re}$. Often flow boundary layers have laminar flow near surfaces and turbulent flows out of this layers.

Boundaries between these two stages are not just lines since transitions are progressive. However, critical values of Reynolds number - named critical Reynold numbers, $R e_{c r}$ - at certain distances give approximations of how far it occurs.

Exceed critical Reynolds number is one of the conditions for similarity with scale models in wind tunnels, since air flow around edged bodies becomes turbulent at relatively low Reynolds numbers.

Concerning temperatures very close to the surfaces of scale models, there are other additional boundary layer surrounding them, called thermal boundary layer, and it is not necessarily coinciding with the air hydrodynamic layer. This layer exists since, within the fluid surrounding the object, a temperature gradient exists.

For example, the study of natural and mechanical ventilation rates in a detached house in wind tunnel were done and predictions were made with a $1 / 20$ scale model for obtaining wind pressure measurements [75,77]. Additionally, in this study air infiltrations by cracks in constructions through scale models in wind tunnels were tested.

In this line, it is possible to find more specific cases related to convection coefficients in buildings (Table 11). For example, the effectiveness of the solar plate mounted on roof's surface of fullscale buildings is studied [51].

Considering that these previous researches are focusing on scale models, this study compares wind tunnel tests with scale models with full-scale collected data.

Measurements of solar radiation, air temperatures and wind speeds are collected at the full-scale prototype. The wind tunnel was located in the University of Sheffield and has a cross section area of $1.2 \mathrm{~m} \times 1.2 \mathrm{~m}$ and a overall length of $7.2 \mathrm{~m}$.

Two scale models at $1 / 32$ and $1 / 64$ were built for testing. The model was placed on a turntable to provide different angles of the wind direction which was produced by the fan.

The solar plate mounted was heated by thermocouples and covered with a cooper plate. The roof has $35^{\circ}$ inclination respect the horizontal.

This thesis [51] is not related to a building per se but to the reproduction of the boundary layer of a plate and the convective coefficient.

A study of the indoor air flow in a room using, among others, what he calls sub-model room is undertaken. In this experiment any heating or cooling sources are acting and therefore, Re number is the most important dimensionless parameter [205].

The $1 / 10$ scale model has $0.914 \mathrm{~m} \times 0.457 \mathrm{~m} \times 0.305 \mathrm{~m}$ dimensions and is made of anodized aluminum with four plane glass windows. There are an inlet and outlet vent on the ceiling both of $10 \mathrm{~cm}^{2}$. There is an indoor partition not reaching the ceiling. The ventilation through these vents is held constant.

For similitude correspondence the ventilation in the scale model was set at $0.25 \mathrm{~m} / \mathrm{s}$ giving a Re of 1600 required.

One of the problems working with so low flow velocity values is the increase of influence of their temperature gradients. For avoiding perturbations in the flow two pressure regulators in the inlet and outlet were set. 
Table 11

Experimental tests of forced ventilation with scale models.

\begin{tabular}{|c|c|c|c|c|c|c|}
\hline \multirow[t]{2}{*}{ Ref. } & \multicolumn{6}{|l|}{ General characteristics } \\
\hline & Dimensions (m) & Scale & Type & Compared with & Thermal & $\begin{array}{l}\text { Tunnel (m) } \\
\text { Wind/water** }\end{array}$ \\
\hline [75] & $0.4 \times 0.21 \times 0.18$ & $1 / 20$ & Building & Dimensional & - & $1.2 \times 1.2 \times 2.28$ \\
\hline [77] & $0.4 \times 0.21 \times 0.18$ & $1 / 20$ & Building & Similitude & - & $1.2 \times 1.2 \times 2.28$ \\
\hline \multirow[t]{2}{*}{ [51] } & $0.3 \times 0.157 \times 0.143$ & $1 / 32$ & Building & Dimensional & Active & $1.2 \times 1.2 \times 7.2$ \\
\hline & $0.15 \times 0.08 \times 0.07$ & $1 / 64$ & Building & Dimensional & Active & $1.2 \times 1.2 \times 7.2$ \\
\hline [205] & $0.91 \times 0.457 \times 0.305$ & $1 / 8^{a}$ & Building & Simulation & - & - \\
\hline [257] & $2.42 \times 1.83 \times 0.90$ & $1 / 3$ & Box & Similitude & Thermal & - \\
\hline [54] & $0.25 \times 0.50 \times 0.2$ & $1 / 8^{\mathrm{a}}$ & Box & Dimensional & - & $2.14 \times 3.21 \times 2.25$ \\
\hline [53] & $0.17 \times 0.17 \times 0.34$ & - & Box & Similitude & Thermal & - \\
\hline [258] & $2.42 \times 1.83 \times 0.90$ & - & Box & Dimensional & Thermal & - \\
\hline [56] & $0.25 \times 0.5 \times 0.20$ & $1 / 12^{\mathrm{a}}$ & Building & Dimensional & Active & $2.14 \times 3.21 \times 2.25$ \\
\hline [183] & $0.51 \times 0.85 \times 0.47$ & $1 / 10$ & Building & - & - & - \\
\hline [160] & $1.25 \times 1.25 \times 0.70$ & $1 / 20$ & Building & Dimensional & Thermal & - \\
\hline [154] & $7.5 \times 1.25 \times 2.5$ & $1 / 20$ & Building & Similitude & Thermal & - \\
\hline [248] & $2.9 \times 1.8 \times 1.2$ & $1 / 12^{\mathrm{a}}$ & Building & Similitude & Thermal & - \\
\hline [249] & $0.25 \times 0.5 \times 0.2$ & - & Box & Similitude & - & $2.14 \times 3.21 \times 2.25$ \\
\hline [167] & $0.137 \times 0.091 \times 0.04$ & $1 / 100$ & Box & Similitude & - & $1.1 \times 0.8 \times 4$ \\
\hline [207] & $2.4 \times 2.4 \times 2.4$ & $1 / 1$ & Room & Simulation & Thermal & - \\
\hline \multirow[t]{2}{*}{ [215] } & $1.75 \times 1 \times 0.53$ & $1 / 6$ & Building & Dimensional & - & - \\
\hline & $0.84 \times 0.5 \times 0.29$ & $1 / 12.5$ & Building & Dimensional & - & - \\
\hline [62] & $0.422 \times 0.67 \times 0.15$ & $1 / 60$ & Building & Similitude & - & $2.2 \times 12 \times 1.9$ \\
\hline \multirow[t]{4}{*}{ [148] } & $1.25 \times 1.25 \times 1.25$ & $1 / 3$ & Room & Dimensional & - & J. Verne CSTB \\
\hline & $1 \times 1 \times 1$ & $1 / 12.5$ & Building & Dimensional & - & J. Verne CSTB \\
\hline & $0.58 \times 0.58 \times 0.58$ & $1 / 12.5$ & Building & Dimensional & - & J. Verne CSTB \\
\hline & $0.42 \times 0.42 \times 0.42$ & $1 / 12.5$ & Building & Dimensional & - & J. Verne CSTB \\
\hline [228] & $0.58 \times 1.2 \times 0.154$ & $1 / 20$ & Building & Simulation & - & $3 \times 9 \times 1.5$ \\
\hline [5] & $0.2 \times 1.8 \times 0.2$ & $1 / 12.5^{\mathrm{a}}$ & Urban & Dimensional & Thermal & $1.9 \times 0.85 \times 7.4$ \\
\hline [234] & $0.163 \times 0.083 \times 0.138$ & $1 / 18$ & Room & Simulation & Thermal & $0.25 \times 0.5 \times 10^{* *}$ \\
\hline [244] & $0.5 \times 0.84 \times 0.45$ & $1 / 12.5$ & Building & Simulation & - & - \\
\hline [57] & $0.12 \times 0.12 \times 0.123$ & $1 / 50$ & Room & Simulation & - & $0.5 \times 0.3 \times 0.6^{* *}$ \\
\hline [69] & $0.5 \times 0.58 \times 0.5$ & $1 / 5^{\mathrm{a}}$ & Room & Similitude & Thermal & - \\
\hline [158] & $0.385 \times 0.17 \times 0.17$ & $1 / 15^{\mathrm{a}}$ & Room & Similitude & - & $0.83 \times 0.83 \times 0.83^{* *}$ \\
\hline [193] & $0.5 \times 0.5 \times 0.27$ & $1 / 10$ & Room & Simulation & Thermal & $0.5 \times 0.5 \times 1$ \\
\hline [247] & - & - & Room & Simulation & Thermal & $4 \times 4 \times 3$ \\
\hline [210] & $0.26 \times 0.442 \times 0.56$ & $1 / 16$ & Tower & Simulation & - & - \\
\hline [241] & $0.08 \times 0.08 \times 0.16$ & $1 / 250$ & Building & Simulation & Thermal & $1.72 \times 0.9 \times 11$ \\
\hline [242] & $0.2 \times 0.2 \times 0.16$ & $1 / 15^{a}$ & Building & Simulation & - & $1.8 \times 1.8 \times 13$ \\
\hline [58] & $0.4 \times 0.16 \times 0.08$ & $1 / 100$ & Urban & Similitude & Thermal & $0.8 \times 0.8 \times 5$ \\
\hline
\end{tabular}

a Not explicitly mentioned in documentation. Here suggested.

Laser Doppler anemometry (LDA) method and particle image velocity (PIV) were used to register fluid flow movements

A $1 / 3$ scale model of a prototype building was used to study airflow performance in a confined enclosure [258]. The dimensions of the scale model were $1.8 \mathrm{~m} \times 2.4 \mathrm{~m} \times 0.9 \mathrm{~m}$.

The scale model was constructed of $12.7 \mathrm{~mm}$ thick plywood. Inner surfaces were sanded and painted black. The front wall was made of Plexiglas to visualization.

Some access holes were made on the top ceiling between the inlet wall and the end wall at intervals of $20 \mathrm{~mm}$. In one of the ceiling edges was a Z-metal profile for forming a continuous inlet slot for air.

Outlet air was occurring through a $150 \mathrm{~mm}$ duct in one of the walls. Anemometer and temperature devices to measure the airflow were employed.

Among the studies of heat transport processes there is an experiment conducted in 2007 about convection between two floors with one horizontal opening in its respective forged stairwell. It combines both physical half scale experimental model and the analytic model [180].

A generic scale model of dimensions $1 \mathrm{~m} \times 1.2 \mathrm{~m} \times 1.2 \mathrm{~m}$ was built to study the unsteady heat transfer by natural convection of a passive heating room in [144].

The full-scale prototype was a passively ventilated room of $4 \mathrm{~m}$ $\times 4 \mathrm{~m} \times 2.8 \mathrm{~m}$ subjected to hourly average radiation during winter.

All walls were of masonry brick of $0.3 \mathrm{~m}$ thickness and the top and bottom were made of concrete $2200 \mathrm{~kg} / \mathrm{m}^{-3}$ density. All enclosure was insulated with glass wool of $0.05 \mathrm{~m}$ thickness. Only the external south wall was built differently. It was a solar absorbent wall (SAW) dark painted and with an additional double glass separate $0.2 \mathrm{~m}$ from its surface forming an air ventilated chamber. In this south wall there were also five lower vents and five upper vents for natural ventilation.

The scale model was not an exact replica of its larger prototype. The scale model had standard brick walls and insulation materials, coated additionally with $0.02 \mathrm{~m}$ of plaster.

The double glass was composed with two layers of $3 \mathrm{~mm}$ and a $6 \mathrm{~mm}$ air chamber between them. Its temperatures were measured with thermocouples of $0.5 \mathrm{~mm}$ diameter on the surface of the glazing and on the SAW in the cavity.

Its indoor air velocity was measured with a thermoelectric flow sensor. The data were collected and recorded by computer aid datalogger.

Gaseous emissions from animal houses cause by internal airflow using a $1 / 10$ scale model are also studied [183]. For example, the case of a scale model of $0.51 \mathrm{~m} \times 0.85 \mathrm{~m} \times 0.47 \mathrm{~m}$ dimensions with $4 \mathrm{~mm}$ thick walls.

Floors were placed at $145 \mathrm{~mm}$ above the slurry channel bottom, and the ceiling height was $325 \mathrm{~mm}$. Ammonia water was circulated from the storage tank to a reservoir of ammonia water at the bottom of each model with an air space between them.

On general ventilation research and, specifically, through scale models, [206] makes a complete review of the use of these scale model techniques. He notes the low costs, usability and quality 
of this technique as well as its under use. Until 2007 only 3\% of researches carried out on ventilation used scale models.

A methodology of study buoyancy-driven ventilation in atrium buildings using scale models is addressed in [160]. For this purpose the Center for Education in the Green Building in Taiwan serves as a full-scale prototype for analyses and a $1 / 20$ scale model is built for validating the results obtained by CFD.

The dimensions of the scale model are $1.25 \mathrm{~m} \times 1.15 \mathrm{~m} \times 0.7 \mathrm{~m}$ but only a single-story space connected to the atrium was considered for this study.

In this case, when considering non-uniform density fluid, the Archimedes number, $A r$, is to be taken into account for similarity between scale model and prototype. In other cases, it is Grashof number, $G r$, the one taken into consideration instead.

Occupancy was simulated in the scale model with a heated plate. Measurements of buoyancy type are difficult to achieve due to the low velocity values. Anemometers, thermocouples and dataloggers were used for collecting and recording experimental data.

Ventilation stacks or chimney and flow reversal and discharged coefficients are tested in wind tunnels with a scale model of a building with two openings in [54,56]. The scale model was a box of dimensions $0.5 \mathrm{~m} \times 0.25 \mathrm{~m} \times 0.2 \mathrm{~m}$. Its two openings were $4 \mathrm{~cm} \times 2 \mathrm{~cm}$ and $3 \mathrm{~cm} \times 1 \mathrm{~cm}$. The wind tunnel has $2.14 \mathrm{~m} \times 3.21 \mathrm{~m}$ $\times 2.25 \mathrm{~m}$ dimensions. The study case of multiple stacks are also tested in $[249,250]$.

In 2011, the Massachusetts Institute of Technology with the University of Wyoming has developed a laboratory test that examines the effects of natural convection on the temperature in a scale model of an office building already built [248].

The prototype building has three floors with a triple height atrium inside. It has been monitored for 16 months collecting data on temperature, air flow, energy used and number of occupants.

The data collected were used for modeling the geometrical, dynamical and thermal characteristics of its functional scale model. The test model has been reduced to $1 / 12$ and it took place in a controlled ventilated chamber of dimensions $5.16 \mathrm{~m} \times 3.65 \mathrm{~m}$ at its base and a height of $2.43 \mathrm{~m}$.

Other specific study related to building ventilation system is done in [193]. It is related to performance of ventilated systems in buildings. The author built a $1 / 10$ scale model prototype tests in the interior of the wind tunnel for validation of the CFD simulation.

The thermal similarity was set with a heater to simulate the constant heat flux of $24 \mathrm{~W} / \mathrm{m}^{2}$ of sedentary human occupancy in an office. The fluid similarity was reached maintaining a constant and proportional flux between the scale model and the full-scale prototype.

Critical Reynolds number was overcome as a necessary condition for similarity. The adoption of a critical Re are sought in scientific papers and a value of 7500 was found to be valid for scale models up to $1 / 60$.

The dimensions of the scale model of the building was $0.5 \mathrm{~m} \times$ $0.5 \mathrm{~m} \times 0.5 \mathrm{~m}$ with a $0.13 \mathrm{~m} \times 0.13 \mathrm{~m}$ square hole at the ceiling for mounting the wind tower. The wind tunnel dimensions were small, $0.5 \mathrm{~m} \times 0.5 \mathrm{~m} \times 1 \mathrm{~m}$, for that reason the wind tower was placed inside but the scale room remained outside of it.

The CFD simulated model was an exact copy of the experimental scale model tested.

A 1/100 scale model of a building was tested in wind tunnel to study corner vortices with oblique wind pressures [167].

The wind tunnel has dimensions $1.1 \mathrm{~m} \times 0.8 \mathrm{~m} \times 4 \mathrm{~m}$. Turbulence wind was generating in wind tunnel through a previous grid placed at the entrance.

A total of eight scale models of dimensions $0.137 \mathrm{~m} \times 0.091 \mathrm{~m}$ $\times 0.04 \mathrm{~m}$ made with Plexiglas were built. From them four were used for pressure and turbulence studies and the others for flow visualization.
They were provided with 108 pressure taps and high-precision Betz-type water manometers were used to record pressure levels. Hot-wire measurements were carried out on roof tops. For visualization of the air movements laser light illumination technique was used.

The ventilation rate of a natural ventilated livestock building subjected to varied wind conditions is tested in [228]. In this research, an overview of the turbulence models use in simulation of buildings is done.

For this research a $1 / 20$ scale model of a full-scale prototype of dimensions $12.2 \mathrm{~m} \times 24 \mathrm{~m} \times 2.7 \mathrm{~m}$ and a tilted roof with $18.7^{\circ}$ was built. The sidewalls had a continuous openings of $55 \mathrm{~mm}$. Four chimneys were used at the roof of the model. The wind tunnel had $9 \mathrm{~m} \times 3 \mathrm{~m} \times 1.5 \mathrm{~m}$ dimensions.

This study does not compared the scale model with a corresponding full-scale prototype but with the CFD simulation of this precise scale model, therefore, there are no similarity conditions.

The ventilation of a swine building typology is performed in [244]. Concretely, airflow velocities with the use of ammonia concentrations through an 1/12.5 scale model swine building were simulated.

This building had a totally open floor and had $0.5 \mathrm{~m} \times 0.84 \mathrm{~m}$ $\times 0.45 \mathrm{~m}$ dimensions. The walls were built with clear acrylic glass. They used Laser Doppler Anemometer.

Ventilation of the model was provided by adjustable flaps beneath the ceiling and spanning the whole width of the building. At the roof a duct pipe was located for upper ventilation helped by a discharging fan. A $0.16 \mathrm{~m}$ of Ammonia water filled the bottom of the scale model.

Other example of gas emissions studies is the case of a pig house through two scale models at $1 / 6$ and $1 / 12.5$ in wind tunnel [215]. The scale models were built with thick transparent acrylic plastic. On the opposite walls, just under the ceiling, regulating flaps were considered for internal ventilation.

The dimension of the scale models were $1.75 \mathrm{~m} \times 1 \mathrm{~m} \times 0.535 \mathrm{~m}$ and $0.84 \mathrm{~m} \times 0.5 \mathrm{~m} \times 0.29 \mathrm{~m}$ for the larger and the smaller, respectively.

Similar parameters for isothermal flow between the model and the prototype are Froude, Reynolds and Euler numbers, $\mathrm{Fr}, \mathrm{Re}, \mathrm{Eu}$, respectively. Measurements of relative humidity (RH) and temperature were recorded.

Smoke was used to visualize flow movements. Ammonia aqueous solution was placed inside the model as a source of emissions to be measured.

The study of the air displacement due to the revolution of revolving doors was addressed in [69]. For this purpose, an approximately $1 / 10$ scale model of a chamber of dimensions $3.65 \mathrm{~m} \times 2.45 \mathrm{~m} \times$ $2.03 \mathrm{~m}$ with a revolving door was built. It represented the hall of a building.

In the interior was placed a heater and a $0.4 \mathrm{~W}$ fan for air distribution and to create an maximal isothermal environment.

Additionally, the revolting door had a mechanism with a motor to rotate it. The walls of the box were insulated by two glued layers of styrofoam of $0.05 \mathrm{~m}$ thickness and covered outside with aluminium paper to reduced heat exchange by radiation between the box and the environmental chamber.

Reynolds numbers of the scale model and prototype were the same value, and were defined in terms of angular speed and the diameter of the revolving door.

Air leakage was negligible due to the good sealing of the models.

In these conditions there was no gravity force considerations, thus the Froude number was not required. For complementing and analyzing the data some thermographic pictures were taken.

Very interesting study is performed with a $1 / 200$ scale model of a complete 19th-century church for testing air flow around and their indoor infiltration [218]. 
Measurements of indoor and outdoor pressure with a manometer were taken. There were some ventilation for the crawl space of the church and measurements of infiltration of these vents were analyzed. This article addressed the infiltration and wind pressure of a building subjected to wind-dominated cases.

Influence on the natural air ventilation of buildings of a street located within a high density urban area by wind pressures on their surfaces was studied in [14]. For this purpose they built a 1/100 scale model. The scale model buildings were cubes made of wood.

The case was tested in the worst situation of natural ventilation, that means, with all scale model buildings of the urban area with the same height. A total of four model configurations were tested in wind tunnel and with different wind pressure angles.

Measurements were made with an 1-D hot wire probe constant temperature anemometer. Wind pressures of the building surfaces were done by fine pressure taps. In this case no full-scale comparison was made.

Buildings with special ventilation requirements are tested in wind tunnels. For example, the case of a nuclear facility. These buildings have a very demanded ventilation system and specific requirements of air pressure compared with the outdoor environmental pressure [148].

These ventilation requirements were considered in the ventilation system down-scaling of the scale models. They were tested at steady and transient state in isothermal flows.

They create different cubic scale models representing the configuration of the nuclear facility. One of them of dimensions $0.9 \mathrm{~m}$ $\times 0.9 \mathrm{~m} \times 0.9 \mathrm{~m}$ is the reference-scale model.

The ventilation system had to be placed outside and under the scale models. They were also under the wind tunnel floor to avoid interfering the wind flow. The system was under these scale models due to ventilation pressure conditions.

Although there are preferences for air direct wind tunnel techniques [76], it exists other types of study techniques for simulating mechanical ventilation in buildings with scale models. The saltbath technique consists on immersing an acrylic scale model into a tank full of water with salted water injection control.

An example of this technique is an experiment consisted on a Plexiglas scale model of dimensions $0.385 \mathrm{~m} \times 0.17 \mathrm{~m} \times 0.17 \mathrm{~m}$ divided into two chambers by a partition and connected with a circular openings on one side of the chamber provided with water forced flow [158].

The reduced scale model was placed in a plexiglas tank of dimensions $0.83 \mathrm{~m} \times 0.83 \mathrm{~m} \times 0.83 \mathrm{~m}$ with constant ambient temperature water. Water was used as the ambient fluid in this case. A duct was connected with one of the holes of the chamber with forced flow and salt water was injected in it. The flow structure was captured by a light-attenuation flow visualization method.

Cross natural ventilation influenced by wind is researched in [234]. For this research a 1/18 experimental model representing a building was considered. It was constructed in Plexiglas with $0.163 \mathrm{~m} \times 0.083 \mathrm{~m} \times 0.138 \mathrm{~m}$ dimensions. It has two openings of $1 \mathrm{~cm}^{2}$ in area and the thickness of the enclosure was $1 \mathrm{~cm}$.

The simulation took place in an open water channel of dimensions $10 \mathrm{~m} \times 0.5 \mathrm{~m} \times 0.25 \mathrm{~m}$. The scale model was submerged in the water channel with pigmented water inside. The water was whether a solution of salt-water or ethanol for density differences between outdoor and indoor pressures.

After the hole openings aperture evolution of the flow water was observed. Rotating blades at the channel end simulate the "wind flow" velocity at $2.3 \mathrm{~m} / \mathrm{s}$.

Finally, new manufacture techniques such as 3D-printed scale models are accelerating the use of models in wind tunnels. For example, the use of 3D-printed scale models of stadiums in Qatar for FIFA World Cup 2022. Dr. Saud Abdul Aziz Abdul Ghani and his team at the College of Engineering at Qatar University have constructed
$1 / 300$ scale models with new designs to be tested in wind tunnel [82]. The principal aim is to determine how to best construct these stadiums for optimal cost efficiency and environmental benefit.

\subsection{Fire and smoke in buildings using scale models}

Other physical phenomenon with a great level of uncertainty is the fire effects on buildings. This is a major issue in buildings because is related to safety. Combustion is a mixed phenomenon of thermal reaction producing smoke that should be extracted by proper ventilation.

Scale models of buildings are set on fire to study the propagation of fire and smoke. Studying the behavior of an incipient fire could help to understand the priorities in building fire safety. For this, scale models are tested in laboratory controlled and monitorized with cameras. Video sequences are possible in these tests and are very useful in analyses.

These kind scale models are used, for example, to study fire whirls occurring after catastrophes such as those occurring after the Great Kanto Earthquake in 1921, which caused so great damage in urban areas [232,145].

The ventilation flow of the upstream smoke provoked by fires in car parks was studied in [107]. For this purpose, a full-scale and scale model were used to analyze these ventilation patterns. A simplified car park was considered: ceiling and wall were plain and horizontal beams and vertical columns supporting the ceiling are not considered.

The prototype has dimensions $28.6 \mathrm{~m} \times 30 \mathrm{~m} \times 2.6 \mathrm{~m}$ and the four extractors were just at the opposite wall of the entrance.

The fire was declared in the center of the car park. Fire heat set in the car park released rates of 200,500, 1000, 2000 and $4000 \mathrm{~kW}$.

In this research the model had different scales, on the one hand, geometrical scale at 1/25 and, on the other hand, velocity scale at $1 / 5$.

The model was reproduced in an isothermal chamber with helium and air mixture in order to accomplish density requirements of the Froude number $(F r)$. The full-scale pool fire were scaled down. The paper does not say exactly the scale applied.

Smoke behavior in building passage typologies was also one of the studies undertaken with scale models [155]. In this case the study of an underground hydropower station was considered.

Underground smoke is specially toxic due to its incomplete combustion processes. As the smoke follows upwards the same direction of the buoyancy-driven air movements, coinciding with the upward direction of evacuation.

In this paper a $1 / 12$ scale model for researching the mechanical smoke exhaust was used. A physical model simulated a fire inside an underground main transformer hall, adjacent to a transport passage. The study focused on the smoke that spilled out from the fire in the main transformer hall and the smoke movement within the transport passage.

The dimensions of the set-on-fire main transformer hall are $0.89 \mathrm{~m} \times 0.85 \mathrm{~m} \times 1.025 \mathrm{~m}$. The opening is $0.13 \mathrm{~m} \times 0.85 \mathrm{~m}$ and the transport passage are $8.12 \mathrm{~m} \times 0.5 \mathrm{~m} \times 1.025 \mathrm{~m}$.

Fire was provoked with a diesel pool at the floor level in the transformer hall. The heat releases were approximately $0.5,1$ and $2 \mathrm{~kW}$ in the scale model. Smoke confinement and exhaust efficiency utilizing a modified opposite double-jet air curtain was studied in [163]. This is a system introduced in high-rise buildings for reducing casualties provoked by smoke.

An experimental 1/12 scale model was considered in this study. Only the stairwell and the hallway of the high-rise building were considered in the experimental tests.

The model was made of transparent Plexiglas. The stairwell was $0.217 \mathrm{~m} \times 0.308 \mathrm{~m} \times 0.5 \mathrm{~m}$ with two-way stairs, while the dimensions of the hallway were $0.8 \mathrm{~m} \times 0.308 \mathrm{~m} \times 0.25 \mathrm{~m}$. 
The right wall was not totally closed and contained twelve rectangular outlets $0.035 \mathrm{~m} \times 0.035 \mathrm{~m}$. The air curtain was specific designed for this experiment. The dimensions of the boxes placed on the ceiling and on the floor were $0.308 \mathrm{~m} \times 0.308 \mathrm{~m} \times 0.1 \mathrm{~m}$.

Reynolds and Froude numbers were the most important for similarity purposes. Re needed only to be over the critical value, therefore, $F r$ was the main design parameter.

Being the geometric scale $1 / 12$, other scale factors were calculated: for temperature 1 , for time 0.2888 , for velocity 0.2886 and for smoke rate 0.002 .

A camera was used to take photos to register these flow patterns. Vertical thermocouples "trees" were set for measuring air temperature at different heights. The air supplied was at $24^{\circ} \mathrm{C}$.

Spread of fire from one floor to another through ejected fire plumes in high-rise buildings through glass façades were studied in [162]. This paper researched the heat flux profile upon building façades with side walls constraints due to ejected fire plumes from a window of an under-ventilated compartment fire.

A 1/8 scale model of a partial portion of glass façade was built. It consisted on a cubic fire compartment of $0.4 \mathrm{~m} \times 0.4 \mathrm{~m} \times 0.4 \mathrm{~m}$ attached to a glass façade wall of $2.2 \mathrm{~m} \times 1 \mathrm{~m}$. Additionally, two side walls of $2 \mathrm{~m} \times 0.6 \mathrm{~m}$ were installed symmetrically at both sides of the window.

\section{Discussion}

Architects and designers demand scale models for buildings as design applications [74], that is, replicas of their designs. The main advantage of replica models for architects is its resemblance to the prototype, so the designer can take decisions about it.

But exact scale model replicas for predictions on full-scale prototypes, to this date, is not possible due to limitations on phenomenological similarities [224,106,147]. For this reason, functional scale models, and particularly those geometrical undistorted, could be considered as these sought design applications instead.

Functional scale models for buildings result from two historic specific analytic lines. On the one hand, scale models of buildings were traditional for architects since renaissance and were incorporated as analytic tool for designing future constructions [182].

On the other hand, scale models in engineering are developed to analyze the physical response of constructions submitted to certain external environmental actions (e.g. $[24,246,243,211,121,133,173,148])$.

Fused both concepts result in functional scale models of buildings.

However, in developing functional scale models specific for buildings, the result is frequently an unbalanced mixture of these two lines. Mostly figurative resemblance of the scale model to its full-scale building, so its geometrical similarity, is sacrificed in favor of its similarity in physical phenomena, that is, kinematic, dynamic and thermal similarity.

In many cases, by pursuing this sought physical phenomenological similarity, functional distorted scale models emerge.

Functional distorted scale model technique in some physic fields is far widespread (e.g. $[95,113,150,206,238,214,107])$ in comparison with functional strictly undistorted scale model $[212,159]$. Both techniques have advantages and disadvantages.

On the one hand, functional distorted scale models techniques for buildings are used mainly in those models where the phenomenological similarity has unavoidable intervention of time as variable.

Geometrical distortions in scale models try to avoid the influence of time and, for that purpose known theories are used, overall dimensional analysis and general similarity laws [95]. In this case, the data recorded from these scale models could be similar to the corresponding full-scale prototype directly or after applying some scale factors previously obtained.

Main disadvantage of functional distorted scale models for architects and designers is the frequent dissimilarity appearance of the models compared with the corresponding full-scale prototype (e.g. $[95,96,150])$.

On the other hand, model replicas of prototypes do not exist and therefore neither perfect undistorted scale models. For that reason, in this context, functional undistorted scale models for buildings are considered those keeping geometrical resemblance to the fullscale prototype as close as possible regardless the physics.

As consequence, in some physical fields, these scale models would be time-dependent. This is a relative issue in cases such as static structural testing, so the influence of time is little and, in some cases, easy to intervene - for example, in progressive loading [27].

The main disadvantage of these undistorted models is the frequent lack of phenomenological physical similarity with the fullscale prototype.

This situation is mended correcting the obtained data through scale factors. This is analogous to distorted technique procedures, however, with more uncertainties in scale change since time plays a very important role, for example in thermal correspondences [159].

In general, it could be said that functional and geometrical distorted scale models are used in time-dependent physics for achieving phenomenological similarity - overall thermal $[95,150]$ and undistorted in time-independent - in general, static structures (e.g. $[186,243,112])$.

However, the difference is not so clear as it seems. Some timedependent physics on buildings such as buildings submitted to motion and aerodynamic loads could be tested through dissimilar material models.

Those models look like undistorted but have changed material characteristics, for example their density [27].

Changing boundary conditions not affecting scale model appearance, for example, wind speed control, result in considering these also as undistorted scale model tests for buildings $[134,231,156,216]$. Same happens with seismic movements tests $[137,90]$.

Whether distorted or undistorted techniques, they are based both on strategies of general similarity [70] and dimensional analysis (e.g. $[217,70,111,196,197,39])$. The difference is how they are implemented.

Strategies based on Euclidean geometry method such as parallel projection are only valid in some specific structural cases [79]. Other attempts of similarity with geometrical method in thermal cases have no definitive final conclusions [159].

Functional undistorted scale models for buildings are the most requested for full-scale comparisons and, at the same time, the most complex to perform.

Even considering scale model and prototype with exact geometry and materials, they are a case of study by themselves and serve also for better physical phenomena understanding.

Their interaction as "miniature model" in the environment yields new challenges on the understanding of physical phenomena $[22,23,60]$ questioning the influence of the size effects on scale models. In some extreme cases, even they test limits in physic law validation at different scales [97].

Multiscale physics [146] and non-Euclidean geometry such as fractals aim in this line.

Fractal geometry is already proven to play a role in geometrical scale change $[45,46,72]$. However, this field is nowadays relatively useful for architects because of its deep mathematical content. For this reason, to this date its use is only considered in scientist and research papers. 


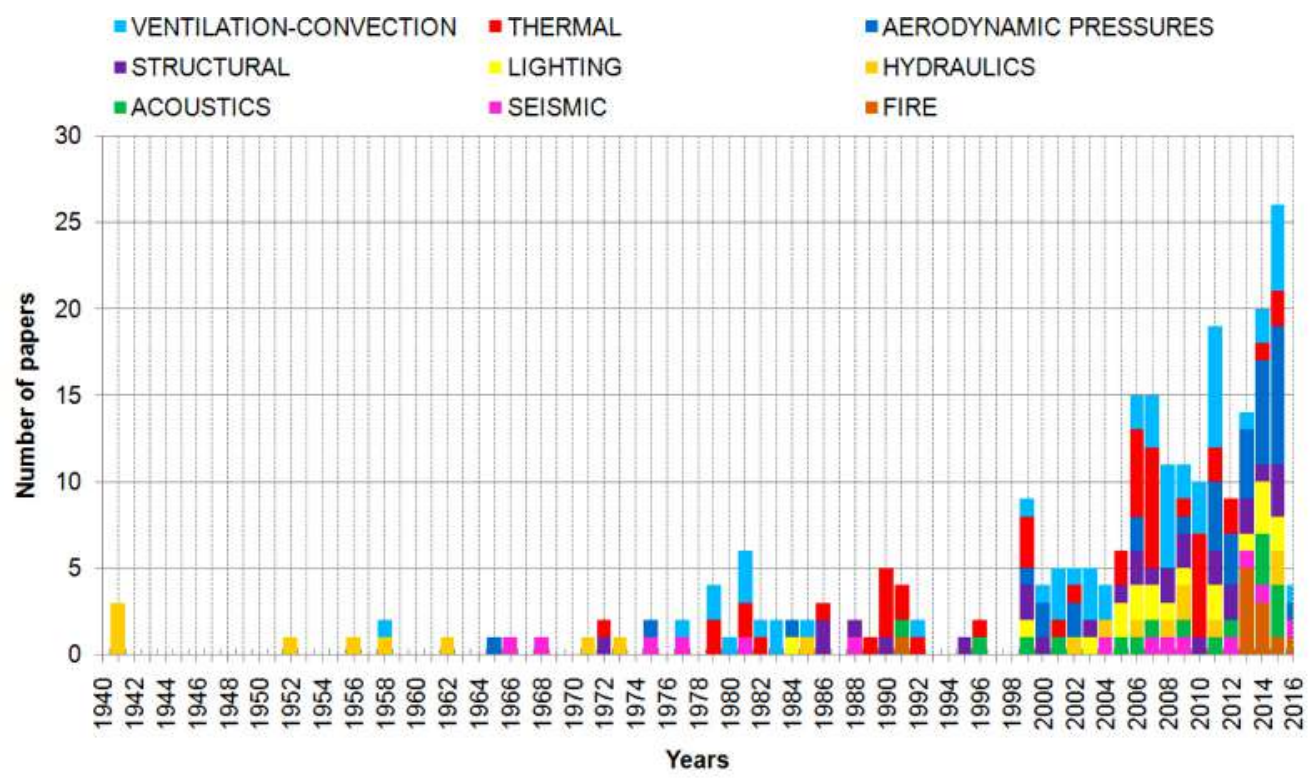

(a)

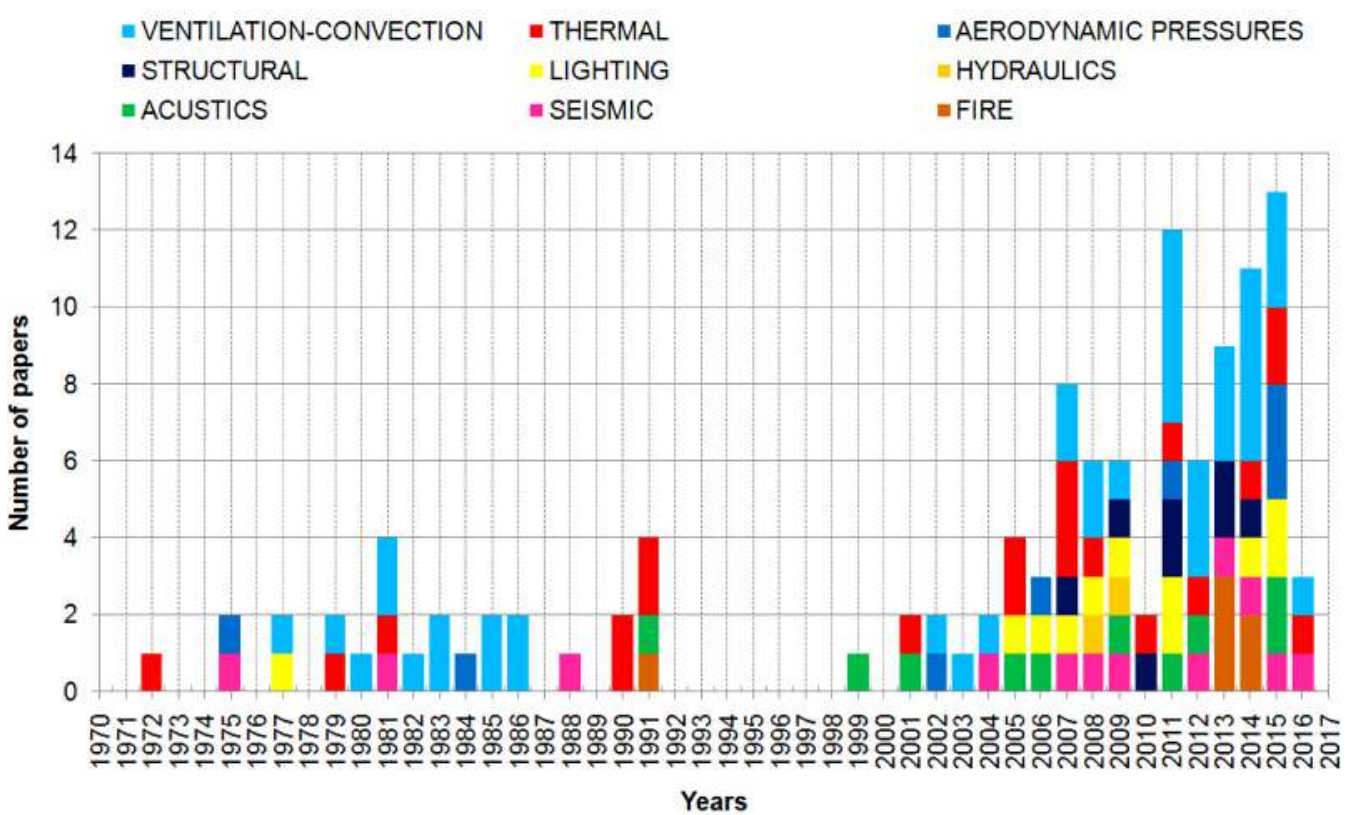

(b)

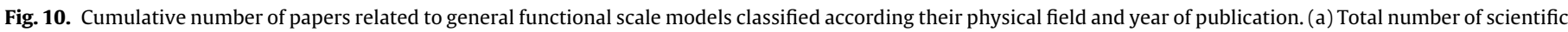
papers. (b) Papers related to buildings.

In any case, the better behavior understanding of the interaction of the "miniature" scale model, the more precise the understanding of a larger full-scale prototype.

Improvements in theoretical strategies on scale models together with the necessity of validation of computer simulations show in general a clear increase of scale model testing as it is depicted in Fig. 10. This figure shows the total number of scientific papers found related to engineer and building scale model testing classified by year and physical field. Fig. 10 shows the number of scientific papers related exclusively to buildings and referenced in this literature review.

Comparing both Fig. 10a and b the increasing tendency parallelism is very clear.

However, the increase in the use of functional scale models is not continuous. In the 90s it seems there are less testing with scale models [204]. This could be due to the incipient improvement in computer simulations and their apparent clear solutions.

After this decade the interest in using scale models comes back, probably by the fact of necessary validation of simulation's solutions. This period last until today, so scientists are still struggling with virtual result corroborations.

Fig. 11 shows the total percentage of scientific papers related to functional scale model testing while Fig. 12 shows the percentage only to building testing.

In Fig. 12 building testing ventilation and thermal analyses with scale models are $50 \%$. The rest is dedicated to other physical fields.

It should be noted that structural building testing is placed in sixth position in buildings, while in engineering testing is almost double frequently with $11.60 \%$. 


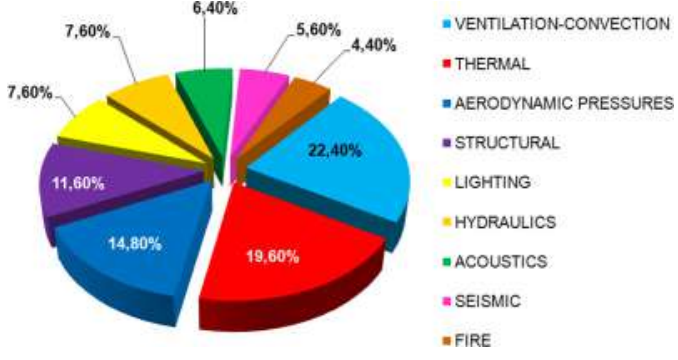

Fig. 11. Percentage of papers of each physical field related to general scientific functional scale models respect its total number.

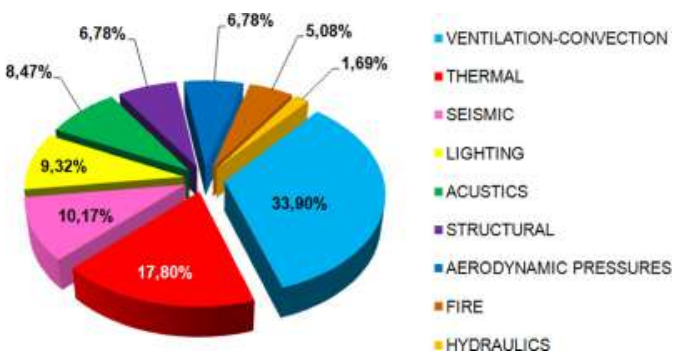

Fig. 12. Percentage of referenced papers (in this literature review) of each physical field related exclusively to functional scale models for buildings respect its total number.

Equally, in Figs. 11 and 12, physics related to fluid and thermodynamics occupy first positions.

In the case of ventilation and convection field, in Fig. 11 this $22.40 \%$ using scale models supposes just around 3\% compared with other methods of analysis, such as computer fluid dynamics or full scale, applied in scientific publications till 2008 according to [206]. This is a relevant example how common in scale model testing in most cases is infra-used.

From the total number of functional scale model testing, the most related to buildings are in seismics (85.71\%), ventilation (71.43\%), acoustics (62.50\%) and lighting (57.89\%), as it is possible to see in Table 12 .

Fig. 13 shows the most applied methods for functional scale models for buildings are similitude methods in blue, - corresponding to $43.55 \%$. Dimensional analysis methods in red follow with a percentage of $34.68 \%$. Simulations with scale model validations in yellow suppose $19.35 \%$ and statistical methods in magenta are $2.42 \%$.

Most of the functional scale models are considering physical rules of similitude for turning the gathered data of their sensors into data useful at full-scale.

They are mostly distorted scale models for thermal and ventilation analysis, however, in ventilation the appearance of the scale model could be kept because these tests are based mainly in fluid speed control not affecting the model appearance itself.

According to Fig. 14 the range of scales is very wide depending on the physical field in which scale models are used.

It is certain that the major part of scales are concentrated in the range from $1 / 2$ to $1 / 12.5$. This range coincides with [159] recommendation for thermal functional undistorted scale

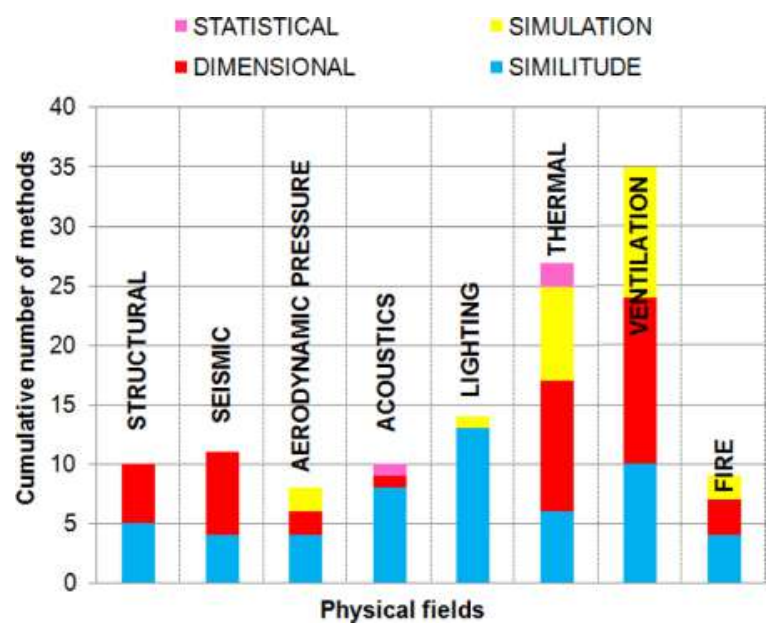

Fig. 13. Cumulative number of methods applied to functional scale model analysis classified by phenomenological field.

models - advisable scales up to $1 / 12$ and scale limit sets to $1 / 24$ for physical reasons.

In general, scale $1 / 5$ is the most used between them and overall in lighting and thermal analysis, followed by $1 / 10$ and $1 / 50$ in lighting and acoustics for the first and thermal and acoustics for the second.

It should be said that tests on aerodynamic pressures over buildings and urban areas are using scales down $1 / 50$, while those dedicated to ventilation are, in most of the cases, up to $1 / 20$ scale.

In contrast with the use of scale models, engineers are focusing on simulations using new generation of multiphysics programs with integrated 3D CAD-Software in which coupled physics phenomena simulation are possible.

Till the day, these programs are mostly using finite element method, very adequate for technical pieces and structure analysis even for buildings. This method is more difficult to implement in cases of fluid or thermodynamics in rooms or buildings because the amount of resources needed to get a solution.

As alternative architect-oriented software such as EnergyPlus opt for simulation methods such as resistance equivalences or equivalent finite different method algorithms [159].

These simulation methods have known divergences from fluid or thermal real behavior [255] and, therefore, validation methods with functional scale model tests for approaching complex physical phenomena come foreground.

Despite all computational advances, functional scale models are getting relevance and are more frequently being essential in validation purposes, as they interact directly with the physical world. Precisely this characteristic makes them indispensable. Moreover, to this increasing interest in distorted or undistorted scale models some breakthroughs are contributing.

Firstly, although it was already known, CAD-modeling has improved very much lately and makes easy the design of new forms of buildings and models and their ulterior production. They create virtual environment with precision and infinite customization possibilities [141]. Additional tools can manipulate the design in order to get in pieces ready for post-production.

Table 12

Percentage of scale model testing for buildings respect to the total number of scale model tests documented in scientific papers classified by physical field.

\begin{tabular}{|c|c|c|c|c|c|c|c|c|c|}
\hline & \multicolumn{9}{|c|}{ References in each physical field } \\
\hline & Ventilation convection & Structural & Seismic & Aerodynamic pressures & Acoustics & Lighting & Thermal & Fire & Hydraulics \\
\hline Total & 56 & 29 & 14 & 37 & 16 & 19 & 49 & 11 & 19 \\
\hline Buildings & 40 & 8 & 12 & 8 & 10 & 11 & 21 & 6 & 2 \\
\hline$\%$ & $71.43 \%$ & $27.59 \%$ & $85.71 \%$ & $21.62 \%$ & $62.50 \%$ & $57.89 \%$ & $42.86 \%$ & $54.55 \%$ & $10.53 \%$ \\
\hline
\end{tabular}




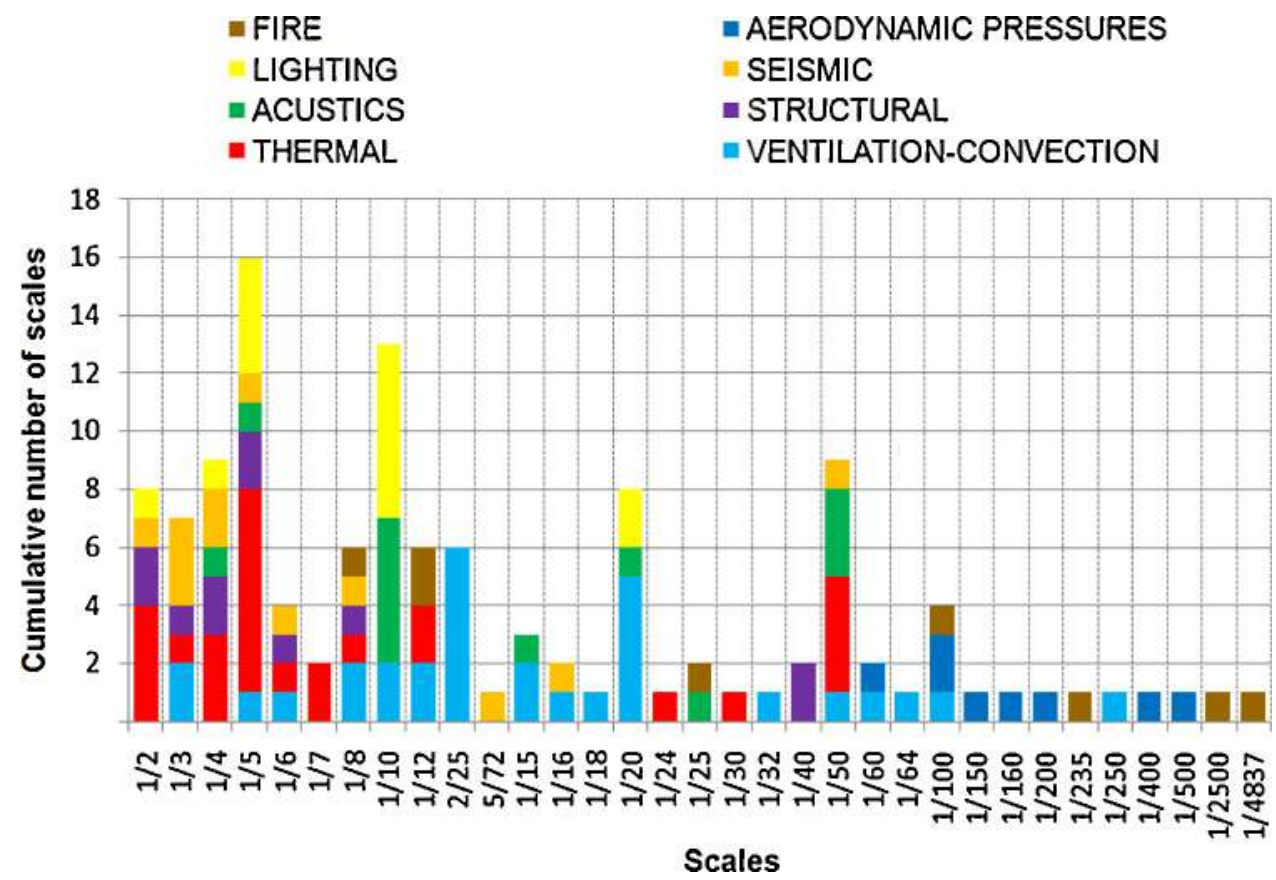

Fig. 14. Cumulative number of scales for functional scale models for buildings classified by phenomenological field.

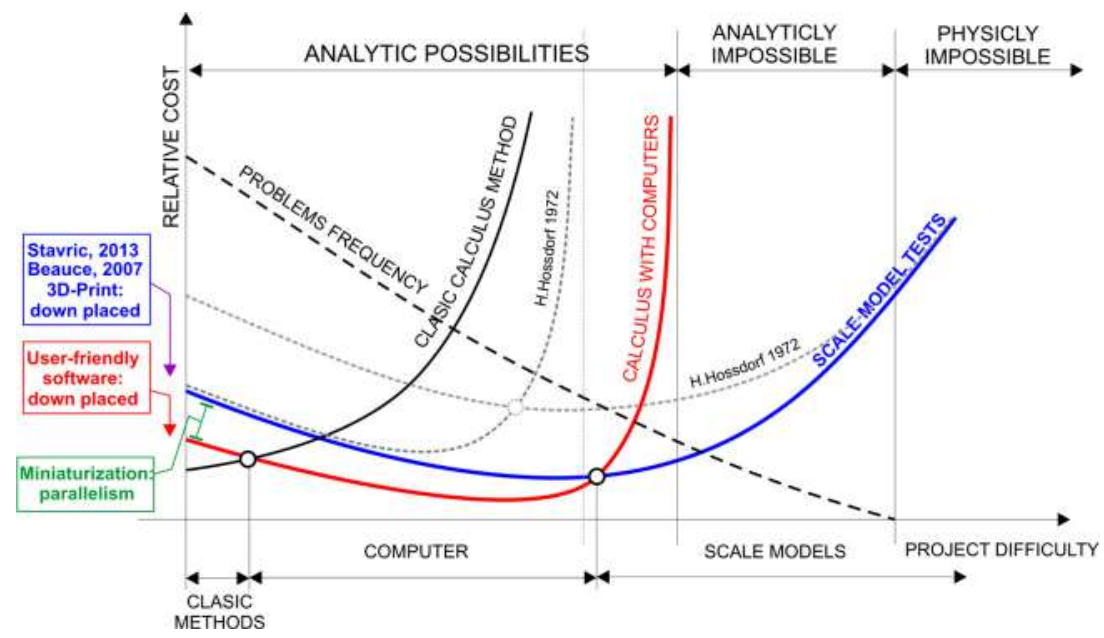

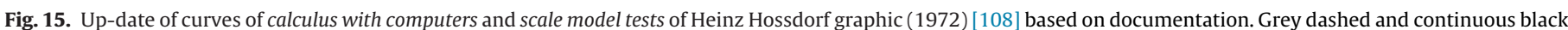

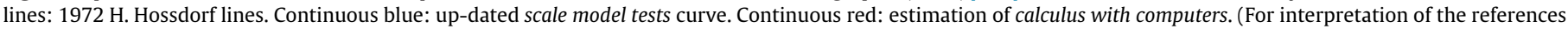
to color in this legend, the reader is referred to the web version of the article.)

Secondly, minituarization and the use of cheap new technical improvements such as the popular Arduino motherboards [9] makes very easy to provide a scale model with the required technological facility in order to record experimental data.

Specially important is this improvement for the undistorted because its divergent physical response should be widely and carefully monitored and analyzed in order to be comparable with the corresponding prototype. Additionally, these micro-sensors and other complements are small enough to avoid distortion of the model.

Finally, the use of new alloy materials in 3D-print manufacturing, such as metal, wood or plastics increment the possibilities of scale models [194,169]. This new trend is nowadays developing very fast and is changing the field of production as to the date is understood.

In general, scale models potential could explode alluding mostly to practical reasons. Traditional scale models, or better to say analogical scale models, do not fit in the "speedy production" of today.
However, they do fit considering new 3D-print techniques, making them precise, flexible, fast and integrated in the design process.

Figurative scale models are being substituted by improved and detailed virtual 3D-models. Architects are using building information modeling (BIM) integrating 3D-model design including construction, facilities, budget and project management. Today more than ever, figurative scale models of buildings seem to be left for advertising purposes [65].

Paradoxically, the possibilities of new form through 3D-virtual buildings keep the necessity of figurative scale modeling construction, thus, new construction methods are to be tested and were never implemented before.

Precisely in this line, 3D-printing modeling is taking an increasingly importance in the coming new buildings and architecture.

With this new perspective, the graphic depicted by [108] in Fig. 1 should be up-dated to actual situation in Fig. 15.

Based in the documentation here presented, it is possible to consider that the scale model test curve of the original Fig. 1 should have 
a new position. Equally, the area of analytic possibilities should be extended due to the improvements in computer simulation and high speed computing.

According with references related to new techniques of fast prototyping $[233,25]$, scale model test curve in blue should be placed down closer to the origin in relative cost level.

Additional, it is coinciding at the beginning with the $1972 \mathrm{cal}$ culus with computers curve because scale models are nowadays computerized, printed and ready for assembling, making them easier to build (Fig. 15).

Miniaturization and micros-sensors [9] makes easy test performance and, therefore, the parallelism of the scale model tests curve in blue with the red curve of calculus with computers, since the former should have some additional cost related to implementation of facilities (Fig. 15).

New calculus with computer curve in red (Fig. 15) should not be totally under the classic calculus method curve in the area of classic methods because there would be always some classic method easy to implement in simple cases in which the use of computer could be more time-consuming than them.

However, calculus with computer curve in red should be place also down due to easy user-friendly computer simulation improvements.

The crossing point between these two new curves (Fig. 15), red and blue, has advanced to the area of analytic possibilities. There is some area where the use of scale models is convenient compared with computers. In the area of analytically impossible approaches through scale models - or eventually with other experimental methods - are still necessary.

Considering all these innovations and rapid changes in different technological fields, it is possible to think about a foreseeable increase in scale models use, similar as it happened in the nineteentwenties [65].

\section{Conclusions}

- Functional scale models for buildings are consequence of the integration of figurative architectural scale models and analytic scale models for engineering.

- Functional scale models for buildings need a theoretical approximation being the most used nowadays general similarity and dimensional analysis. Parallel projection is barely used and restricted to historical buildings according with the required conditions for similarity of this theory. Considerations of size effects and fractals are still infra-used due to their complexities.

- Distorted scale model technique for buildings are used mainly for studying stochastic phenomena, such as thermal. For this reason there are less undistorted scale models in this physical field.

- Undistorted scale model technique for buildings are used mainly in those less time-dependent physical fields.

- Considering dissimilar material models the scope of undistorted scale models could be extended to other time-dependent physical fields, such as seismic and aerodynamic pressure.

- For building testing is the replica model the most appropriate, however, due to difficulty of reaching perfect match with the full-scale prototype, dissimilar material scale model is the best alternative. Material property changes should be first option for undistorted scale model testing for buildings.

- Till this date, functional scale models for buildings in ventilation and thermal analysis are the most used reaching $50 \%$ of the total tested.

- In general, scales up to $1 / 12$ are the most frequent in functional scale models for buildings. Scales $1 / 20$ and 1/50 are also more frequent.
- For ventilation analysis (included convection) with functional scale models for buildings, scales around $1 / 12$ are the most frequent, however $1 / 20$ is also very frequent. The use of one or another depends on the building size configuration of the study case.

- In thermal analysis with functional scale models for buildings is $1 / 5$ the most frequent scale. Recommended are scales up to $1 / 12$ and limits on $1 / 24$. Scale $1 / 50$ is also used but only related to urban areas.

- Functional lighting scale models for buildings used mostly $1 / 5$ and $1 / 10$, being the smallest $1 / 20$. In indoor tests, the scale is dependent of the size of artificial sky.

- Functional acoustic scale models for buildings use mostly 1/10 scale.

- Scales in general structural functional scale model tests for buildings, and particularly in seismic, are up to $1 / 10$. However, those related to aerodynamic pressures analysis over buildings are down to $1 / 50$. This $1 / 50$ scale is optimal for aerodynamic pressures normally considering only external appearance of tall buildings and no details of internal rooms are needed.

- Heinz Hossdorf graphic is obsolete according with the actual state of the technique and research. Sufficient reasons have been exposed to state that the proposed depicted graphic in the discussion reflects more properly the new improvements and overall situation in scale modeling testing.

- More research should be done for reaching practical application of functional undistorted scale model of buildings in order to predict full-scale building behavior. In this line, multiscale physics research and non-Euclidean geometry could contribute to improvements.

- This literature review exposes not only the compilation of architectural scale model techniques, but an incipient great potential for future functional scale model testing. Indeed, all requirements are set: technological minituarization, material improvements, 3D CAD-modeling and 3D-manufacturing techniques.

\section{Acknowledgements}

Research by Juan M. Lirola Pérez has been also supported by a PICATA predoctoral fellowship of the Moncloa Campus of International Excellence (UCM-UPM).

\section{References}

[1] N. Abdul-Jabbar, Natural convective heat transfer coefficient - a review I. Isolated vertical and horizontal surfaces, Energy Convers. Manag. 42 (2001) 491-504.

[2] N. Abdul-Jabbar, Natural convective heat transfer coefficient - a review II. Surfaces in two- and three-dimensional enclosures, Energy Convers. Manag. 42 (2001) 505-517.

[3] C. Aghemo, A. Pellegrino, V.R.M. LoVerso, The approach to daylighting by scale models and sun and sky simulators: a case study for different shading systems, Build. Environ. 43 (5) (2008) 917-927.

[4] F. Alhama, C.N. Madrid, Discriminated dimensional analysis versus classical dimensional analysis and applications to heat transfer and fluid dynamics, Chin. J. Chem. Eng. 15 (5) (2007) 626-631

[5] J. Allegrini, V. Dorer, J. Carmeliet, Wind tunnel measurements of buoyant flows in street canyons, Build. Environ. 59 (2013) 315-326.

[6] M.S. Alrubaih, M.F.M. Zain, M.A. Alghoul, N.L.N. Ibrahim, M.A. Shameri, O. Elayeb, Research and development on aspects of daylighting fundamentals, Renew. Sustain. Energy Rev. 21 (2013) 494-505.

[7] E. Altmayer, F. Bauman, A. Gadgil, R. Kammerud, Correlations for convective heat transfer from room surfaces, ASHRAE Trans. (United States) (1983), 89 (CONF-830640-).

[8] G.D. Ander, Daylighting Performance and Design, John Wiley and Sons, 2003

[9] Arduino, Arduino, 2016, URL https://www.arduino.cc/.

[10] F. Asdrubali, A scale model to evaluate water evaporation from indoor swimming pools, Energy Build. 41 (3) (2009) 311-319.

[11] ASHRAE, American Society of Heating, Refrigerating and Air Conditioning Engineers, American Society of Heating, Refrigerating and Air Conditioning Engineers, USA, 2009 
[12] G. Astarita, Dimensional analysis, scaling, and orders of magnitude, Chem. Eng. Sci. 52 (24) (1997) 4681-4698.

[13] H.B. Awbi, Calculation of convective heat transfer coefficients of room surfaces for natural convection, Energy Build. 28 (1998) 219-227.

[14] M. Bady, S. Kato, T. Takahashi, H. Huang, Experimental investigations of the indoor natural ventilation for different building configurations and incidences, Build. Environ. 46 (1) (2011) 65-74.

[15] W.E. Baker, P.S. Westine, F.T. Dodge, Similarity Methods in Engineering Dynamics: Theory and Practice of Scale Modeling, Spartan Books, 1973 ([distributed by] Hayden Book Co).

[16] C. Balocco, Thermal behaviour of interactive mechanically ventilated double glazed façade: non-dimensional analysis, Energy Build. 38 (1) (2006) 1-7.

[17] N.K. Bansal, S.G.R. Gaur, Application of U and g Values for Sizing Passive Heating Concepts, Solar Energy, 1996.

[18] B. Barsky, Computer graphics: a personal history, IEEE Ann. History Comput. 20 (2) (1998) 36-37.

[19] C. Bartenbach, Modellbau - Lighting Design, 2016, URL https://www. bartenbach.com/lichtplanung/modellbau/tageslichtmodelle.html.

[20] T. Basak, S. Roy, A. Balakrishnan, Effects of thermal boundary conditions on natural convection flows within a square cavity, Int. J. Heat Mass Transf. 49 (2006) 4525-4535.

[21] F. Bauman, Buoyancy-driven convection in a rectangular enclosure: experimental results and numerical calculations, in: American Society of Mechanical Engineers Conference on Heat Transfer in Passive Solar Systems, Orlando, FL, July 27-30, 1980, 2013.

[22] Z.P. Bažant, Size effect on structural strength: a review, Arch. Appl. Mech. 69 (9-10) (1999) 703-725.

[23] Z.P. Bažant, Size effect, Int. J. Solids Struct. 37 (1) (2000) 69-80.

[24] J.T. Baylot, T.L. Bevins, Effect of responding and failing structural components on the airblast pressures and loads on and inside of the structure, Comput. Struct. 85 (11-14) (2007) 891-910.

[25] P. Beaucé, B. Cache, Objectile: Fast-Wood: A Brouillon Project, Springer Vienna, 2007.

[26] L.L.W. Beckman, J. Mitchell, An Experimental Study of Natural Convection in Room (Unpublished Report), 1983.

[27] C. Benito Hernandez, Estudio experimental de cubiertas laminares con modelos reducidos, Revista de Obras Públicas (2910) (October 1957) 523-531.

[28] H. Bennett, Taking Stock of 3D Printing, 2014.

[29] B. Berman, 3-D printing: the new industrial revolution, Bus. Horiz. 55 (2) (2012) 155-162.

[30] S. Billington, A.S. Elnashai, M.D. Lepech, B. Gencturk, Behavior of concrete and ECC structures under simulated earthquake motion, J. Struct. Eng. 139 (3) (2013) 389-399.

[31] P. Block, Equilibrium y'all !!, 2009, URL https://equilibriumstone.wordpress. $\mathrm{com} /$.

[32] P. Block, L. Lachauer, M. Rippmann, Validating thrust network analysis using 3D-printed, structural models, in: Proceedings of the International Association for Shell and Spatial Structures (IASS), Shanghai, 2010.

[33] B. Blocken, 50 years of computational wind engineering: past, present and future, J. Wind Eng. Ind. Aerodyn. 129 (2014) 69-102.

[34] O. Boccia, P. Zazzini, Daylight in buildings equipped with traditional or innovative sources: a critical analysis on the use of the scale model approach, Energy Build. 86 (2015) 376-393.

[35] M. Bodart, A. Deneyer, A. De Herde, P. Wouters, A guide for building daylight scale models, Arch. Sci. Rev. 50 (1) (2007) 31-36.

[36] M. Bohn, A. Kirkpatrik, D. Olson, Experimental study of three-dimensional natural convection and high-Rayleigh numbers, ASME Trans. J. Heat Transf. 106 (1984) 339-345.

[37] D. Bourell, D. Rosen, M. Leu, The roadmap for additive manufacturing and its impact, 3D Print. Addit. Manuf. 1 (1) (2014) 6-9.

[38] L. Bps, 2014. URL http://www.bwk.tue.nl/nl/unit-bps/bps-laboratories/bpslaboratories-extended/.

[39] H. Braddick, Dimensional analysis and scale factors, J. Phys. D: Appl. Phys. 16 (5) (1965) 741

[40] D. Briggs, D. Jones, Two-dimensional periodic natural convection in a rectangular enclosure of aspect ratio one, J. Heat Transf. 107 (4) (1985) $850-854$.

[41] V. Brophy, J. Lewis, A Green Vitruvius: Principles and Practice of Sustainable Architectural Design, 2nd ed., 2012, pp. 1-146.

[42] I. Cantor, Structural scale models: beyond the computer, Civ. Eng. 58 (11) (1988) 42-45.

[43] A. Carpinteri, Size-scale effects in the failure mechanisms of materials and structures, Spon (E F), GB 1996 (1995).

[44] A. Carpinteri, M. Corrado, G. Lacidogna, Three different approaches for damage domain characterization in disordered materials: fractal energy density, b-value statistics, renormalization group theory, Mech. Mater. 53 (2012) 15-28.

[45] A. Carpinteri, S. Puzzi, Self-similarity in concrete fracture: size-scale effects and transition between different collapse mechanisms, Int. J. Fract. 154 (1) (2008) 167-175.

[46] A. Carpinteri, S. Puzzi, The fractal-statistical approach to the size-scale effects on material strength and toughness, Probab. Eng. Mech. 24 (1) (2009) 75-83.

[47] P. Cassinello, En memoria de heinz hossdorf, Informes de la Construcción 58 (502) (2006) 63-81.
[48] E. Casta neda, B. Lauret, J.M. Lirola, G. Ovando, Free-form architectural envelopes: digital processes opportunities of industrial production at a reasonable price, J. Facade Des. Eng. 3 (1) (2015) 1-13.

[49] P.T. Centre, Pilkington Glass Development, Pilkington Glass Limited, 1987.

[50] A.K.C. Chan, Impact Behaviour of Model Prestressed Concrete Beams (Ph.D. Thesis), University of Sheffield, 1986.

[51] P.S. Charlesworth, A Full-Scale and Model Study of Convective Heat Transfer From Roof Mounted Flat-Plate Solar Collectors (Ph.D. Thesis), University of Sheffield, 1986.

[52] C.L. Cheng, C.L. Chen, C.P. Chou, C.Y. Chan, A mini-scale modeling approach to natural daylight utilization in building design, Build. Environ. 42 (1) (2007) 372-384.

[53] T. Chenvidyakarn, A. Woods, Stratification and oscillations produced by pre-cooling during transient natural ventilation, Build. Environ. 42 (1) (2007) 99-112.

[54] Y. Chiu, D.W. Etheridge, Experimental technique to determine unsteady flow in natural ventilation stacks at model scale, J. Wind Eng. Ind. Aerodyn. $92(3-4)(2004) 291-313,3$.

[55] A. Cordier, C. Durou, M. Forqernie, T. Lafon, Natural convection in a test cell-the use of a reduced scale model, in: Proceedings of the 9th Biennial Congress of the ISES, INTERSOL85, 1985, pp. 282-286.

[56] D. Costola, D.W. Etheridge, Unsteady natural ventilation at model scale flow reversal and discharge coefficients of a short stack and an orifice, Build. Environ. 43 (9) (2008) 1491-1506.

[57] M.V. Cruz-Salas, J.A. Castillo, G. Huelsz, Experimental study on natural ventilation of a room with a windward window and different wind exchangers, Energy Build. 84 (2014) 458-465.

[58] P.-Y. Cui, Z. Li, W.-Q. Tao, Wind-tunnel measurements for thermal effects on the air flow and pollutant dispersion through different scale urban areas, Build. Environ. 97 (2016) 137-151.

[59] W.A. Dalgliesh, Comparison of model/full-scale wind pressures on a high-rise building, J. Ind. Aerodyn. (1975) 55.

[60] D. Dannelley, J. Baker, Natural convection fin performance using fractal-like geometries, J. Thermophys. Heat Transf. 26 (4) (2012) 657-664, http://dx. doi.org/10.2514/1.T3906;24.

[61] P.L. Datin, D.O. Prevatt, Using instrumented small-scale models to study structural load paths in wood-framed buildings, Eng. Struct. 54 (2013) 47-56.

[62] M. De Paepe, J.G. Pieters, W.M. Cornelis, D. Gabriels, B. Merci, P. Demeyer, Airflow measurements in and around scale model cattle barns in a wind tunnel: effect of ventilation opening height, Biosyst. Eng. 113 (1) (2012) 22-32.

[63] M.J. DeJong, Seismic Assessment Strategies for Masonry Structures, 2009

[64] Q.-H. Deng, G.-F. Tang, Y. Li, A combined temperature scale for analyzing natural convection in rectangular enclosures with discrete wall heat sources, Int. J. Heat Mass Transf. 45 (2002) 3437-3446.

[65] D. Deriu, The architectural model in the age of its mechanical reproducibility, in: Second International Conference of the European Architectural History Network. Koninklijke Vlaamse Academie van Belgi voor Wetenschappen en Kunsten, 2012, pp. 166-170.

[66] M. Domizio, D. Ambrosini, O. Curadelli, Experimental and numerical analysis to collapse of a framed structure subjected to seismic loading, Eng. Struct. 82 (2015) 22-32.

[67] J.F. Douglas, An Introduction to Dimensional Analysis for Engineers, Sir Isaac Pitman and Sons LTD, Toronto, Canada, 1969.

[68] J. Du, S. Sharples, Assessing and predicting average daylight factors of adjoining spaces in atrium buildings under overcast sky, Build. Environ. 46 (11) (2011) 2142-2152, 11.

[69] L. Du, R. Zmeureanu, T. Stathopoulos, An empirical model of air displacement by revolving doors, Energy Build. 70 (2014) 127-134.

[70] W.J. Duncan, Physical Similarity and Dimensional Analysis: An Elementary Treatise, Edward Arnold, London, 1953.

[71] G. Efremidis, A. Carpinteri, E. Aifantis, Multifractal scaling law versus gradient elasticity in the evaluation of disordered materials compressive strength, J. Mech. Behav. Mater. 12 (2) (2001) 107-120.

[72] G. Elsinga, I. Marusic, Universal aspects of small-scale motions in turbulence 62 (2010).

[73] D. Etheridge, Scale Modelling. Natural Ventilation of Buildings, John Wiley and Sons, Ltd, 2011, pp. 293-337.

[74] D. Etheridge, A perspective on fifty years of natural ventilation research, Build. Environ. 91 (2015) 51-60.

[75] D.W. Etheridge, Crack flow equations and scale effect, Build. Environ. 12 (3) (1977) 181-189.

[76] D.W. Etheridge, Nondimensional methods for natural ventilation design, Build. Environ. 37 (11) (2002) 1057-1072.

[77] D.W. Etheridge, J.A. Nolan, Ventilation measurements at model scale in a turbulent flow, Build. Environ. 14 (1) (1979) 53-64.

[78] P. Exton, The room acoustic design of the Guangzhou Opera House, Proc. Inst. Acoust. 33 (2011).

[79] S.H. Fernández, Galileo was wrong: the geometrical design of masonry arches, Nexus Netw. J. Archit. Math. 8 (2006) 25-51.

[80] A. Fernández-González, Analysis of the thermal performance and comfort conditions produced by five different passive solar heating strategies in the united states midwest, Sol. Energy 81 (5) (2007) 581-593.

[81] A. Fernndez-Gutiérrez, I. González-Prieto, L. Parras, J.M. Cejudo-López, C. del Pino, Experimental and numerical study of a small-scale and low-velocity 
indoor diffuser coupled with radiant floor cooling, Int. J. Heat Mass Transf. 87 (2015) 71-78.

[82] FIFA 2016, URL http://www.fifa.com/worldcup/news/y=2016/m=6/ news=3d-printed-stadiums-shaping-2022-design-2802070.html.

[83] L. Fontana, Thermal performance of radiant heating floors in furnished enclosed spaces, Appl. Therm. Eng. 31 (10) (2011) 1547-1555.

[84] R.D. Francisco, Digital Automation in Scale Models Fabrication (Ph.D. Thesis), Universidade de Liusboa, 2013.

[85] A. Gade, Recent experiences in using room acoustic scale models, Proc. Inst. Acoust. 28 (2006)

[86] A. Gadgil, F. Bauman, R. Kammerud, Natural convection in passive solar buildings: experiments, analysis and results, Passive Sol. J. 1 (1982) 28-40.

[87] M.A. Gálvez Huerta, Estudio dimensional de las teorías termológicas clásicas, M. A. Gálvez Huerta, Madrid, 1997.

[88] M.A. Gálvez Huerta, F. González de Posada, Estudio dimensional de las teorías termológicas clásicas (Ph.D. Thesis), 1997.

[89] M. Garevski, V. Hristovski, K. Talaganov, M. Stojmanovska, Experimental investigations of $1 / 3$-scale $\mathrm{R} / \mathrm{C}$ frame with infill walls building structures, in: Proc., 13th World Conf. on Earthquake Engineering, 2004.

[90] B. Gencturk, F. Hosseini, Evaluation of reinforced concrete and reinforced engineered cementitious composite (ECC) members and structures using small-scale testing, Can. J. Civ. Eng. (3) (2013) 164.

[91] B.M. Gibbs, J. Lewis, Sound insulation of diaphram walls - I. Scale model measurement and statistical energy analysis, Build. Environ. 2 (1991) 165-172.

[92] D. Goldsman, R.E. Nance, J.R. Wilson, A Brief History of Simulation, 2009, pp. 310-313.

[93] D.P. González, Teorias fsicas analógicas de transporte de tipo Fourier: lecciones teóricas y experimentales, Francisco González de Posada, Madrid, 1992.

[94] F.A. González Redondo, Historia del análisis dimensional, F. A. González Redondo, Madrid, 2000.

[95] D.P. Grimmer, Theoretical considerations in the use of small passive-solar test-boxes to model the thermal performance of passively solar-heated building designs, Sol. Energy 22 (4) (1979) 343-350.

[96] D.P. Grimmer, R.D. McFarland, J.D. Balcomb, Initial experimental tests on the use of small passive-solar test-boxes to model the thermal performance of passively solar-heated building designs, Sol. Energy 22 (4) (1979) 351-354

[97] S. Grossmann, D. Lohse, Scaling in thermal convection: a unifying theory, J. Fluid Mech. 407 (2000) 27-56.

[98] L.R. Grumbine, Using scale models advantageously, Arch. Forum L (1) (1929) $105-110$.

[99] K.M. Hangos, I.T. Cameron, Process Modelling and Model Analysis, Academic Press, San Diego, CA, 2001.

[100] T.C. Hansen, Influence of size and shape of member on the shrinkage and creep of concrete, J. Proc. 63 (2) (1966).

[101] H.G. Harris, G. Sabnis, Structural Modeling and Experimental Techniques, 2nd ed., CRC Press, Boca Raton, 1999.

[102] M. Hauschild, R. Karzel, Digital Processes: Planning, Designing, Production, Birkhäuser, 2011.

[103] F. Heidt, H. Streppel, Steady State Heat Balance and Surface Temperature of Solar Radiated Indoor Walls, University of Siegen, 1986.

[104] R.R. Heisler, C.L. Ratliff, Wind tunnel model design and test using rapid prototype materials and processes, in: The Annual AIAA/BMDO Technology Conference [10th], Williamsburg, Virginia, 2001, pp. 5-11.

[105] V. Heller, Scale effects in physical hydraulic engineering models, J. Hydraul. Res. 49 (3) (2011) 293-306.

[106] A. Herranz García, A. Arenas Gómez, Análisis dimensional y sus aplicaciones, 2nd ed., DM, Murcia, 2006.

[107] I. Horváth, J. van Beeck, B. Merci, Full-scale and reduced-scale tests on smoke movement in case of car park fire, Fire Saf. J. 57 (2013) 35-43, 4

[108] H. Hossdorf, Modelos reducidos. Método de cálculo, Instituto Eduardo Torroja de la construcción y del cemento, 1972.

[109] S. Huerta Fernández, El clculo de estructuras en la obra de Gaudí, E. T. S. Arquitectura. (UPM) (2003).

[110] S. Huerta Fernández, R. Aroca Hernández-Ros, Cúpulas de fábrica: un estudio de sus dimensiones y semejanzas, 1990.

[111] H. Huntley, Dimensional Analysis, Macdonald and CO, London, 1952.

[112] R. Illampas, D.C. Charmpis, I. Ioannou, Laboratory testing and finite element simulation of the structural response of an adobe masonry building under horizontal loading, Eng. Struct. 80 (2014) 362-376.

[113] M.S. Imbabi, Computer validation of scale model tests for building energy simulation, Int. J. Energy Res. 14 (7) (1990) 727-736,

[114] M.S. Imbabi, General procedure for the small-scale modelling of buildings, Int. J. Energy Res. 14 (3) (1990) 311-321.

[115] M.S. Imbabi, Scale modelling of the built environment, Energy Build. 17 (1) (1991) 7-12.

[116] M.R. Ismail, A scale model investigation of sound reflection from building facades, Appl. Acoust. 66 (22) (2005).

[117] N. Isyumov, Cn tower, toronto - model and full scale response to wind, 1984 , pp. 737.

[118] H.S. Jang, H.J. Kim, J.Y. Jeon, Scale-model method for measuring noise reduction in residential buildings by vegetation, Build. Environ. 86 (2015) $81-88$.

[119] M. Jensen, The model-law for phenomena in natural wind, Ingeniøren-Int. Ed. 2 (4) (1958) 121-128.
[120] J.Y. Jeon, J.H. Kim, C.K. Seo, Acoustical remodeling of a large fan-type auditorium to enhance sound strength and spatial responsiveness for symphonic music, Appl. Acoust. 73 (11) (2012) 1104-1111.

[121] Y.J. Jin, Influence of absorption properties of materials on the accuracy of simulated acoustical measures in 1:10 scale model test, Appl. Acoust. 70 (4) (2009) 615.

[122] B. Jones, A. Sereni, M. Ricci, Building Brunelleschi's Dome: a practical methodology verified by experiment, J. Soc. Arch. Hist. 69 (1) (2010) 39-61.

[123] M. Kanda, Progress in the scale modeling of urban climate: review, Theor. Appl. Climatol. 84 (1) (2006) 23-33.

[124] M. Kanda, M. Kanega, T. Kawai, R. Moriwaki, H. Sugawara, Roughness lengths for momentum and heat derived from outdoor urban scale models, J. Appl. Meteorol. Climatol. 46 (7) (2007) 1067-1079.

[125] M. Kanda, T. Kawai, M. Kanega, R. Moriwaki, K. Narita, A. Hagishima, A simple energy balance model for regular building arrays, Bound. Layer Meteorol. 116 (3) (2005) 423-443.

[126] T. Kawai, M. Kanda, Urban Energy Balance Obtained from the Comprehensive Outdoor Scale Model Experiment. Part I: Basic Features of the Surface Energy Balance, 2010.

[127] T. Kawai, M. Kanda, Urban Energy Balance Obtained from the Comprehensive Outdoor Scale Model Experiment. Part II: Comparisons with Field Data Using an Improved Energy Partition, 2010.

[128] T. Kawai, M. Kanda, Urban Energy Balance Obtained from the Comprehensive Outdoor Scale Model Experiment. Part II: Comparisons With Field Data Using an Improved Energy Partition (Ph.D. Thesis), 2010.

[129] T. Kawai, M. Kanda, K. Narita, A. Hagishima, Validation of a numerical mode for urban energy exchange using outdoor scale model measurements, Int. J. Climatol. 27 (14) (2007) 1931-1942.

[130] A. Khalifa, R. Marshall, Natural and forced convection on interior building surfaces. Preliminary results, in: Applied Energy Research Conference, University of Swansea, UK, 1989.

[131] A. Khalifa, R. Marshall, Validation of heat transfer coefficients on interior building surfaces using a real sized indoor passive test cell, Int. J. Heat Mass Transf. 33 (1990) 2219-2236.

[132] N. Khan, Y. Su, S.B. Riffat, A review on wind driven ventilation techniques, Energy Build. 40 (8) (2008) 1586-1604.

[133] C.-S. Kim, S.-J. Chung, Daylighting simulation as an architectural design process in museums installed with toplights, Build. Environ. 46 (1) (2011) $210-222$.

[134] N.-S. Kim, J.-H. Lee, S.-P. Chang, Equivalent multi-phase similitude law for pseudodynamic test on small scale reinforced concrete models, Eng. Struct. 31 (4) (2009) 834-846.

[135] W. Kim, A. El-Attar, R.N. White, Small-Scale Modeling Techniques for Reinforced Concrete Structures Subjected to Seismic Loads. NCEER Report NCEER-88-0041, National Center for Earthquake Engineering Research, 1988.

[136] U. Knaack, T. Klein, M. Bilow, Rapids. Imagine 04, 2010.

[137] J. Knappett, C. Reid, S. Kinmond, K. O'Reilly, Small-scale modeling of reinforced concrete structural elements for use in a geotechnical centrifuge, J. Struct. Eng. 137 (11) (2011) 1263-1271.

[138] W. Knoll, M. Hechinger, Architectural Models: Construction Techniques, 2nd ed., J. Ross Pub., Fort Lauderdale, USA, 2007.

[139] R.L. Knowles, The solar envelope: its meaning for energy and buildings, Energy Build. 35 (1) (2003) 15-25.

[140] B. Kolarevic, Architecture in the Digital Age. Design and Manufacturing, Spon Press/Taylor \& Francis Group, New York/London, 2003.

[141] B. Kolarevic, Digital praxis: from digital to material, in: 3rd International Conference on Innovation in Architecture, Engineering and Construction (AEC), 2005, p. p. 5.

[142] P.A. Kottke, T.P. Ferguson, A.G. Fedorov, Scale analysis of combined thermal radiation and convection heat transfer, J. Heat Transf. 126 (2) (2004) $250-258$.

[143] F. Kreith, R. Manglik, M. Bohn, Principles of Heat Transfer, Cengage Learning, 2010.

[144] I. Kurtbas, A. Durmus, Unsteady heat transfer by natural convection in the cavity of a passive heating room, Int. J. Therm. Sci. 47 (2008) 1026-1042.

[145] K. Kuwana, K. Sekimoto, T. Minami, T. Tashiro, K. Saito, Scale-model experiments of moving fire whirl over a line fire, Proc. Combust. Inst. 34 (2) (2013) 2625-2631.

[146] Y.W. Kwon, D.H. Allen, R. Talreja, Multiscale Modeling and Simulation of Composite Materials and Structures, 2008, pp. 1-630.

[147] H.L. Langhaar, Dimensional Analysis and Theory of Models, Reprint ed., Robert E. Krieger, Malabar, FL, 1983.

[148] N. Le Roux, X. Faure, C. Inard, S. Soares, L. Ricciardi, Reduced-scale study of wind influence on mean airflows inside buildings equipped with ventilation systems, Build. Environ. 58 (2012) 231-244.

[149] J. Lebrun, Temperature Without Heating a Building and Heating Energy Consumption Experimental Steady State Analysis on Reduced-Scale Models, 1981.

[150] K.S. Lee, Development of a Passive Solar Simulation Technique Using Small-Scale Models (Ph.D. Thesis), 1981.

[151] P.J. Lee, Y.H. Kim, J.Y. Jeon, K.D. Song, Effects of apartment building façade and balcony design on the reduction of exterior noise, Build. Environ. 42 (10) (2007) $3517-3528$.

[152] Y.J. Lee, A scaled model study on the solid flow in a shaft type furnace, Powder Technol. 102 (2) (1999) 194-201. 
[153] A. Lenardic, L. Moresi, Thermal convection below a conducting lid of variable extent: heat flow scalings and two-dimensional, infinite Prandtl number numerical simulations, Phys. Fluids 15 (2) (2003) 455-466.

[154] A. Li, Z. Liu, J. Zhang, J. Wang, Reduced-scale model study of ventilation for large space of generatrix floor in HOHHOT underground hydropower station, Energy Build. 43 (4) (2011) 1003-1010.

[155] A. Li, Y. Wu, J. Ma, R. Gao, J. Hu, B. Xiao, P. Zhang, Experimental studies of mechanically exhausted smoke within the transport passage of the main transformer of an underground hydropower station, Tunn. Undergr. Space Technol. 33 (2013) 111-118.

[156] Q.S. Li, J.Y. Fu, Y.Q. Xiao, Z.N. Li, Z.H. Ni, Z.N. Xie, M. Gu, Wind tunnel and full-scale study of wind effects on China's tallest building, Eng. Struct. 28 (12) (2006) 1745-1758.

[157] N.N. Lin, A. Bejan, Natural convection in a partially divided enclosure, Int. J. Heat Mass Transf. 26 (12) (1983) 1867-1878.

[158] Y.J.P. Lin, C.L. Lin, A study on flow stratification in a space using displacement ventilation, Int. J. Heat Mass Transf. 73 (2014) 67-75.

[159] J.M. Lirola, Simulation of Thermal Performance of Glazing in Architecture Using Scale Models (Ph.D. Thesis), School of Architecture, Madrid, 2016.

[160] P.C. Liu, Evaluation of buoyancy-driven ventilation in atrium buildings using computational fluid dynamics and reduced-scale air model, Build. Environ. 44 (9) (2009)

[161] D. Lohse, K.-Q. Xia, Small-scale properties of turbulent Rayleigh-Bénard convection, Annu. Rev. Fluid Mech. 42 (2010) 335-364.

[162] K.H. Lu, L.H. Hu, F. Tang, L.H. He, X.C. Zhang, Z.W. Qiu, Heat flux profile upon building facade with side walls due to window ejected fire plume: an experimental investigation and global correlation, Fire Saf. J. 70 (2014) $14-22$.

[163] N. Luo, A. Li, R. Gao, Z. Tian, W. Zhang, S. Mei, L. Feng, P. Ma, An experiment and simulation of smoke confinement and exhaust efficiency utilizing a modified opposite double-jet air curtain, Saf. Sci. 55 (2013) 17-25.

[164] F. Maamari, M. Andersen, J. de Boer, W. Caroll, D. Dumortier, P. Greenup, Experimental validation of simulation methods for bi-directional transmission properties at the daylighting performance level, Energy and Build. 38 (7) (2006) 878-889.

[165] C.N. Madrid, F. Alhama, Discriminated dimensional analysis of the energy equation: application to laminar forced convection along a flat plate, Int. J. Therm. Sci. 44 (4) (2005) 333-341.

[166] C.N. Madrid, F. Alhama, Discrimination: a fundamental and necessary extension of classical dimensional analysis theory, Int. Commun. Heat Mass Transf. 33 (3) (2006) 287-294.

[167] M. Mahmood, Experiments to study turbulence and flow past a low-rise building at oblique incidence, J. Wind Eng. Ind. Aerodyn. 99 (5) (2011) $560-572$.

[168] C.M. Mak, Z. Wang, Recent advances in building acoustics: an overview of prediction methods and their applications, Build. Environ. 91 (2015) $118-126$.

[169] Makerbot, Makerbot: 3D Printing Platform, 2016, URL http://www. makerbot.com.

[170] C. Marschallday, 2014. URL http://marshallday.com/project/ocpacsegerstrom-hall-orange-county-california-usa.

[171] C. Martin, M. Watson, Measurement of Convective Heat Transfer Coefficients in a Realistic Room Geometry. Tech. Rep., Energy Monitoring Company Limited EMC, 1988.

[172] O.G. Martynenko, P.P. Khramtsov, Free-Convective Heat Transfer: With Many Photographs of Flows and Heat Exchange, Springer Verlag, 2005.

[173] M. Matsumoto, S. Fujiwara, A study of annual moisture variation in an internally insulated building wall under a mild climate using a small-scale model and the similarity laws, Energy Build. 16 (3-4) (1991) 933-945.

[174] M.S. Mayhoub, Innovative daylighting systems challenges: a critical study, Energy Build. 80 (2014) 394-405.

[175] J. Meseguer Ruiz, A.P. Sanz Andres, J.M. Perales Perales, S. Pindado Carrión, Túneles aerodinámicos para aplicaciones de ingeniería civil, 2002

[176] T. Min, L.S.L.G. Parmelee, J. Vouris, Natural convection and radiation in a panel-heated room, ASHRAE Trans. (1956) 337-358.

[177] M. Mirsadeghi, D. Cóstola, B. Blocken, J.L.M. Hensen, Review of external convective heat transfer coefficient models in building energy simulation programs: implementation and uncertainty, Appl. Therm. Eng. 56 (1-2) (2013) 134-151.

[178] A. Mohammed, T.G. Hughes, A. Mustapha, The effect of scale on the structural behaviour of masonry under compression, Construct. Build. Mater. 25 (1) (2011) 303-307, 1.

[179] A. Mohammed, N. Muazu, B. Waziri, T. Ahmad, Models and size effects: a review, IOSR J. Mech. Civ. Eng. 12 (2015) 54-59.

[180] M.R. Mokhtarzadeh-Dehghan, Natural convection between two floors of a building via a horizontal opening - measurements in a one-half scale model, Int. J. Heat Mass Transf. 50 (15-16) (2007) 3141-3151, 7.

[181] P.D. Moncarz, Theory and Application of Experimental Model Analysis in Earthquake Engineering. Tech. Rep., 1981.

[182] C. Montes Serrano, Modelos ingleses del siglo xvii: de balthazar gerbier a christopher wren //English models in the 17th century: from Baltazar Gerbier to Christopher Wren, Revista de arquitectura (4) (2000) 37-48.

[183] S. Morsing, J.S. Strm, G. Zhang, P. Kai, Scale model experiments to determine the effects of internal airflow and floor design on gaseous emissions from animal houses, Biosyst. Eng. 99 (1) (2008) 99-104.
[184] L. Mudarra Bello, M. Casta ns Camargo, Estudio de la transmisin de calor en las superficies planas y en las cmaras de aire con aplicacin del anlisis dimensional (Ph.D. Thesis), 1992.

[185] G. Murphy, Similitude in Engineering, Ronald Press Co, 1950.

[186] T. Murray, Study of thin-walled metal building roof systems using scale models, in: Reports of the Working Commissions (International Association for Bridge and Structural Engineering, 1986, pp. 177-183.

[187] C. Nagata, 2014. URL http://www.nagata.co.jp/e-news/news0901-e.html.

[188] N. Nakashima, K. Kawashima, H. Ukon, K. Kajiwara, Shake table experimental project on the seismic performance of bridges using e-defense, in: 14th World Conference on Earthquake Engineering, Beijing, China, 2008 (Paper S17-02-010 (CD-ROM)).

[189] M. Nansteel, R. Greif, Natural convection in undivided and partially divided rectangular enclosures, J. Heat Transf. 103 (4) (1981) 623-629.

[190] S. Nayak, S.C. Dutta, Failure of masonry structures in earthquake: a few simple cost effective techniques as possible solutions, Eng. Struct. 106 (2016) 53-67.

[191] F. Neila, Arquitectura Bioclimtica en un Entorno Sostenible. Ed, Munilla-leira, Madrid, 2004

[192] A. Nottrott, S. Onomura, A. Inagaki, M. Kanda, J. Kleissl, Convective heat transfer on leeward building walls in an urban environment: measurements in an outdoor scale model, Int. J. Heat Mass Transf. 54 (15) (2011) 3128-3138.

[193] D. O'Connor, J.K. Calautit, B.R. Hughes, A study of passive ventilation integrated with heat recovery, Energy Build. 82 (2014) 799-811.

[194] OrbiTech, Orbi-Tech. The World of Plastic Welding, 2016, URL http://www. orbi-tech.com.

[195] S. Ostrach, Natural convection in enclosures, Adv. Heat Transf. 8 (1972) $161-178$.

[196] J. Palacios, Análisis Dimensional, 2nd ed., Espasa-Calpe, Madrid, 1964.

[197] R.C. Pankhurst, Dimensional Analysis and Scale Factors, Chapman and Hall Limited, New York/London, 1964.

[198] M. Park, A. Hagishima, J. Tanimoto, K. Narita, Effect of urban vegetation on outdoor thermal environment: field measurement at a scale model site, Build. Environ. 56 (2012) 38-46.

[199] D. Pearlmutter, P. Berliner, E. Shaviv, Evaluation of Urban Surface Energy Fluxes Using an Open-Air Scale Model, 2005.

[200] M.-L. Persson, A. Roos, M. Wall, Influence of window size on the energy balance of low energy houses, Energy Build. 38 (3) (2006) 181-188.

[201] S. Petry, K. Beyer, Scaling unreinforced masonry for reduced-scale seismic testing, Bull. Earthquake Eng. 12 (6) (2014) 2557-2581.

[202] J. Picaut, L. Simon, A scale model experiment for the study of sound propagation in urban areas, Appl. Acoust. 62 (3) (2001) 327-340.

[203] A. Piccolo, A. Pennisi, F. Simone, Daylighting performance of an electrochromic window in a small scale test-cell, Sol. Energy 83 (6) (2009) 832-844.

[204] T. Porter, J. Neale, Architectural Supermodels: Physical Design Simulation, Architectural Press, 2000

[205] J.D. Posner, C.R. Buchanan, D. Dunn-Rankin, Measurement and prediction of indoor air flow in a model room, Energy Build. 35 (5) (2003) 515-526.

[206] C. Qingyan, Ventilation performance prediction for buildings: a method overview and recent applications, Build. Environ. 44 (4) (2009) 848-858.

[207] M. Rahimi, K. Tajbakhsh, Reducing temperature stratification using heated air recirculation for thermal energy saving, Energy Build. 43 (10) (2011) 2656-2661.

[208] R.V. Ralegaonkar, R. Gupta, Design development of a static sunshade using small scale modeling technique, Renew. Energy 30 (6) (2005) 867-880.

[209] W.J.M. Rankine, A Manual of Applied Mechanisms, Richard Griffin and Company, London/Glasgow, 1858, pp. 45-47, Chapter IV.

[210] V.A. Reyes, F.Z. Sierra-Espinosa, S.L. Moya, F. Carrillo, Flow field obtained by PIV technique for a scaled building-wind tower model in a wind tunnel, Energy Build. 107 (2015) 424-433.

[211] L. Ricciardi, T. Glain, S. Soares, Experimental and numerical characterization of wind-induced pressure coefficients on nuclear buildings and chimney exhausts, Nucl. Eng. Des. 292 (2015) 248-260.

[212] K. Ruberg, Heat Distribution by Natural Convection (Ph.D. Thesis), Massachusetts Institute of Technology, Cambridge, 2001

[213] G. Ryder, B. Ion, G. Green, D. Harrison, B. Wood, Rapid design and manufacture tools in architecture, Autom. Construct. 11 (3) (2002) 279-290.

[214] D. Sabzi, P. Haseli, M. Jafarian, G. Karimi, M. Taheri, Investigation of cooling load reduction in buildings by passive cooling options applied on roof, Energy Build. 109 (2015) 135-142.

[215] C.K. Saha, G. Zhang, J.-O. Ni, Z. Ye, Similarity criteria for estimating gas emission from scale models, Biosyst. Eng. 108 (3)(2011) 227-236.

[216] S. Sakamoto, A. Aoki, Numerical and experimental study on noise shielding effect of eaves/louvers attached on building façade, Build. Environ. 94 (Part 2) (2015) 773-784.

[217] R. San Juan Llosa, Teoría de las magnitudes físicas y sus fundamentos algebráicos, C. Bermejo, Madrid, 1947.

[218] M. Sandberg, M. Mattsson, H. Wig, A. Hayati, L. Claesson, E. Linden, M.A. Khan, Viewpoints on wind and air infiltration phenomena at buildings illustrated by field and model studies, Build. Environ. 92 (2015) 504-517.

[219] A.P. Sanz Andres, J.M. Perales Perales, J. Meseguer Ruiz, A. Laverón Simavilla, N.A. Bezdenejnykh, Las instalaciones de aerodinámica experimental de la e.t.s.i. aeronáuticos. Parte I: 1960-1993, 2000. 
[220] A.P. Sanz Andres, J.M. Perales Perales, J. Meseguer Ruiz, A. Laverón Simavilla, N.A. Bezdenejnykh, Las instalaciones de aerodinmica experimental de la e.t.s.i. aeronuticos. Parte II: 1994, 2000.

[221] R. Saraiji, M.Y. Al Safadi, N. Al Ghaithi, R.G. Mistrick, A comparison of scale-model photometry and computer simulation in day-lit spaces using a normalized daylight performance index, Energy Build. 89 (2015) 76-86.

[222] M. Sathiyamoorthy, T. Basak, S. Roy, I. Pop, Steady natural convection flows in a square cavity with linearly heated side wall(s), Int. J. Heat Mass Transf. 50 (2007) 766-775.

[223] D. Schlapmann, Convection with Floor Heating-Development of a Test Method. Tech. Rep., Universitaet Stuttgart, Report No. BMFT FB-T 81-158, 1981.

[224] D.J. Schuring, Scale Models in Engineering: Fundamentals and Applications, Pergamon Press, Oxford, 1977.

[225] Sciencephoto, 2014. URL http://www.sciencephoto.com/media/82870/ enlarge.

[226] V. Sernas, E. Lee, Heat transfer in air enclosures of aspect ratio less than one, J. Heat Transf. 103 (4) (1981) 617-622.

[227] D.R. Shelden, Digital Surface Representation and the Constructibility of Gehry's Architecture (Architecture PhD), 2002, pp. 340.

[228] X. Shen, G. Zhang, B. Bjerg, Comparison of different methods for estimating ventilation rates through wind driven ventilated buildings, Energy Build. 54 (2012) 297-306.

[229] O. Shishkina, C. Wagner, Analysis of thermal dissipation rates in turbulent Rayleigh-Bénard convection, J. Fluid Mech. 546 (2006) 51-60.

[230] A. Simondetti, Computer-generated physical modelling in the early stages of the design process, Autom. Construct. 11 (2002) 303-311.

[231] Snæbjörnsson, J. Thór, Full-and Model Scale Study of Wind Effects on a Medium-Rise Building in a Built Up Area (Ph.D. Thesis), Norwegian University of Science and Technology, Trondheim, Norway, 2002 September.

[232] S. Soma, K. Saito, Reconstruction of fire whirls using scale models, Combust. Flame 86 (3) (1991) 269-284.

[233] M. Stavric, P. Sidanin, B. Tepavcevic, Architectural Scale Models in the Digital Age: Design, Representation and Manufacturing, Springer, 2013.

[234] A.D. Stavridou, P.E. Prinos, Natural ventilation of buildings due to buoyancy assisted by wind: investigating cross ventilation with computational and laboratory simulation, Build. Environ. 66 (2013) 104-119.

[235] E. Steffanny, Design Communication Through Model Making: A Taxonomy of Physical Models in Interior Design Education (Ph.D. Thesis), 2009.

[236] R. Stevens, D. Lohse, R. Verzicco, Prandtl and Rayleigh number dependence of heat transport in high Rayleigh number thermal convection, J. Fluid Mech. 688 (2011) 31-43, 1102.2307, Provided by the SAO/NASA Astrophysics Data System.

[237] T. Szirtes, P. Rózsa, Applied Dimensional Analysis and Modeling, McGraw-Hill, New York, 1997.

[238] M. Taleghani, M. Tenpierik, A. van den Dobbelsteen, D.J. Sailor, Heat mitigation strategies in winter and summer: field measurements in temperate climates, Build. Environ. 81 (2014) 309-319.

[239] V.I. Terekhova, A.L. Ekaida, Three dimensional laminar convection in a parallelepiped with heating of two side walls. High temperature, Heat Mass Transf. Phys. Gasdyn. 49 (6) (2011) 874-880.

[240] A. Thanachareonkit, J. Scartezzini, M. Andersen, Comparing daylighting performance assessment of buildings in scale models and test modules, Sol. Energy 79 (2) (2005) 168-182.
[241] F. Toja-Silva, C. Peralta, O. Lopez-Garcia, J. Navarro, I. Cruz, Effect of roof-mounted solar panels on the wind energy exploitation on high-rise buildings, J. Wind Eng. Ind. Aerodyn. 145 (2015) 123-138.

[242] Y. Tominaga, B. Blocken, Wind tunnel experiments on cross-ventilation flow of a generic building with contaminant dispersion in unsheltered and sheltered conditions, Build. Environ. 92 (2015) 452-461.

[243] M. Tomaževič, M. Gams, Shaking table study and modelling of seismic behaviour of confined AAC masonry buildings, Bull. Earthq. Eng. 10 (3) (2012) 863-893.

[244] G. Tong, G. Zhang, D.M. Christopher, B. Bjerg, Z. Ye, J. Cheng, Evaluation of turbulence models to predict airflow and ammonia concentrations in a scale model swine building enclosure, Comput. Fluids 71 (2013) 240-249.

[245] B. Turner, R. Flack, The experimental measurement of natural convective heat transfer in rectangular enclosures with concentrated energy sources, J. Heat Transf. 102 (2) (1980) 236-241.

[246] J.M. Vallejera, Behavior and testing of small scale columns under combined action loads, in: Proceedings of the 2007 Earthquake Engineers Symposium for Young Researchers, Seattle, Washington, 2007.

[247] S. Venko, D. Vidal de Vents, C. Arkar, S. Medved, An experimental study of natural and mixed convection over cooled vertical room wall, Energy Build. 68 (Part A) (2014) 387-395.

[248] C. Walker, G. Tan, L. Glicksman, Reduced-scale building model and numerical investigations to buoyancy-driven natural ventilation, Energy Build. 43 (9) (2011) 2404-2413.

[249] B. Wang, D.W. Etheridge, M. Ohba, Wind tunnel investigation of natura ventilation through multiple stacks. Part 1: Mean values, Build. Environ. 46 (7) (2011) 1380-1392.

[250] B. Wang, D.W. Etheridge, M. Ohba, Wind tunnel investigation of natura ventilation through multiple stacks. Part 2: Instantaneous values, Build. Environ. 46 (7) (2011) 1393-1402.

[251] L. Wang, Q. Chen, Evaluation of some assumptions used in multizone airflow network models, Build. Environ. 43 (10) (2008) 1671-1677.

[252] A.H.C.a.R.N. White, Materials and modeling techniques for reinforced concrete frames, J. Proc. 74 (11) (1977).

[253] R. White, The calibration and error analysis of an artificial mirrored sky converted to a clear sky luminance distribution, Energy Build. 6 (3) (1984) 229-240, iD: 271089271089.

[254] G.K. Wilby, Response of Concrete Structures to Seismic Motions (Ph.D. Thesis), University of Canterbury, Christchurch, New Zealand, 1975.

[255] S.D. Wit, Uncertainty in Predictions of Thermal Comfort in Buildings (Ph.D.), Delft University of Technology, Delft, Netherlands, 2001.

[256] J. Yi, Q.S. Li, Wind tunnel and full-scale study of wind effects on a super-tall building, J. Fluids Struct. 58 (2015) 236-253.

[257] H. Yu, C.-M. Liao, H.-M. Liang, Scale model study of airflow performance in a ceiling slot-ventilated enclosure: isothermal condition, Build. Environ. 38 (11) (2003) 1271-1279.

[258] H. Yu, C.-M. Liao, H.-M. Liang, K.-C. Chiang, Scale model study of airflow performance in a ceiling slot-ventilated enclosure: non-isothermal condition, Build. Environ. 42 (3) (2007) 1142-1150.

[259] G. Yun, K.C. Yoon, K.S. Kim, The influence of shading control strategies on the visual comfort and energy demand of office buildings, Energy Build. 84 (2014) 70-85. 